\title{
Evaluation of Annealing Treatments for Producing Si-Rich Fuel/Matrix Interaction Layers in Low-Enriched U-Mo Dispersion Fuel Plates Rolled at a Low Temperature
}

Dennis D. Keiser, Jr. Jan-Fong Jue Nicolas E. Woolstenhulme Ashley Ewh

June 2010

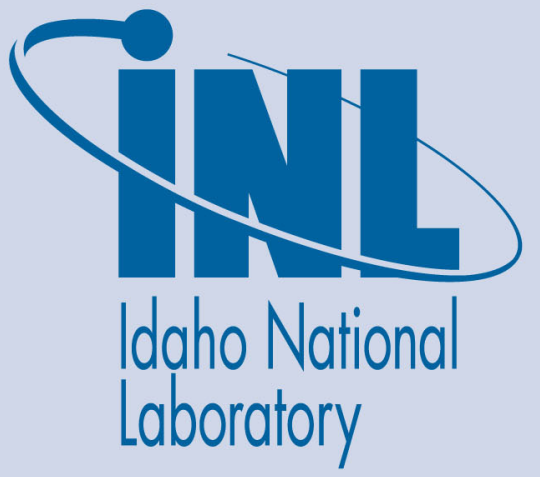

The INL is a U.S. Department of Energy National Laboratory operated by Battelle Energy Alliance 


\section{DISCLAIMER}

This information was prepared as an account of work sponsored by an agency of the U.S. Government. Neither the U.S. Government nor any agency thereof, nor any of their employees, makes any warranty, expressed or implied, or assumes any legal liability or responsibility for the accuracy, completeness, or usefulness, of any information, apparatus, product, or process disclosed, or represents that its use would not infringe privately owned rights. References herein to any specific commercial product, process, or service by trade name, trade mark, manufacturer, or otherwise, does not necessarily constitute or imply its endorsement, recommendation, or favoring by the U.S. Government or any agency thereof. The views and opinions of authors expressed herein do not necessarily state or reflect those of the U.S. Government or any agency thereof. 


\title{
Evaluation of Annealing Treatments for Producing Si- Rich Fuel/Matrix Interaction Layers in Low-Enriched U-Mo Dispersion Fuel Plates Rolled at a Low Temperature
}

\author{
Dennis D. Keiser, Jr. \\ Jan-Fong Jue
}

Nicolas E. Woolstenhulme

Ashley Ewh

June 2010

Idaho National Laboratory Idaho Falls, Idaho 83415

http://www.inl.gov

Prepared for the

U.S. Department of Energy

Office of National Nuclear Security Administration

Office of Nuclear Materials Threat Reduction

Under DOE Idaho Operations Office

Contract DE-AC07-05ID14517 



\title{
Evaluation of Annealing Treatments for Producing Si- Rich Fuel/Matrix Interaction Layers in Low-Enriched U-Mo Dispersion Fuel Plates Rolled at a Low \\ Temperature
}

\author{
INL/EXT-10-18920
}

June 2010

Approved by:

Name

Date

Title [optional]

Name

Title [optional]

Title [optional] 



\section{ABSTRACT}

During fabrication of U-7Mo dispersion fuels, exposure to relatively high temperatures affects the final microstructure of a fuel plate before it is inserted into a reactor. One impact of this high temperature exposure is a chemical interaction that can occur between dissimilar materials. For U-7Mo dispersion fuels, the U-7Mo particles will interact to some extent with the Al or Al alloy matrix to produce interaction products. It has been observed that the final irradiation behavior of a fuel plate can depend on the amount of interaction that occurs at the U-7Mo/matrix interface during fabrication, along with the type of phases that develop at this interface. For the case where a U-7Mo dispersion fuel has a Si-containing $\mathrm{Al}$ alloy matrix and is rolled at around $500^{\circ} \mathrm{C}$, a Si-rich interaction product has been observed to form that can potentially have a positive impact on fuel performance during irradiation. This interaction product can exhibit stable irradiation behavior and it can act as a diffusion barrier to additional U-Mo/matrix interaction during irradiation. However, for U-7Mo dispersion fuels with softer claddings that are rolled at lower temperatures (e.g., near $425^{\circ} \mathrm{C}$ ), a significant interaction layer has not been observed to form. As a result, the bulk of any interaction layer that develops in these fuels happens during irradiation, and the layer that forms may not exhibit as stable a behavior as one that is formed during fabrication. Therefore, it may be beneficial to add a heat treatment step during the fabrication of dispersion fuel plates with softer cladding alloys that will result in the formation of a uniform, Si-rich interaction layer that is a few microns thick around the U-Mo fuel particles. This type of layer would have characteristics like the one that has been observed in dispersion fuel plates with AA6061 cladding that are fabricated at $500^{\circ} \mathrm{C}$, which may exhibit increased stability during irradiation. This report discusses the result of annealing experiments that were performed using samples from fuel plates that were fabricated at $425^{\circ} \mathrm{C}$ that had Alloy 5052 cladding. As part of these experiments, samples with Al-Si matrices that had different Si contents were tested. The samples had Al-2Si, Al-4Si, Al-5Si, or Al-6Si as the matrix alloy. The heat treatment temperatures and times that were investigated were $450^{\circ} \mathrm{C}$ (4 hours), $475^{\circ} \mathrm{C}$ ( 4 hours), and $500^{\circ} \mathrm{C}$ ( 2 hours) for all the matrix alloy compositions and $525^{\circ} \mathrm{C}$ ( 1 hour) for just the Al-4Si and Al-6Si matrix alloy compositions. The results of these experiments showed that the initial interaction layers that form around the U-7Mo particles during fabrication at $425^{\circ} \mathrm{C}$ continue to grow in thickness and uniformity during each of the heat treatments, though the composition of the layers remains similar to that observed in the as-fabricated samples. The Al-6Si matrix sample annealed at $450^{\circ} \mathrm{C}$ for 4 hours and the $\mathrm{Al}-5 \mathrm{Si}$ and Al-6Si matrix samples annealed at $475^{\circ} \mathrm{C}$ for 4 hours formed fuel/matrix interaction layers most similar to those observed in fuel plates with AA6061 cladding that are fabricated at $500^{\circ} \mathrm{C}$. 


\section{ACKNOWLEDGMENTS}

This work was supported by the U.S. Department of Energy, Office of Nuclear Materials Threat Reduction (NA-212), National Nuclear Security Administration, under DOE-NE Idaho Operations Office Contract DE-AC0705ID14517. Accordingly, the U.S. Government retains a non-exclusive, royaltyfree license to publish or reproduce the published form of this contribution, or allow others to do so, for U.S. Government purposes. Personnel in the Fuel and Applied Sciences Building are recognized for their contributions in fabricating the test samples and conducting the annealing treatments. Mariela Bentancur is recognized for her contributions with some of the image analysis conducted as a part of this study. 


\section{CONTENTS}

ABSTRACT

ACKNOWLEDGMENTS

ACRONYMS vii

ACRONYMS

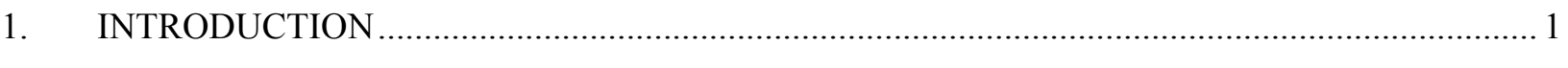

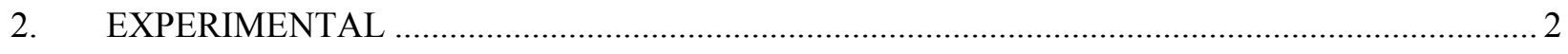

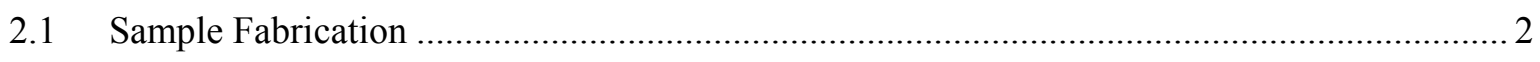

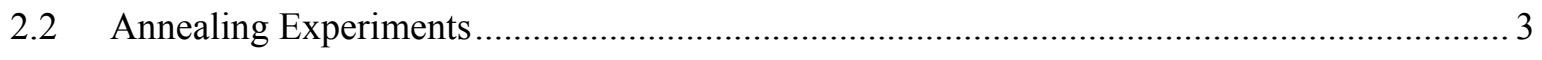

2.3 Microstructural Characterization .............................................................................. 5

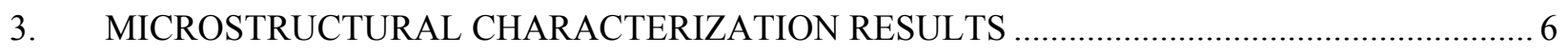

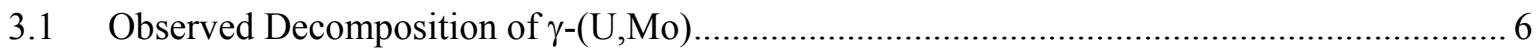

3.2 Interaction Layers in As-Fabricated Fuel Plates ............................................................ 6

3.2 Interaction Layer Development after Annealing Treatment at $450^{\circ} \mathrm{C}$ for 4 Hours ............... 14

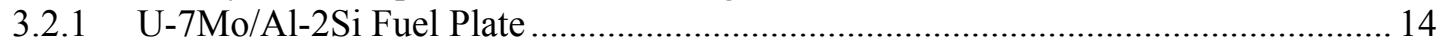

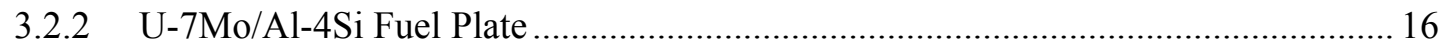

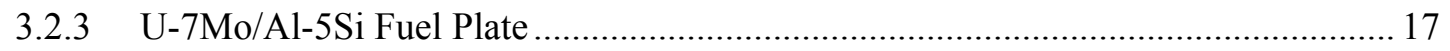

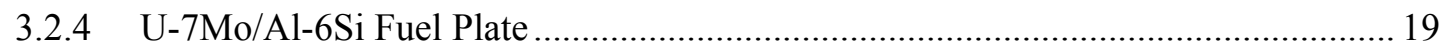

3.3 Interaction Layer Development after Annealing Treatment at $475^{\circ} \mathrm{C}$ for 4 Hours ............... 21

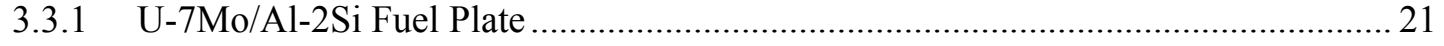

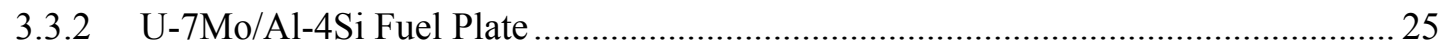

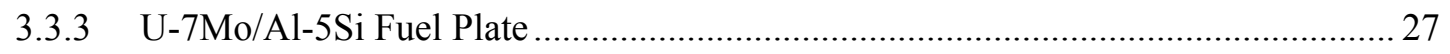

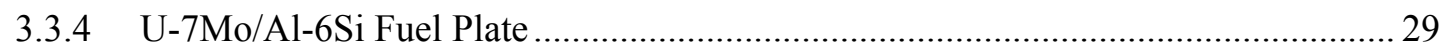

3.4 Interaction Layer Development after Annealing Treatment at $500^{\circ} \mathrm{C}$ for 2 Hours............... 33

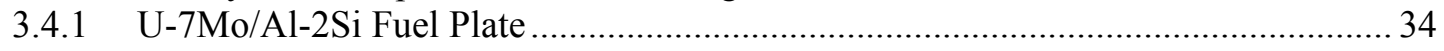

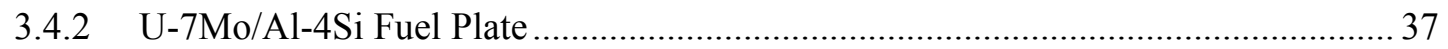

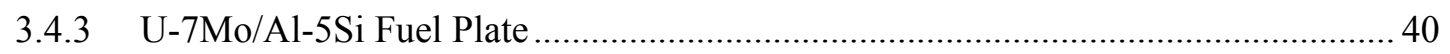

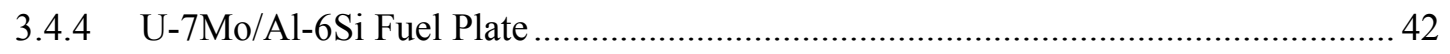

3.5 Interaction Layer Development after Annealing Treatment at $525^{\circ} \mathrm{C}$ for $1 \mathrm{Hour} \ldots \ldots \ldots \ldots . . . . . .46$

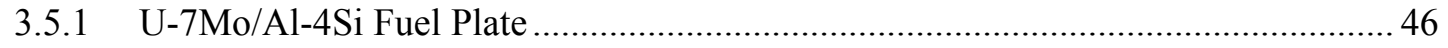

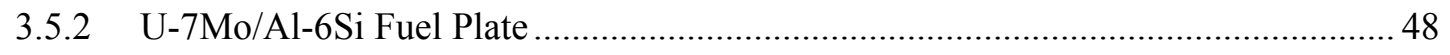

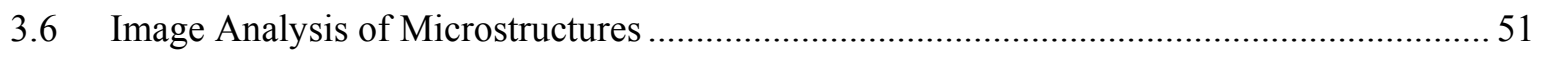

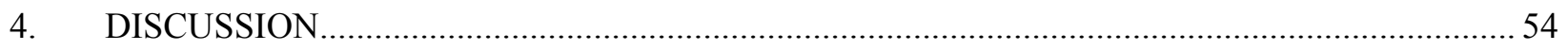

4.1 Development of FMI Layers in Annealing Study Samples .............................................. 54

4.2 Comparison of FMI Layer Development in Annealing Study Samples to Diffusion Experiment Results Reported in the Literature ..................................................................... 56

4.3 Comparison of FMI Layers in Annealing Study Samples to Those Observed in

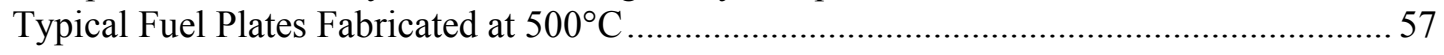

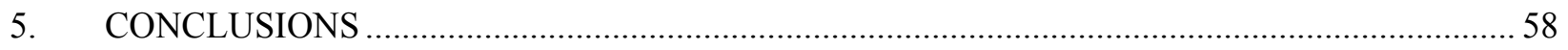

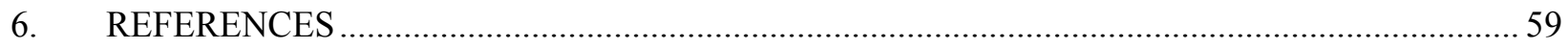




\section{FIGURES}

Figure 1. An example UT scan that was produced for an annealing study fuel plate................................. 3

Figure 2. Schematic diagram of an annealing capsule............................................................................... 4

Figure 3. Swagelok fitting at the end of an evacuation tube .................................................................. 4

Figure 4. Measured temperature profiles for some different annealing treatments. ................................5

Figure 5. BSE images of decomposition observed in particular U-7Mo particles from samples in the (a) as-fabricated condition (Al-5Si matrix sample), (b,c) after annealing at $450^{\circ} \mathrm{C}$ for 4 hours (Al-5Si matrix sample), (d) after annealing at $475^{\circ} \mathrm{C}$ for 4 hours (Al-2Si matrix sample), (e) after annealing at $475^{\circ} \mathrm{C}$ for 4 hours (Al-4Si matrix sample), (f) after annealing at $500^{\circ} \mathrm{C}$ for 2 hours (Al-4Si matrix sample), and (g) after annealing at $525^{\circ} \mathrm{C}$ for 1 hour (Al-4Si matrix sample).

Figure 6. BSE image (a) and WDS oxygen x-ray map (b) showing where localized regions in transformed U-7Mo are enriched in oxygen. 8

Figure 7. BSE images $(\mathrm{a}, \mathrm{b})$ of the microstructure of the as-fabricated Al-2Si matrix fuel plate................. 8

Figure 8. BSE image (a) and Si x-ray map (b) for the as-fabricated Al-2Si matrix fuel plate.................... 8

Figure 9. BSE image showing locations where point-to-point composition analysis was performed in the interaction layer of the Al-2Si matrix sample in the as-fabricated condition. (see Table 5 for results)

Figure 10. BSE image (a) and Si x-ray map (b) for the as-fabricated Al-4Si matrix fuel plate. 10

Figure 11. BSE image (a) and WDS Si x-ray map (b) of the microstructure of the as-fabricated Al-5Si matrix fuel plate.

Figure 12. BSE image of the microstructure of the as-fabricated Al-5Si matrix fuel plate and the locations where point-to-point composition analysis was performed (see Table 6 for results). 11

Figure 13. BSE images $(\mathrm{a}, \mathrm{b})$ of the microstructure of the as-fabricated Al-6Si matrix fuel plate.............. 12

Figure 14. BSE images $(a, c)$ and WDS Si x-ray maps $(b, d)$ of the microstructure of the asfabricated Al-6Si matrix fuel plate.

Figure 15. BSE image of the microstructure of the as-fabricated Al-6Si matrix fuel plate with the locations where point-to-point composition analysis was performed (see Table 7 for results).

Figure 16. BSE image of the microstructure of the as-fabricated Al-6Si matrix fuel plate and locations where point-to-point composition analyses were performed (results in Table $8)$.

Figure 17. BSE images $(a, b)$ of the microstructure of the Al-2Si matrix fuel plate annealed for 4 hours at $450^{\circ} \mathrm{C}$.

Figure 18. BSE image (a) and Si x-ray map (b) for the Al-2Si matrix fuel plate annealed for 4 hours at $450^{\circ} \mathrm{C}$

Figure 19. BSE image of the microstructure of a fuel/matrix interaction layer in the Al-2Si matrix fuel plate annealed for 4 hours at $450^{\circ} \mathrm{C}$ and the locations where point-to-point composition analysis was performed (see Table 9 for results). 
Figure 20. BSE image of the microstructure of the Al-4Si matrix fuel plate annealed for 4 hours at $450^{\circ} \mathrm{C}$.

Figure 21. Backscattered electron image (a) and WDS Si x-ray map (b) for the Al-4Si matrix fuel plate annealed for 4 hours at $450^{\circ} \mathrm{C}$......

Figure 22. BSE image of the microstructure of the Al-5Si matrix fuel plate annealed for 4 hours at $450^{\circ} \mathrm{C}$.

Figure 23. Backscattered electron images $(a, b)$ of the microstructure of the Al-5Si matrix fuel plate annealed for 4 hours at $450^{\circ} \mathrm{C}$.

Figure 24. BSE image of the microstructure of a fuel/matrix interaction layer in the Al-5Si matrix fuel plate annealed for 4 hours at $450^{\circ} \mathrm{C}$ and the locations where point-to-point composition analysis was performed (see Table 10 for results).

Figure 25. BSE images $(a, b)$ of the microstructure of the Al-6Si matrix fuel plate annealed for 4 hours at $450^{\circ} \mathrm{C}$.

Figure 26. Backscattered electron image (a) and WDS Si x-ray map (b) for the Al-6Si matrix fuel plate annealed for 4 hours at $450^{\circ} \mathrm{C}$.

Figure 27. BSE image of the microstructure of a fuel/matrix interaction layer in the Al-6Si matrix fuel plate annealed for 4 hours at $450^{\circ} \mathrm{C}$ and the locations where point-to-point composition analysis was performed (see Table 11 for results).

Figure 28. Backscattered electron images (a-c) of the microstructure of the Al-2Si matrix fuel plate annealed for 4 hours at $475^{\circ} \mathrm{C}$

Figure 29. Backscattered electron image (a) and Si x-ray map (b) for the Al-2Si matrix fuel plate annealed for 4 hours at $475^{\circ} \mathrm{C}$.

Figure 30. Backscattered electron image of the microstructure of the Al-2Si matrix fuel plate annealed for 4 hours at $475^{\circ} \mathrm{C}$ and the locations where point-to-point composition analysis was performed (see Table 12 for results).

Figure 31. BSE image showing, potentially, two different layers, based on morphology, that constitute the interaction zone in the Al-2Si matrix sample annealed at $475^{\circ} \mathrm{C}$ for 4 hours. Locations where point-to-point composition analysis was performed are identified.

Figure 32. Low magnification BSE image (a) and high magnification BSE image (b) of a localized area in the microstructure of the Al-2Si matrix fuel plate annealed at $475^{\circ} \mathrm{C}$ for 4 hours where a bulk interaction layer has formed, as indicated by the arrow in (a). The locations where point-to-point composition analysis was performed are identified (see Table 13 for results).

Figure 33. Backscattered electron images (a-c) of the microstructure of the Al-4Si matrix fuel plate annealed for 4 hours at $475^{\circ} \mathrm{C}$.

Figure 34. Backscattered electron image (a) and Si x-ray map (b) of the microstructure of the Al4Si matrix fuel plate annealed for 4 hours at $475^{\circ} \mathrm{C}$.

Figure 35. Backscattered electron images (a-d) of the microstructure of the Al-5Si matrix sample annealed at $475^{\circ} \mathrm{C}$ for 4 hours.

Figure 36. Backscattered electron image of the microstructure of the Al-5Si matrix fuel plate annealed for 4 hours at $475^{\circ} \mathrm{C}$ with the locations in the interaction layers where pointto-point composition analysis was performed (see results in Table 14). 
Figure 37. BSE image (a) and x-ray maps for (b) Si and (c) Mg for the Al-5Si matrix sample annealed at $475^{\circ} \mathrm{C}$ for 4 hours.

Figure 38. Backscattered electron images (a-c) of the microstructure of the Al-6Si matrix fuel plate annealed for 4 hours at $475^{\circ} \mathrm{C}$

Figure 39. Backscattered electron image (a) and Si x-ray map (b) of the microstructure for the A1$6 \mathrm{Si}$ matrix fuel plate annealed for 4 hours at $475^{\circ} \mathrm{C}$.

Figure 40. Backscattered electron images (a, c, e, and g) and Si x-ray maps (b, d, f, and h) at different locations of the microstructure for the Al-6Si matrix fuel plate annealed for 4 hours at $475^{\circ} \mathrm{C}$.

Figure 41. BSE image of an area in the microstructure for the Al-6Si matrix fuel plate annealed at $475^{\circ} \mathrm{C}$ for 4 hours where relatively thick interaction layers were observed. Locations where point-to-point composition analysis was performed are shown (results listed in Table 15).

Figure 42. BSE image of a particle in the Al-6Si matrix plate annealed at $475^{\circ} \mathrm{C}$ for 4 hours with a relatively thick interaction layer. Locations where point-to-point composition analysis was performed are shown (results listed in Table 16).

Figure 43. BSE images (a-c) of the microstructure of the as-fabricated Al-2Si matrix fuel plate annealed at $500^{\circ} \mathrm{C}$ for 2 hours. The arrows in (a) and (b) identify regions where relatively thick interaction layers are present. The image in (c) shows the presence of a relatively uniform interaction layer around a U-7Mo fuel particle.

Figure 44. BSE image (a) and Si x-ray map (b) in the Al-2Si matrix sample annealed at $500^{\circ} \mathrm{C}$ for 2 hours.

Figure 45. BSE image showing where point-to-point composition analysis was performed on the Al-2Si matrix sample annealed at $500^{\circ} \mathrm{C}$ for 2 hours (results listed in Table 17).

Figure 46. BSE images (a,b) of an interaction layer in the Al-2Si sample annealed at $500^{\circ} \mathrm{C}$ for 2 hours with negligible Si (medium contrast) that reveals the lamellar microstructure of decomposed U-7Mo alloy...

Figure 47. BSE image showing where point-to-point composition analysis was performed on the Al-2Si matrix sample annealed at $500^{\circ} \mathrm{C}$ for 2 hours (results listed in Table 18).

Figure 48. Backscattered electron image of the microstructure of the as-fabricated Al-4Si matrix fuel plate annealed at $500^{\circ} \mathrm{C}$ for 2 hours. The arrows identify where increased fuel/matrix interaction has occurred at areas of decomposed U-7Mo alloy.

Figure 49. BSE image (a) of the microstructure of the as-fabricated Al-4Si matrix fuel plate annealed at $500^{\circ} \mathrm{C}$ for 2 hours, and (b) a Si x-ray map.

Figure 50. Backscattered electron image of the microstructure of the as-fabricated Al-4Si matrix fuel plate annealed at $500^{\circ} \mathrm{C}$ for 2 hours. The arrows indicate a location in the U-7Mo alloy where fuel decomposition has occurred.

Figure 51. BSE image (a) of the microstructure of the as-fabricated Al-4Si matrix fuel plate annealed at $500^{\circ} \mathrm{C}$ for 2 hours, and x-ray maps for (b) Mo, (c) U, (d) Al, and (e) Si

Figure 52. BSE image showing an area where Si-deficient interaction layer has developed near a Si-rich interaction layer. Points where composition analysis was performed (see Table 19) are identified. 
Figure 53. Backscattered electron images $(\mathrm{a}, \mathrm{b})$ of the microstructure of the Al-5Si matrix fuel plate annealed at $500^{\circ} \mathrm{C}$ for 2 hours.

Figure 54. Backscattered electron image (a) and Si x-ray map (b) of the microstructure of the Al$5 \mathrm{Si}$ matrix fuel plate annealed at $500^{\circ} \mathrm{C}$ for 2 hours.

Figure 55. Backscattered electron image of locations in the microstructure of the Al-5Si matrix fuel plate annealed at $500^{\circ} \mathrm{C}$ for 2 hours where point-to-point composition analysis was performed (see Table 20 for results)

Figure 56. Backscattered electron images $(\mathrm{a}, \mathrm{b})$ of the microstructure of the Al-6Si matrix fuel plate annealed at $500^{\circ} \mathrm{C}$ for 2 hours

Figure 57. Backscattered electron image (a) and (b) Si x-ray map of the microstructure of the Al$6 \mathrm{Si}$ matrix fuel plate annealed at $500^{\circ} \mathrm{C}$ for 2 hours.

Figure 58. Backscattered electron image of locations in the microstructure of the Al-6Si matrix fuel plate annealed at $500^{\circ} \mathrm{C}$ for 2 hours where point-to-point composition analysis was performed (see Table 21 for results).

Figure 59. Backscattered electron image of locations in the microstructure of the Al-6Si matrix fuel plate annealed at $500^{\circ} \mathrm{C}$ for 2 hours where point-to-point composition analysis was performed (see Table 22 for results).....

Figure 60. BSE images (a-c) of the microstructure of the Al-4Si matrix fuel plate annealed at $525^{\circ} \mathrm{C}$ for 1 hour.

Figure 61. Backscattered electron images (a,c) and Si x-ray maps $(b, d)$ of the microstructure for the Al-4Si matrix fuel plate annealed for 1 hour at $525^{\circ} \mathrm{C}$

Figure 62. Backscattered electron image of locations in the microstructure of the as-fabricated Al4Si matrix fuel plate annealed at $525^{\circ} \mathrm{C}$ for 1 hour where point-to-point composition analysis was performed (see Table 23 for results).

Figure 63. Backscattered electron images $(\mathrm{a}, \mathrm{b})$ of the microstructure of the Al-6Si matrix fuel plate annealed at $525^{\circ} \mathrm{C}$ for 1 hour.

Figure 64. Backscattered electron image (a) and Si x-ray map (b) of the microstructure for the Al$6 \mathrm{Si}$ matrix fuel plate annealed for 1 hour at $525^{\circ} \mathrm{C}$

Figure 65. Backscattered electron image of locations in the microstructure of the as-fabricated Al6Si matrix fuel plate annealed at $525^{\circ} \mathrm{C}$ for 1 hour where point-to-point composition analysis was performed (see Table 24 for results).

Figure 66. Backscattered electron image of locations in the microstructure of the Al-6Si matrix fuel plate annealed at $525^{\circ} \mathrm{C}$ for 1 hour where point-to-point composition analysis was performed (see Table 25 for results)... .50

Figure 67. Plots of (a) IL thickness vs. Si content, and (b) IL area fraction vs. Si content. .52

Figure 68. Plot of $\lambda$ vs. Si content. .53 


\section{TABLES}

Table 1. DU-7Mo Powder Size Distribution for Annealing Study Fuel Plates. ......................................... 2

Table 2. Powder size distribution for $\mathrm{Al}$ powder....................................................................................... 2

Table 3. Composition of Al-Si Powder Mixtures. ....................................................................................... 2

Table 4. Fuel Plate Rolling Schedule

Table 5. Compositions (at $\%$ ) at various interaction layer locations in the as-fabricated Al-2Si

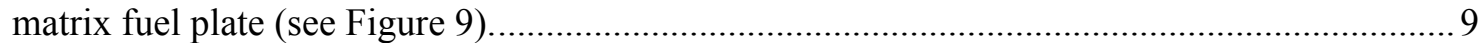

Table 6. Compositions (at $\%$ ) at various interaction layer locations in the as-fabricated Al-5Si

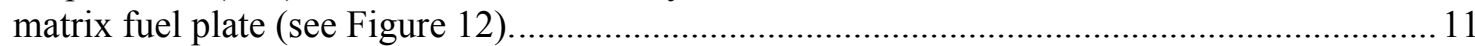

Table 7. Compositions (at\%) at various interaction layer locations in the as-fabricated Al-6Si matrix sample (see Figure 15)

Table 8. Compositions (at\%) at various interaction layer locations in the as-fabricated Al-6Si matrix fuel plate (see Figure 16).

Table 9. Results (at\%) of point-to-point composition analysis performed in the interaction layer depicted in Figure 19.

Table 10. Results (at\%) of point-to-point composition analysis performed in the interaction layer depicted in Figure 24.

Table 11. Results (at\%) of point-to-point composition analysis performed in the interaction layer depicted in Figure 27.

Table 12. Results of point-to-point composition analysis, in at \%, at locations in the interaction layer for the Al-2Si matrix sample annealed at $475^{\circ} \mathrm{C}$ for 4 hours (see Figure 30).

Table 13. Results of point-to-point composition analysis, in at $\%$, conducted near and in some bulk interaction zone in the Al-2Si matrix sample annealed at $475^{\circ} \mathrm{C}$ for 4 hours (see Figure 32).

Table 14. Results of point-to-point composition analysis, in at $\%$, conducted in different interaction layers in the Al-5Si matrix sample annealed at $475^{\circ} \mathrm{C}$ for 4 hours (see Figure 36).

Table 15. Results of point-to-point composition analysis, in at $\%$, conducted at specific locations in the interaction zone (see Figure 41) in the Al-6Si matrix sample annealed at $475^{\circ} \mathrm{C}$ for 4 hours.

Table 16. Results of point-to-point composition analysis, in at $\%$, conducted at specific locations in the interaction zone (see Figure 42) in the Al-6Si matrix sample annealed at $475^{\circ} \mathrm{C}$ for 4 hours.

Table 17. Results of point-to-point composition analysis, in at $\%$, conducted at specific locations in the interaction zone (see Figure 45) in the Al-2Si matrix sample annealed at $500^{\circ} \mathrm{C}$ for 2 hours.

Table 18. Results of point-to-point composition analysis, in at $\%$, conducted at specific locations in the interaction zone (see Figure 47) in the Al-2Si matrix sample annealed at $500^{\circ} \mathrm{C}$ for 2 hours. 
Table 19. Results of point-to-point composition analysis, in at $\%$, conducted at specific locations in the interaction zone (see Figure 52) in the Al-4Si matrix sample annealed at $500^{\circ} \mathrm{C}$ for 2 hours.

Table 20. Results of point-to-point composition analysis, in at $\%$, conducted at specific locations in the interaction zone (see Figure 55) in the Al-5Si matrix sample annealed at $500^{\circ} \mathrm{C}$ for 2 hours.

Table 21. Results of point-to-point composition analysis, in at $\%$, conducted at specific locations in the interaction zone (see Figure 58) in the Al-6Si matrix sample annealed at $500^{\circ} \mathrm{C}$ for 2 hours.

Table 22. Results of point-to-point composition analysis, in at $\%$, conducted at specific locations in the interaction zone (see Figure 59) in the Al-6Si matrix sample annealed at $500^{\circ} \mathrm{C}$ for 2 hours.

Table 23. Results of point-to-point composition analysis, in at $\%$, conducted at specific locations in the interaction zone (see Figure 62) in the Al-4Si matrix sample annealed at $525^{\circ} \mathrm{C}$ for 1 hour.

Table 24. Results of point-to-point composition analysis, in at $\%$, conducted at specific locations in the interaction zone (see Figure 65) in the Al-6Si matrix sample annealed at $525^{\circ} \mathrm{C}$ for 1 hour.

Table 25. Results of point-to-point composition analysis, in at $\%$, conducted at specific locations in the interaction zone (see Figure 66) in the Al-6Si matrix sample annealed at $525^{\circ} \mathrm{C}$ for 1 hour. .50

Table 26. FMI Layer Attributes. 


\section{ACRONYMS}

BSE Backscattered electron

EDS Energy dispersive spectroscopy

FMI Fuel/matrix interaction

Kip thousand inch pounds

IL Interaction layer

INL Idaho National Laboratory

LEU low enriched uranium

Mo Molybdenum

SE Secondary electron

SEM Scanning electron microscopy

TC Thermocouple

TEM Transmission electron microscopy

TIG Tungsten Inert Gas

UT Ultrasonic testing

U Uranium

WDS Wavelength dispersive spectroscopy 


\section{Evaluation of Annealing Treatments for Producing Si- Rich Fuel/Matrix Interaction Layers in Low-Enriched U-Mo Dispersion Fuel Plates Rolled at a Low Temperature}

\section{INTRODUCTION}

Fuel/matrix interaction (FMI) can impact the performance of a low-enriched U-Mo dispersion fuel during irradiation. This can be in terms of the FMI layers that form during fabrication and then are exposed to irradiation or in terms of any continued FMI that occurs during irradiation. The layers that form due to FMI effect fuel plate attributes like thermal conductivity, mechanical properties, or irradiation stability. For U-Mo dispersion fuels with pure $\mathrm{Al}$ as the matrix, it has been observed that relatively large porosity can develop at the FMI layer/matrix interface during irradiation, and this porosity can link up and cause fuel plate failure. ${ }^{1}$ To potentially remedy this phenomenon, it has been suggested that the addition of Si to the matrix of a dispersion fuel can influence the development of a FMI layer such that it will exhibit more stability during irradiation. ${ }^{2}$ Irradiation experiments have shown that in fact U-7Mo dispersion fuel plates with enough $\mathrm{Si}$ added to the matrix do exhibit better irradiation behavior compared to irradiated fuel plates with pure $\mathrm{Al}$ matrix. ${ }^{3}$ It has also been observed that when a Si-rich interaction layer is formed during fabrication of a fuel plate at $500^{\circ} \mathrm{C}$ not much change in the layer thickness may be observed after irradiation for fuel plates with relatively large amounts of Si in the matrix. ${ }^{4}$ This layer appears to be stable during irradiation (i.e., does not develop a large number of gross fission gas bubbles), and the layer appears to act as a diffusion barrier to further FMI during irradiation. ${ }^{5}$ However, when a fuel plate is fabricated at a lower temperature (e.g., $425^{\circ} \mathrm{C}$ ) due to the use of a softer cladding material, the FMI that occurs is reduced and as a result the interaction layer that forms is narrower and less uniform around the U-7Mo fuel particles. This means that with the reduction in the amount of potentially stable Si-rich interaction layer present in the fuel plate, the irradiation performance of the fuel plate may be impacted. Consequently, the formation of a more uniform Si-rich interaction layer around the U-7Mo particles during fuel plate fabrication could improve fuel plate irradiation behavior. This could be achieved by incorporating an annealing step into the fuel plate production process.

To help identify some potential annealing treatments for producing uniform Si-rich interaction layers around U-7Mo fuel particles in fuel plates fabricated at relatively low temperatures, annealing studies were performed using fuel plates fabricated at $425^{\circ} \mathrm{C}$. These plates were produced using the softer cladding AA5052 instead of the AA6061 that is used to fabricate plates at $500^{\circ} \mathrm{C}$. The goal of this work was to identify heat treatments that produce FMI layers most similar to those observed in fuel plates fabricated at $500^{\circ} \mathrm{C}$ that have been observed to exhibit favorable irradiation behavior. Four different heat treatments were tested, viz. $450^{\circ} \mathrm{C}, 475^{\circ} \mathrm{C}, 500^{\circ} \mathrm{C}$, and $525^{\circ} \mathrm{C}$ for $4,4,2$, and 1 hour(s), respectively, using fuel plates with matrices that contained 2, 4, 5, or $6 \mathrm{wt} \% \mathrm{Si}$. Microstructural analysis using scanning electron microscopy (SEM) with energy-dispersive and wavelength-dispersive spectroscopy (EDS/WDS) was performed on the annealed samples. Image analysis was performed using SEM generated images to determine the thickness and area fraction of the FMI layer that was present in the various tested samples.

This report describes the results of these experiments in terms of the interaction layer thickness that was observed around the fuel particles and the amount of Si present in the layers for each test condition. Qualitative comments are made about the uniformity of the layers. The optimal combination of heat treatment and matrix Si content of a dispersion fuel plate with U-7Mo particles is identified for producing FMI layers in fuel plates rolled at the relatively low temperature of $425^{\circ} \mathrm{C}$ that are most similar to those that develop in fuel plates fabricated at $500^{\circ} \mathrm{C}$. 


\section{EXPERIMENTAL}

\subsection{Sample Fabrication}

DU-7Mo alloy pins were first fabricated using arc melting and gravity casting. These pins were made into powders using the rotating electrode process. The produced powders were sieved and the final powder size distribution for the 333.57 grams of powder that was produced is shown in Table 1. Highpurity $\mathrm{Si}(99.999 \% \mathrm{Si})$ and $\mathrm{Al}(99.5 \% \mathrm{Al}, 0.12 \% \mathrm{Fe}, 0.15 \% \mathrm{Si})$ powders were mixed in the various ratios for 30 minutes in a Turbula Mixer, and then vacuum degassed in a tube furnace. The Si powders were all less than $45 \mu \mathrm{m}$ ( $325 \mathrm{mesh})$ in size, and the available information on the Al powder size distribution is listed in Table 2. Results of chemical analysis of the final Al and Si powder mixtures are enumerated in Table 3.

Table 1. DU-7Mo Powder Size Distribution for Annealing Study Fuel Plates.

\begin{tabular}{|l|c|c|}
\hline \multicolumn{1}{|c|}{ Sieve Size $(\mu \mathrm{m})$} & Powder Mass $(\mathrm{g})$ & Weight \% \\
\hline $106 \mu \mathrm{m}(140 \mathrm{mesh})$ & 0 & 0 \\
\hline $90 \mu \mathrm{m}(170 \mathrm{mesh})$ & 61.9 & 18.56 \\
\hline $75 \mu \mathrm{m}(200 \mathrm{mesh})$ & 113.54 & 34.04 \\
\hline $63 \mu \mathrm{m}(230 \mathrm{mesh})$ & 54.70 & 16.40 \\
\hline $53 \mu \mathrm{m}(270 \mathrm{mesh})$ & 13.49 & 4.05 \\
\hline $45 \mu \mathrm{m}(325 \mathrm{mesh})$ & 22.79 & 6.83 \\
\hline Fines $(<45 \mathrm{~mm})$ & 67.12 & 20.12 \\
\hline
\end{tabular}

Table 2. Powder size distribution for $\mathrm{Al}$ powder.

\begin{tabular}{|l|c|}
\hline \multicolumn{1}{|c|}{ Sieve Size $(\mu \mathrm{m})$} & $(\%)$ \\
\hline$>150 \mu \mathrm{m}(100 \mathrm{mesh})$ & 0 \\
\hline$>75 \mu \mathrm{m}(200 \mathrm{mesh})$ & 3.6 \\
\hline$>45 \mu \mathrm{m}(325 \mathrm{mesh})$ & 12.8 \\
\hline$<45 \mu \mathrm{m}(325 \mathrm{mesh})$ & 83.5 \\
\hline
\end{tabular}

Table 3. Composition of Al-Si Powder Mixtures.

\begin{tabular}{|l|l|c|c|}
\hline \multicolumn{1}{|c|}{ FASB Powder No. } & \multicolumn{1}{c|}{$\begin{array}{c}\text { Nominal Composition } \\
(\mathrm{Wt} \%)\end{array}$} & $\begin{array}{c}\text { Measured Si } \\
(\mathrm{Wt} \%)\end{array}$ & $\begin{array}{c}\text { Measured Fe } \\
(\mathrm{Wt} \%)\end{array}$ \\
\hline FASB-151 & $\mathrm{Al}-2 \mathrm{Si}$ & 1.98 & 0.20 \\
\hline FASB-156 & $\mathrm{Al}-4 \mathrm{Si}$ & 3.69 & 0.18 \\
\hline FASB-153 & $\mathrm{Al}-5 \mathrm{Si}$ & 4.82 & 0.18 \\
\hline FASB-168 & $\mathrm{Al}-6 \mathrm{Si}$ & 5.98 & 0.17 \\
\hline All other impurities were under $0.02 \mathrm{wt} \%$ & \multicolumn{2}{|l}{} \\
\hline
\end{tabular}

Powder compacts that could be used to produce $8 \mathrm{gU} / \mathrm{cc}$ fuel plates were made in a hardened tool steel die that was designed to make miniplates at 6:1 rolling reduction, where the compact dimensions were ( 0.586 " long x 0.702 " wide x 0.120 " high). A compacting force of 30 kip was applied for 60 seconds. The cladding material used for fuel plate fabrication was AA5052, with a nominal composition of (95.7-97.7)Al-(2.20-2.80)Mg-(0.15-0.35)Cr with less than 0.10, 0.40, 0.10, 0.25, and $0.10 \mathrm{wt} \% \mathrm{Cu}, \mathrm{Fe}, \mathrm{Mn}, \mathrm{Si}$, and $\mathrm{Zn}$, respectively. This alloy was selected because of its similar 
composition compared to AG3NE cladding, which is a cladding used when fabricating fuel plates at low temperatures. The difference in alloying additives between the two alloys is around $2 \mathrm{wt} \%$. The cladding pocket and cover plates were cleaned, put into a glovebox, loaded with compacts, and TIG welded together along the full perimeter. Rolling of fuel plates was performed by following the schedule listed in Table 4, and no blister anneal was used on the as-fabricated plates. The fuel plates that were produced had nominally Al-2Si, Al-4Si, Al-5Si, or Al-6Si matrices. Ultrasonic testing (UT) was employed to determine the bonding quality of the final plates. Some isolated debonds were observed in the fuel plates, and an example UT scan is presented in Figure 1. Since these plates were going to be used for annealing studies, not reactor testing, it was determined that they were of sufficient quality. Radiography was utilized to locate the fuel zones in the fuel plates. Small samples ( 0.3"x 1") were sliced from each plate to be used in the annealing experiments.

Table 4. Fuel Plate Rolling Schedule.

\begin{tabular}{|c|c|c|c|c|c|}
\hline Pass & $\begin{array}{c}\text { Soak before pass } \\
\text { (min) }\end{array}$ & $\begin{array}{c}\text { Thickness in } \\
\text { (inches) }\end{array}$ & $\begin{array}{c}\text { Thickness out } \\
\text { (inches) }\end{array}$ & $\begin{array}{c}\text { Reduction } \\
\text { (X:1) }\end{array}$ \\
\hline 1 & 30 & 0.375 & 0.263 & 30 & 1.4 \\
\hline 2 & 10 & 0.263 & 0.197 & 25 & 1.9 \\
\hline 3 & 10 & 0.197 & 0.148 & 25 & 2.5 \\
\hline 4 & 10 & 0.148 & 0.118 & 20 & 3.2 \\
\hline 5 & 5 & 0.118 & 0.095 & 20 & 4 \\
\hline 6 & 5 & 0.095 & 0.076 & 20 & 5 \\
\hline 7 & 5 & 0.076 & 0.062 & 17 & 6 \\
\hline 8 & 5 & 0.062 & 0.062 & 0 & 6 \\
\hline
\end{tabular}

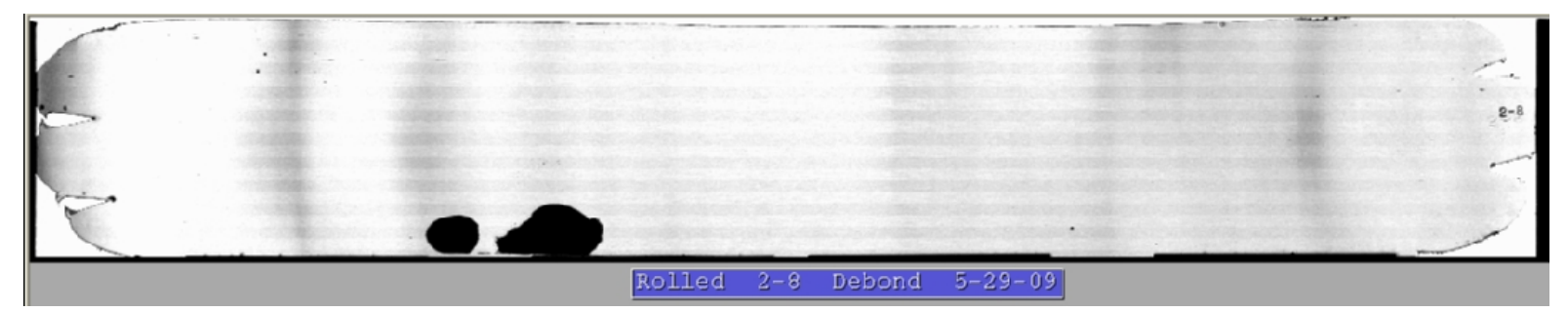

Figure 1. An example UT scan that was produced for an annealing study fuel plate.

\subsection{Annealing Experiments}

Each sample was cleaned with acetone/ethanol, wrapped in 0.0005 " thick tantalum foil, and loaded into a Type 304 stainless steel annealing capsule (see Figure 2). For the case where a capsule was not completely filled with test samples, plain Al dummy plates were used to fill any empty slots. The capsules were then transported to an argon glovebox where steel caps were hermetically welded to each capsule using TIG welding. These assemblies were then removed from the glovebox and Swagelok fittings were installed at the end of the evacuation tube (see Figure 3). To perform an annealing treatment, the capsule evacuation tube was attached to a vacuum roughing pump and evacuated to $\sim 24 \mathrm{mmHg}$. The capsule was then inserted into a preheated box furnace (Thermo Scientific Thermolyne) along with a Type K thermocouple (TC) that was attached to a data-logger TC reader, which were left in the furnace for the prescribed temperature and time. The evacuation of the capsule continued throughout the entire heat treatment. The annealing treatments were performed at $450^{\circ} \mathrm{C}, 475^{\circ} \mathrm{C}, 500^{\circ} \mathrm{C}$, and $525^{\circ} \mathrm{C}$ for 4 hours, 4 hours, 2 hours, and 1 hour, respectively, using fuel plates with matrices that contained 2, 4, 5, or $6 \mathrm{wt} \%$ $\mathrm{Si}$. Only the fuel plates with 4 and $6 \mathrm{wt} \% \mathrm{Si}$ were tested at $525^{\circ} \mathrm{C}$. The measured TC temperature readings for the duration of some specific annealing treatments are shown in Figure 4. 


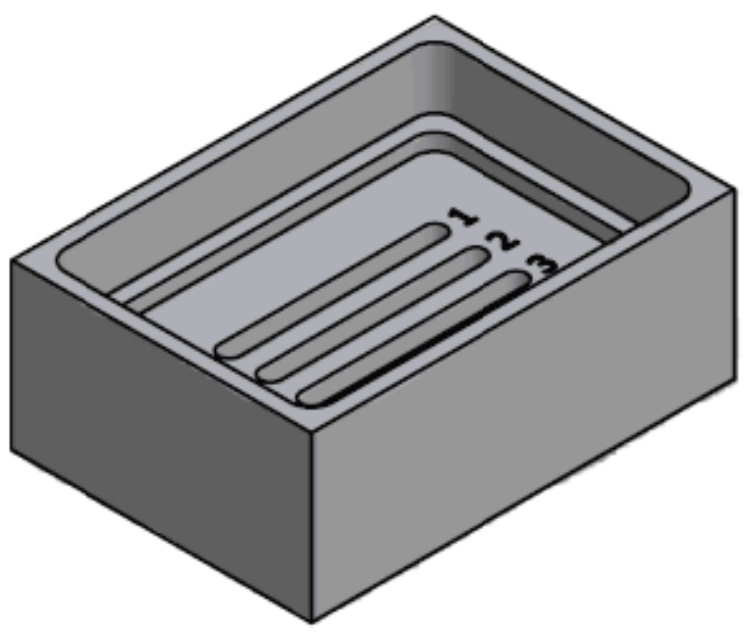

Figure 2. Schematic diagram of an annealing capsule.

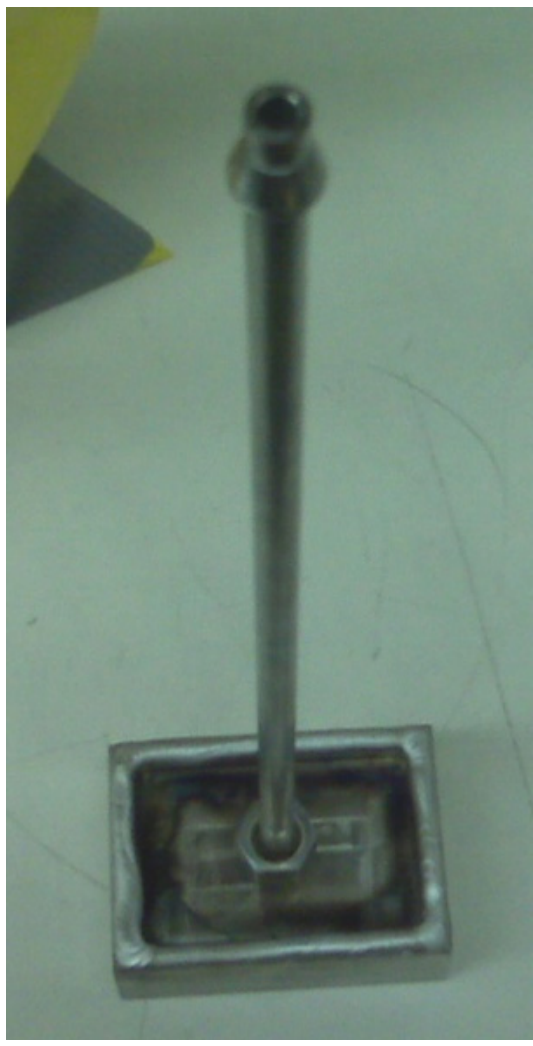

Figure 3. Swagelok fitting at the end of an evacuation tube. 


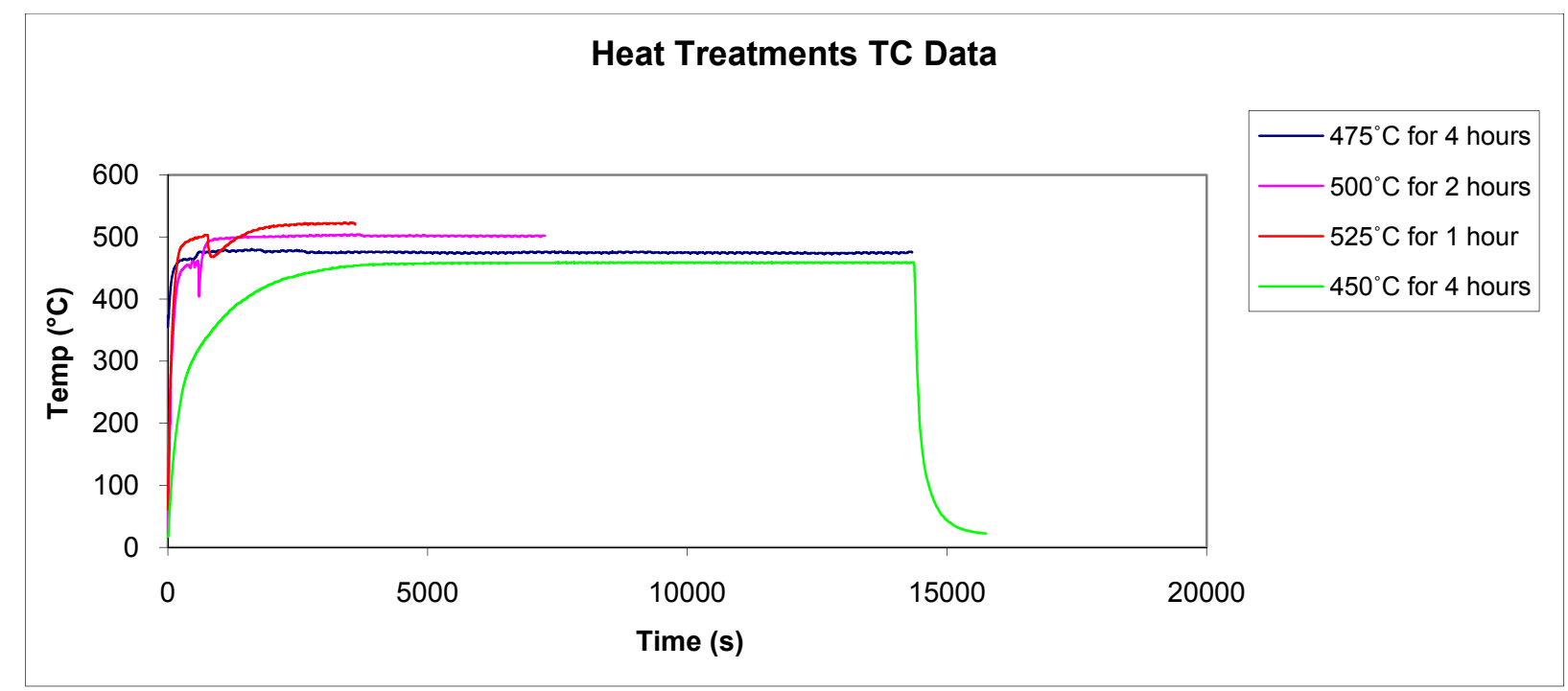

Figure 4. Measured temperature profiles for some different annealing treatments.

\subsection{Microstructural Characterization}

The annealed samples were removed from the capsules by sawing off the welded edges. Samples were removed from the capsule slots, unwrapped from the Ta foils, and then mounted to expose sample cross sections using a 12-hour curing time epoxy. Mounted samples were polished through 1200 grit sandpaper. The mounted samples were then coated with Pd and inserted into a JEOL JSM-7000F FEG SEM equipped with energy dispersive and wavelength dispersive spectrometers (EDS/WDS) and Oxford INCA software for the generation of backscattered electron (BSE) and secondary electron (SE) images, semi-quantitative point-to-point composition analysis, and X-ray mapping. A software correction was used to account for the Pd coating. Some results of the semi-quantitative point-to-point composition analysis are listed in tables included in this report, and due to rounding of the measured values, the summation of $\mathrm{U}, \mathrm{Mo}, \mathrm{Al}$, and $\mathrm{Si}$ does not always add to 100 atomic percent.

Using SEM micrographs from the characterization of the annealing study samples, the software program, "Image J," was used to calculate average thickness, minimum thickness, maximum thickness, average fuel area fraction, average IL area fraction, and IL to fuel area fraction ratio. These values were determined using the threshold command in Image $J$ to highlight the matrix, fuel, and interaction layers separately. A total of five 500x-magnification micrographs were analyzed per sample for statistical purposes. 


\section{MICROSTRUCTURAL CHARACTERIZATION RESULTS \\ 3.1 Observed Decomposition of $\gamma-(\mathrm{U}, \mathrm{Mo})$}

Decomposition of $\gamma$-(U,Mo) phase was observed in all of the samples that were characterized, including the as-fabricated samples. Figure 5 gives examples of decomposition that were observed in U-7Mo particles in the as-fabricated or heat-treated condition. In many cases, the decomposed regions appeared as bumps on the surface of the U-7Mo particles. These localized areas that were in relief contained elevated concentrations of oxygen. The oxygen x-ray map in Figure 6 shows some localized areas elevated in oxygen within a decomposed region of a U-7Mo particle from a sample that was annealed for 2 hours at $500^{\circ} \mathrm{C}$. The effect on FMI layer formation of having the areas of decomposition in the U-7Mo particles in the different samples will be described in subsequent sections.

\subsection{Interaction Layers in As-Fabricated Fuel Plates}

To adequately understand the effect of a particular heat treatment on the microstructure of an as-fabricated fuel plate, it is necessary to perform characterization to determine the starting microstructure of a fuel plate immediately following fabrication. Figure 7 shows the microstructure of the fuel plate with Al-2Si matrix after fabrication. A very thin interaction layer was observed around the U-7Mo fuel particles. The Si x-ray map in Figure 8 indicates that these layers were enriched in Si. Figure 9 shows the locations where EDS point-to-point composition analysis was performed in an interaction layer, and Table 5 enumerates the results. The measured Si concentrations varied between 24 and $47 \mathrm{at} \% \mathrm{Si}$. In Figure 10, a Si x-ray map for the Al-4Si matrix sample indicated the presence of Si-rich interaction layers around the U-7Mo particles. Also, the Si x-ray map in Figure 11 shows the presence of Si-rich interaction layers in the Al-5Si matrix sample. Figure 12 shows where point-to-point composition analysis was performed in a selected region of the interaction layer in the Al-5Si matrix sample. Based on the results listed in Table 6, the Si concentrations in the layer varied between 21 and 35 at\%. Finally, thin interaction layers were observed around U-7Mo particles in the Al-6Si matrix sample (see Figure 13), and these layers were enriched in Si (see Figure 14). However, in some cases U-7Mo particles could be found with negligible interaction layer present at the U-7Mo/matrix interface (see Figure 14). Based on composition analysis of an interaction layer in the Al-6Si matrix sample (see Figure 15 and Table 7), the Si content in the interaction layer varied between 13 and 23 at\%. Analysis of the composition of another interaction layer in the Al-6Si sample (see Figure 16 and Table 8) indicated that the Si concentration varied between 18 and 30 at\%. Due to the narrow thickness of the interaction layer in these samples, the composition values that were determined should be treated as being very qualitative. Even so, these values do show that appreciable $\mathrm{Si}$ is present in the interaction layers that formed in each of the as-fabricated samples. 


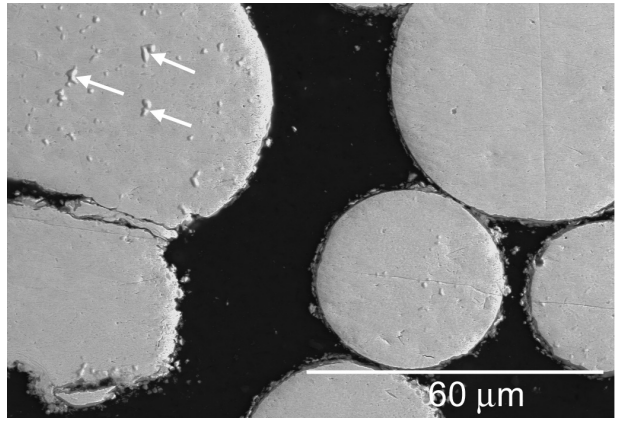

(a)

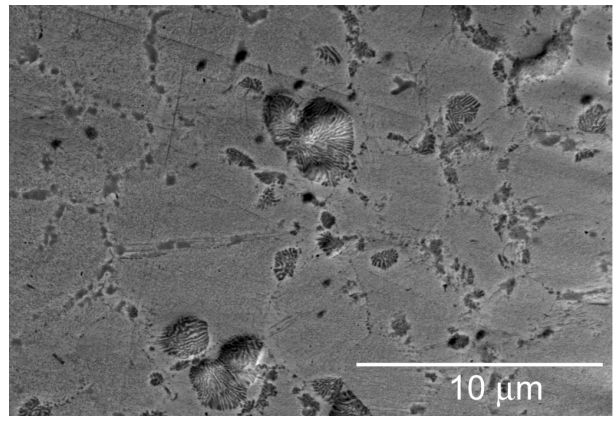

(c)

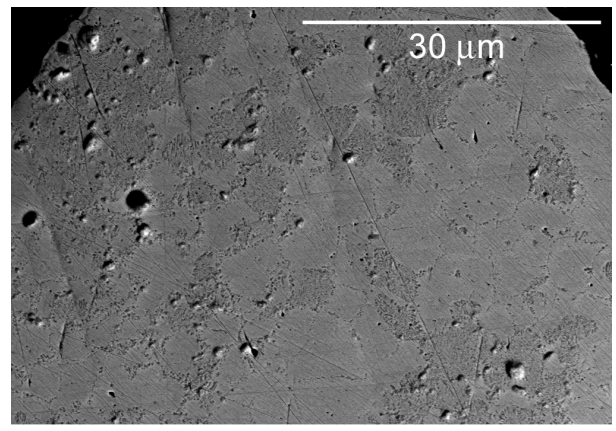

(e)

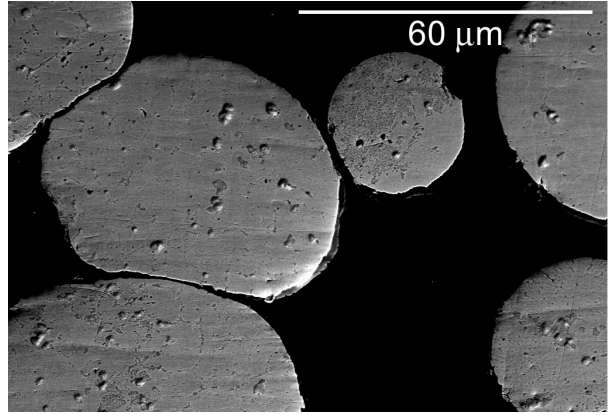

(b)

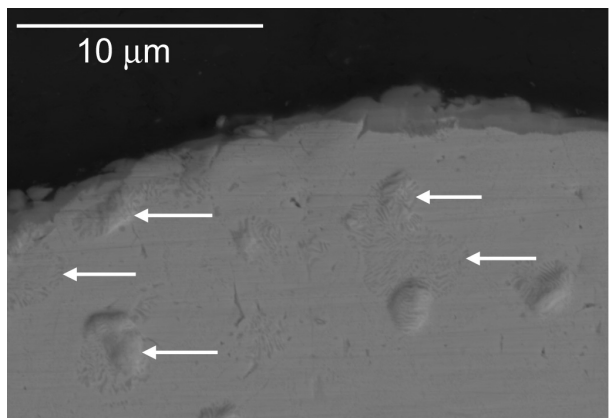

(d)

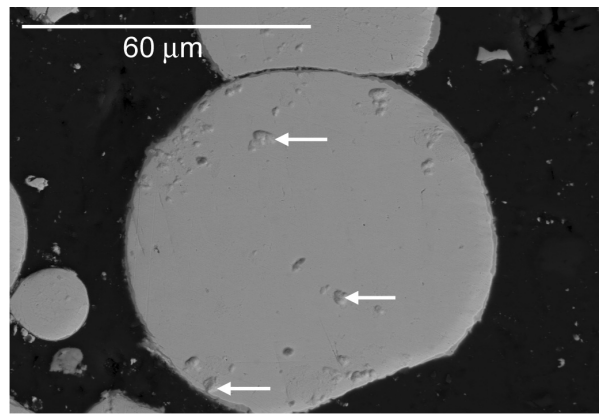

(f)

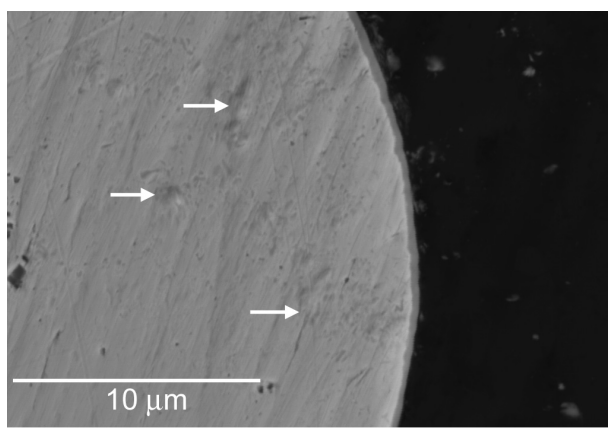

(g)

Figure 5. BSE images of decomposition observed in particular U-7Mo particles from samples in the (a) as-fabricated condition (Al-5Si matrix sample), (b,c) after annealing at $450^{\circ} \mathrm{C}$ for 4 hours (Al-5Si matrix sample), (d) after annealing at $475^{\circ} \mathrm{C}$ for 4 hours (Al-2Si matrix sample), (e) after annealing at $475^{\circ} \mathrm{C}$ for 4 hours (Al-4Si matrix sample), (f) after annealing at $500^{\circ} \mathrm{C}$ for 2 hours (Al-4Si matrix sample), and (g) after annealing at $525^{\circ} \mathrm{C}$ for 1 hour (Al-4Si matrix sample). 


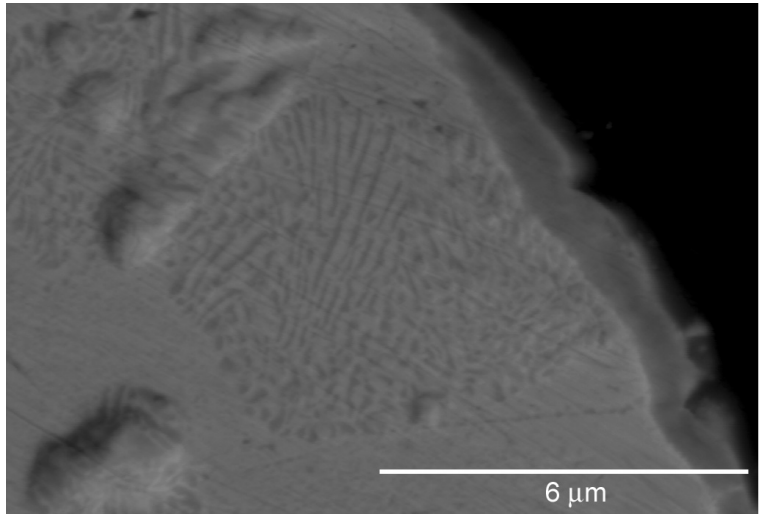

(a)

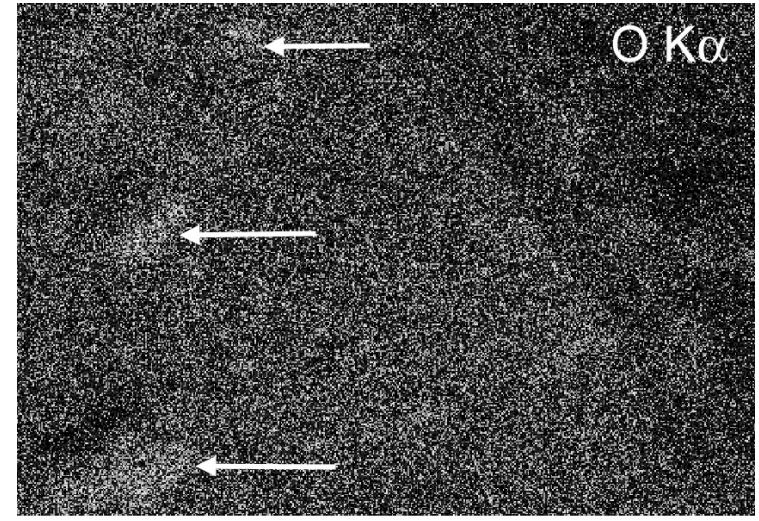

(b)

Figure 6. BSE image (a) and WDS oxygen x-ray map (b) showing where localized regions in transformed U-7Mo are enriched in oxygen.

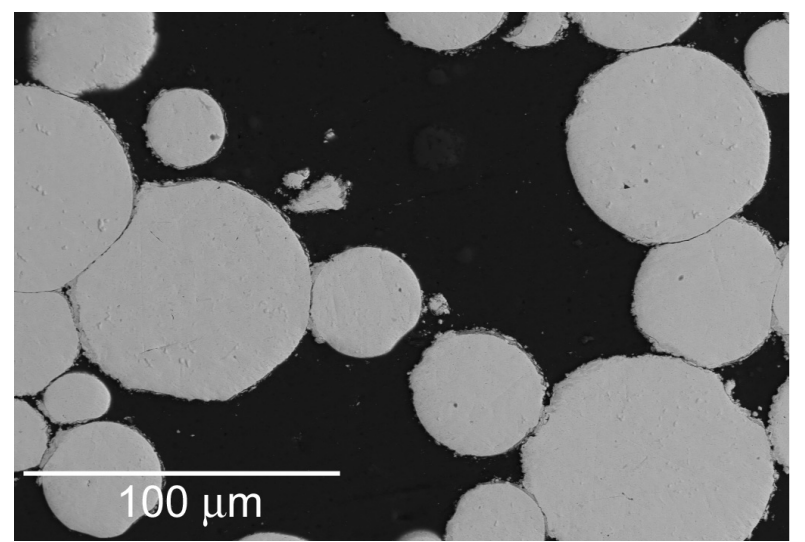

(a)

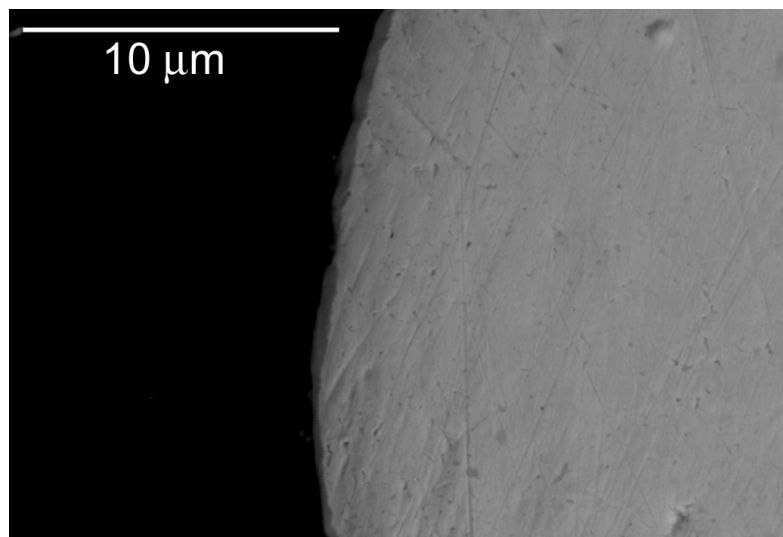

(b)

Figure 7. BSE images $(\mathrm{a}, \mathrm{b})$ of the microstructure of the as-fabricated Al-2Si matrix fuel plate.

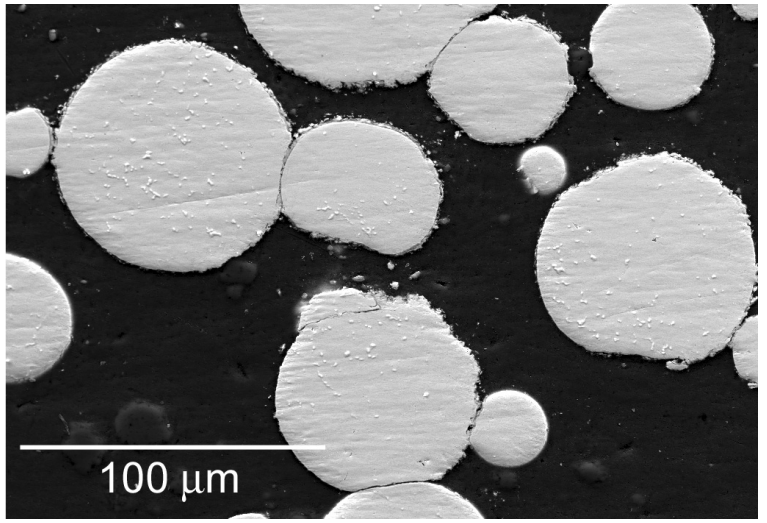

(a)

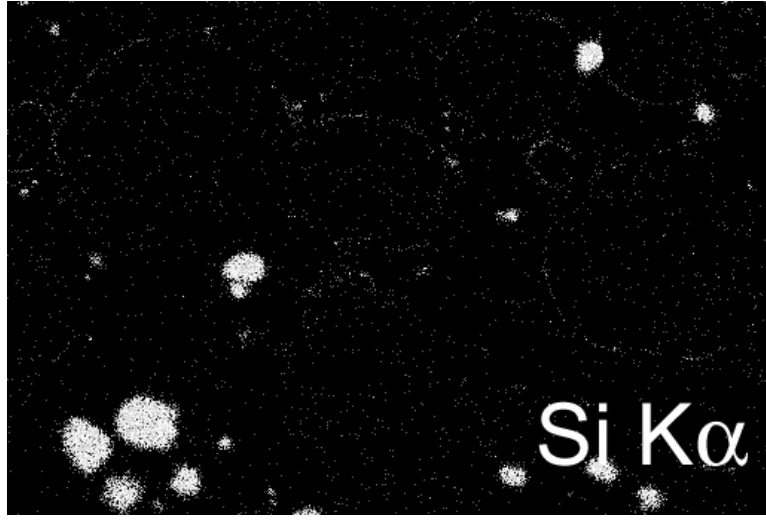

(b)

Figure 8. BSE image (a) and Si x-ray map (b) for the as-fabricated Al-2Si matrix fuel plate. 


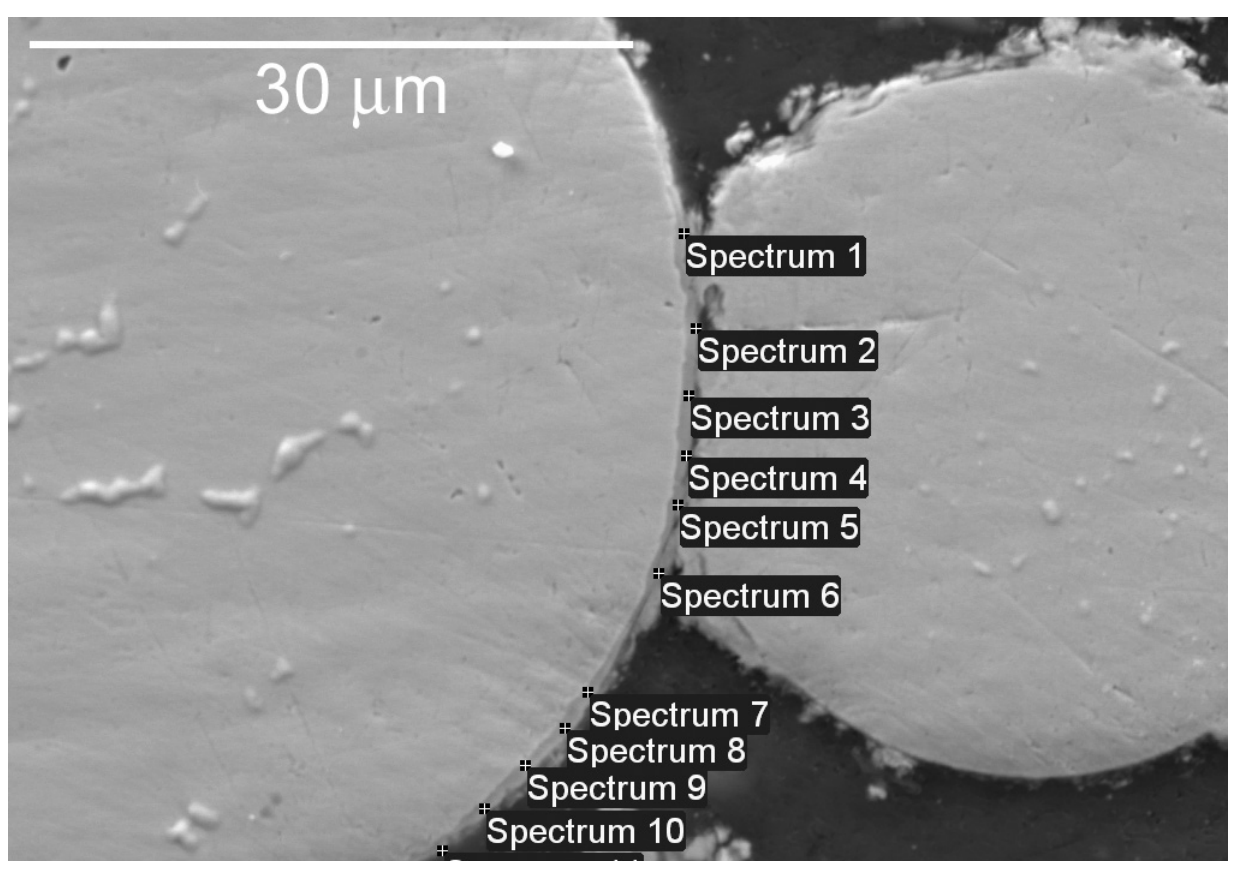

Figure 9. BSE image showing locations where point-to-point composition analysis was performed in the interaction layer of the Al-2Si matrix sample in the as-fabricated condition. (see Table 5 for results).

Table 5. Compositions (at $\%$ ) at various interaction layer locations in the as-fabricated Al-2Si matrix fuel plate (see Figure 9).

\begin{tabular}{|c|c|c|c|c|}
\hline Spectrum No. & $\mathrm{Al}$ & $\mathrm{Si}$ & Mo & $\mathrm{U}$ \\
\hline 1 & 27 & 36 & 4 & 33 \\
\hline 2 & 49 & 24 & 4 & 24 \\
\hline 3 & 17 & 44 & 4 & 34 \\
\hline 4 & 28 & 37 & 3 & 32 \\
\hline 5 & 33 & 27 & 4 & 35 \\
\hline 6 & 37 & 30 & 5 & 28 \\
\hline 7 & 22 & 41 & 5 & 32 \\
\hline 8 & 24 & 44 & 5 & 28 \\
\hline 9 & 16 & 39 & 6 & 39 \\
\hline 10 & 19 & 47 & 4 & 29 \\
\hline 11 & 36 & 45 & 2 & 17 \\
\hline Mean & 28 & 38 & 4 & 30 \\
\hline
\end{tabular}




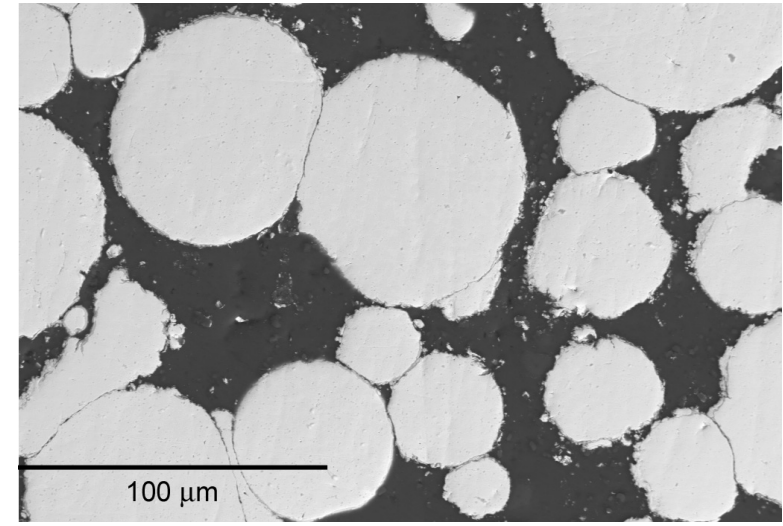

(a)

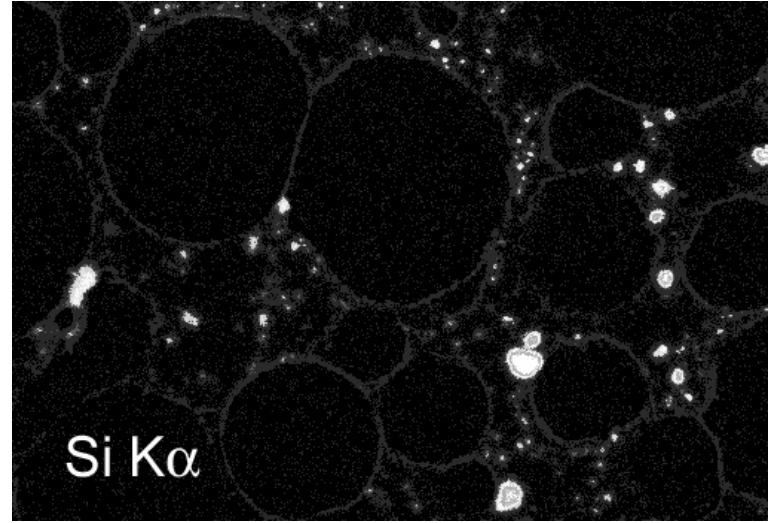

(b)

Figure 10. BSE image (a) and Si x-ray map (b) for the as-fabricated Al-4Si matrix fuel plate.

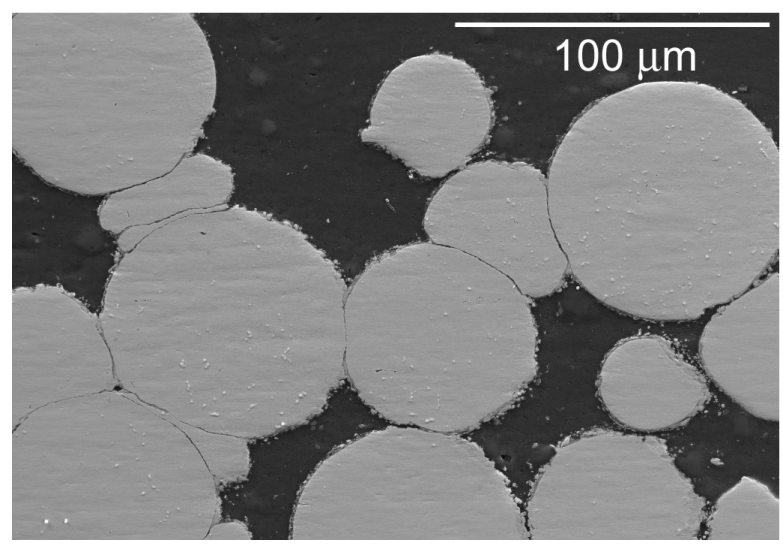

(a)

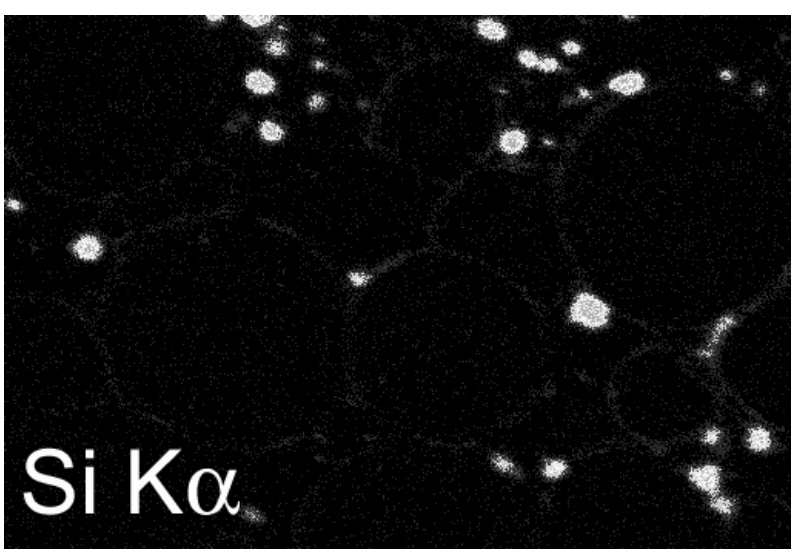

(b)

Figure 11. BSE image (a) and WDS Si x-ray map (b) of the microstructure of the as-fabricated Al-5Si matrix fuel plate. 


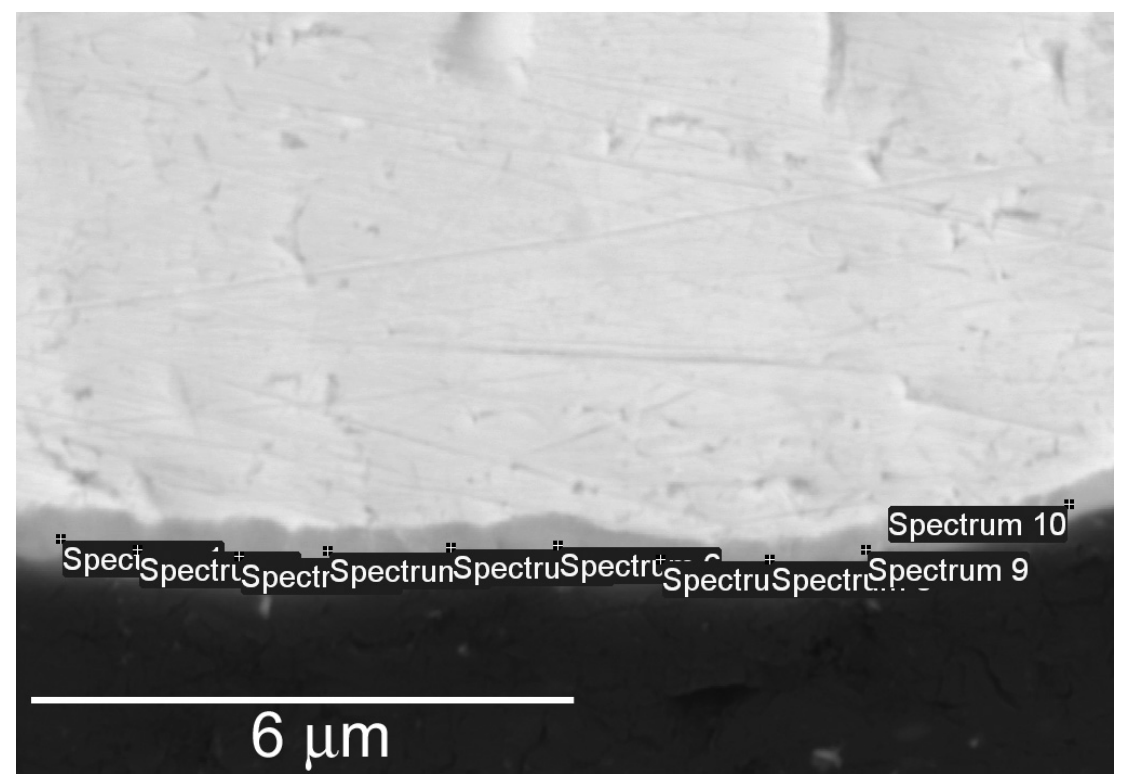

Figure 12. BSE image of the microstructure of the as-fabricated Al-5Si matrix fuel plate and the locations where point-to-point composition analysis was performed (see Table 6 for results).

Table 6. Compositions (at $\%$ ) at various interaction layer locations in the as-fabricated Al-5Si matrix fuel plate (see Figure 12).

\begin{tabular}{|c|c|c|c|c|}
\hline Spectrum No. & $\mathrm{Al}$ & $\mathrm{Si}$ & $\mathrm{Mo}$ & $\mathrm{U}$ \\
\hline 1 & 38 & 35 & 3 & 25 \\
\hline 2 & 41 & 33 & 3 & 23 \\
\hline 3 & 42 & 31 & 3 & 24 \\
\hline 4 & 41 & 32 & 3 & 24 \\
\hline 5 & 50 & 25 & 3 & 22 \\
\hline 6 & 38 & 33 & 3 & 25 \\
\hline 7 & 61 & 21 & 2 & 16 \\
\hline 8 & 53 & 23 & 3 & 21 \\
\hline 9 & 52 & 24 & 3 & 22 \\
\hline 10 & 49 & 26 & 3 & 23 \\
\hline Mean & 47 & 28 & 3 & 22 \\
\hline
\end{tabular}




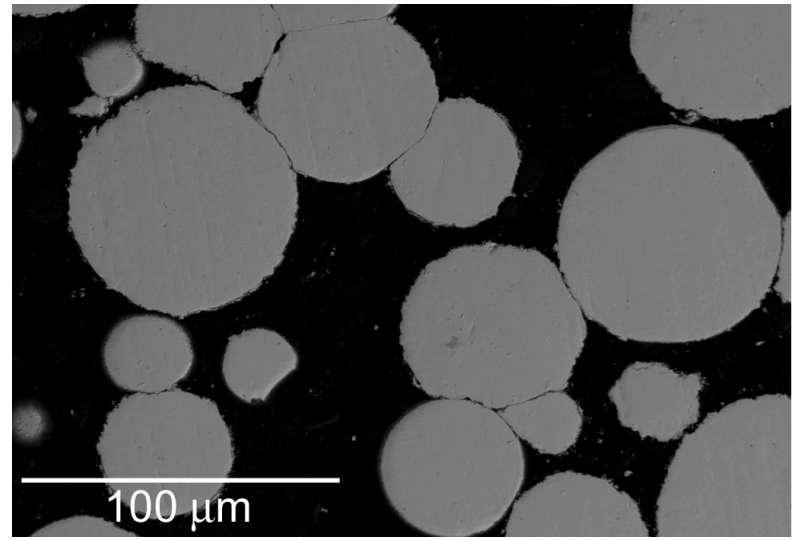

(a)

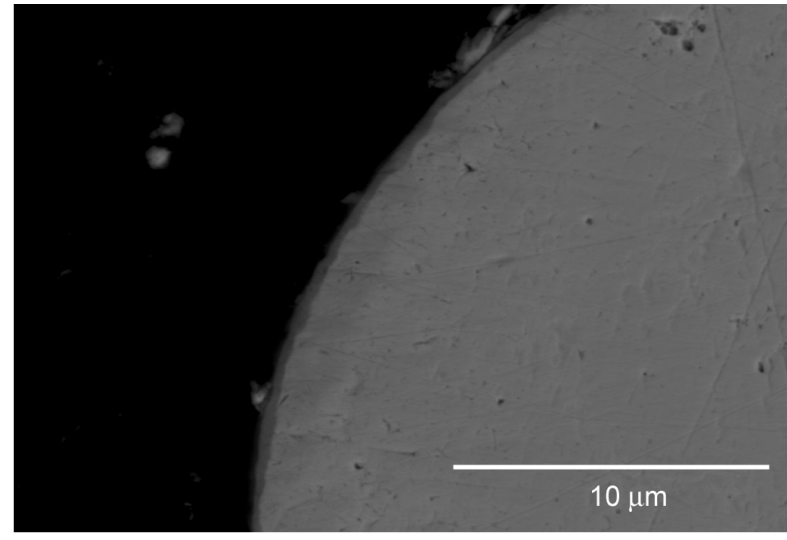

(b)

Figure 13. BSE images $(a, b)$ of the microstructure of the as-fabricated Al-6Si matrix fuel plate.

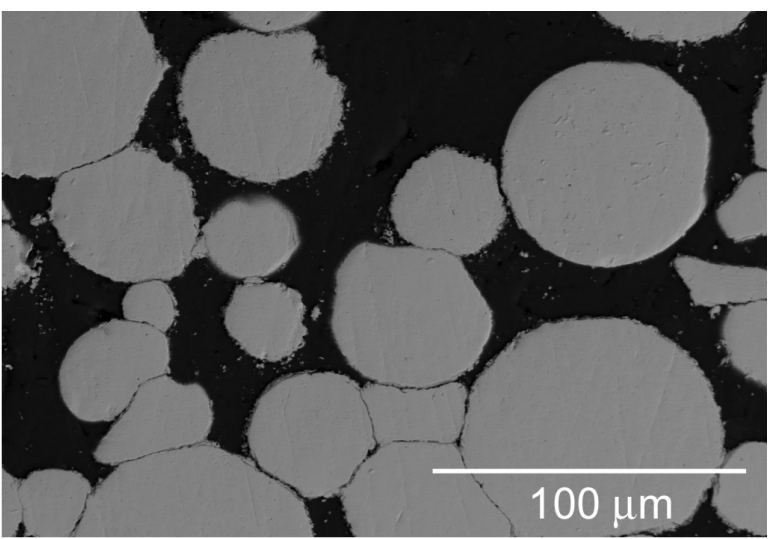

(a)

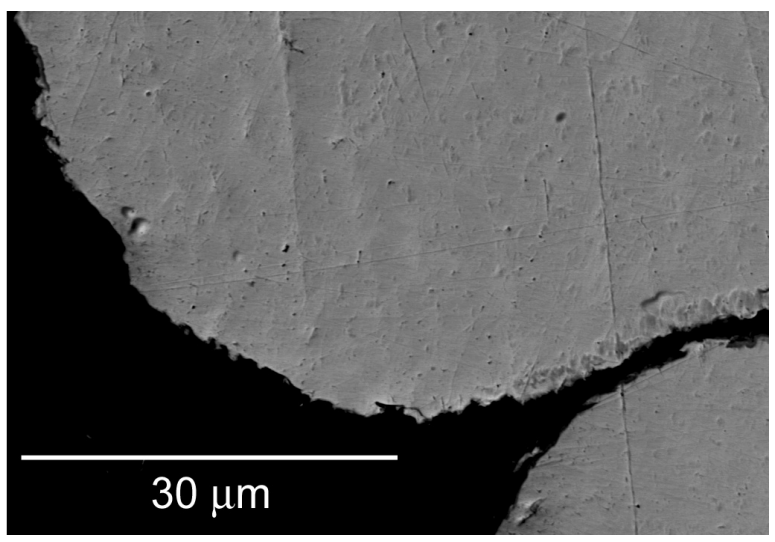

(c)

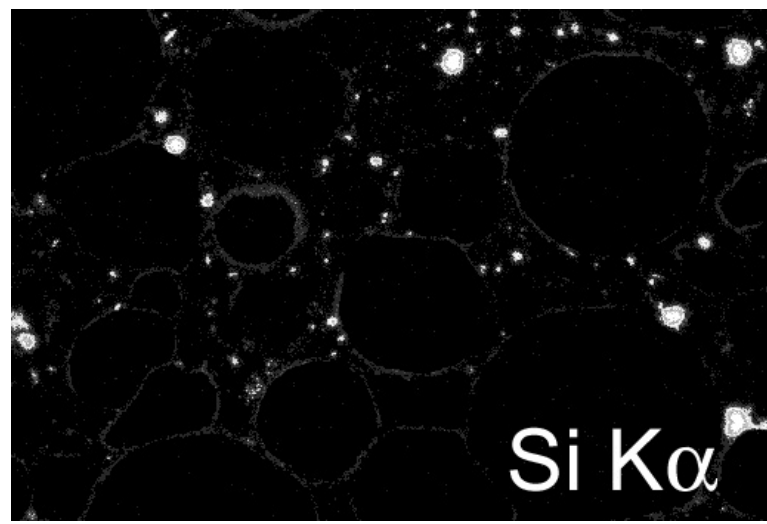

(b)

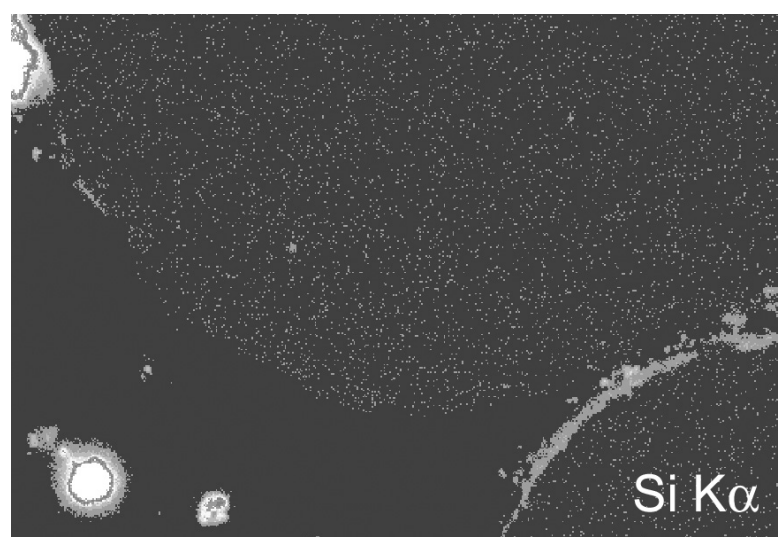

(d)

Figure 14. BSE images (a,c) and WDS Si x-ray maps (b,d) of the microstructure of the as-fabricated Al6 Si matrix fuel plate. 


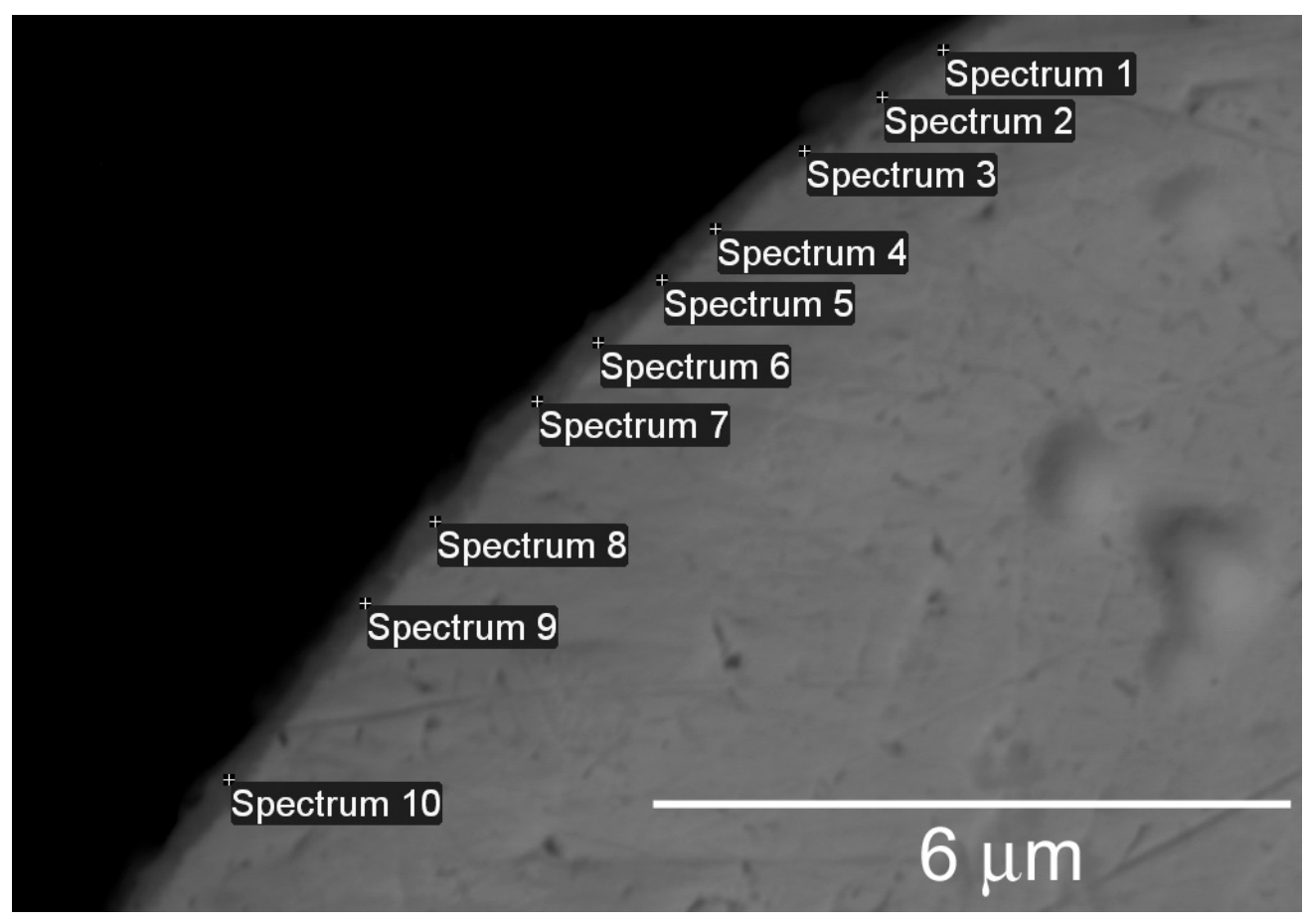

Figure 15. BSE image of the microstructure of the as-fabricated Al-6Si matrix fuel plate with the locations where point-to-point composition analysis was performed (see Table 7 for results).

Table 7. Compositions (at $\%$ ) at various interaction layer locations in the as-fabricated Al-6Si matrix sample (see Figure 15).

\begin{tabular}{|c|c|c|c|c|}
\hline Spectrum No. & $\mathrm{Al}$ & $\mathrm{Si}$ & Mo & $\mathrm{U}$ \\
\hline 1 & 43 & 17 & 5 & 35 \\
\hline 2 & 31 & 14 & 6 & 49 \\
\hline 3 & 36 & 14 & 6 & 45 \\
\hline 4 & 32 & 13 & 7 & 49 \\
\hline 5 & 33 & 15 & 7 & 46 \\
\hline 6 & 29 & 22 & 6 & 43 \\
\hline 7 & 34 & 20 & 6 & 40 \\
\hline 8 & 33 & 20 & 6 & 41 \\
\hline 9 & 42 & 15 & 5 & 38 \\
\hline 10 & 36 & 23 & 5 & 36 \\
\hline Mean & 35 & 17 & 6 & 42 \\
\hline
\end{tabular}




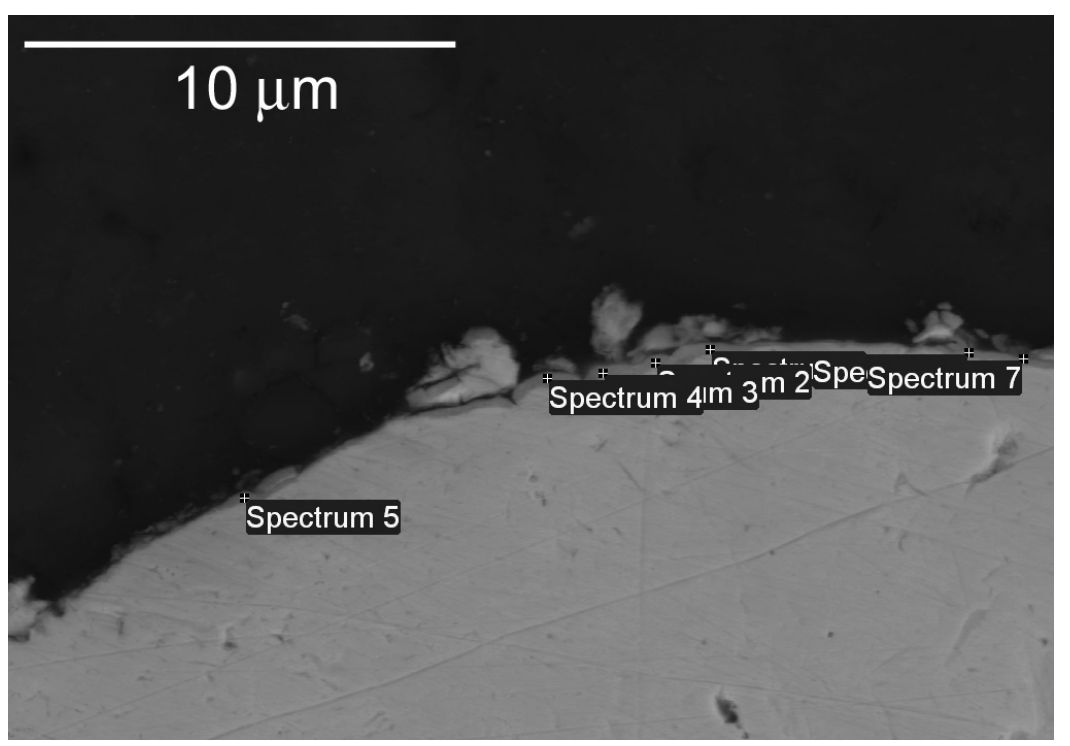

Figure 16. BSE image of the microstructure of the as-fabricated Al-6Si matrix fuel plate and locations where point-to-point composition analyses were performed (results in Table 8).

Table 8. Compositions (at $\%$ ) at various interaction layer locations in the as-fabricated Al-6Si matrix fuel plate (see Figure 16).

\begin{tabular}{|c|c|c|c|c|}
\hline Spectrum No. & Al & Si & Mo & U \\
\hline 1 & 30 & 30 & 5 & 34 \\
\hline 2 & 27 & 30 & 5 & 38 \\
\hline 3 & 32 & 24 & 5 & 39 \\
\hline 4 & 42 & 24 & 4 & 30 \\
\hline 5 & 39 & 22 & 4 & 35 \\
\hline 6 & 44 & 22 & 4 & 30 \\
\hline 7 & 53 & 18 & 4 & 25 \\
\hline Mean & 38 & 24 & 4 & 33 \\
\hline
\end{tabular}

\subsection{Interaction Layer Development after Annealing Treatment at $450^{\circ} \mathrm{C}$ for 4 Hours}

\subsubsection{U-7Mo/Al-2Si Fuel Plate}

Like was the case for the as-fabricated Al-2Si matrix sample, the Al-2Si sample annealed for 4 hours at $450^{\circ} \mathrm{C}$ contained a similar thin interaction layer (see Figure 17). It appears that there was not much change in thickness during the annealing treatment at $450^{\circ} \mathrm{C}$ over what was observed after fabrication. The Si x-ray map presented in Figure 18 indicates that the layers that formed were enriched in $\mathrm{Si}$, but they were not uniformly present around the U-7Mo particles. Point-to-point composition analysis was performed on a particular layer (see Figure 19) and the results are enumerated in Table 9. The Si concentration values varied between 15 and 22 at $\%$. 


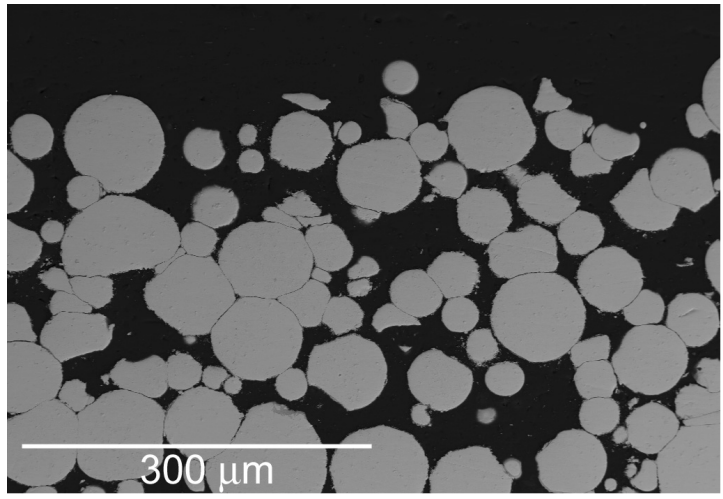

(a)

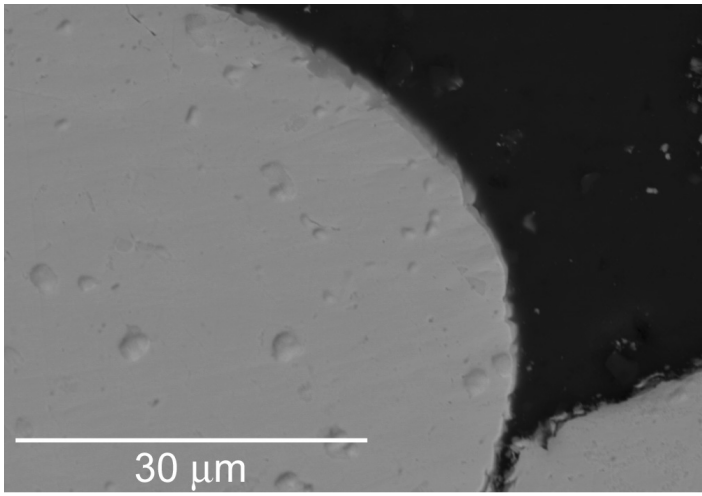

(b)

Figure 17. BSE images $(\mathrm{a}, \mathrm{b})$ of the microstructure of the Al-2Si matrix fuel plate annealed for 4 hours at $450^{\circ} \mathrm{C}$.

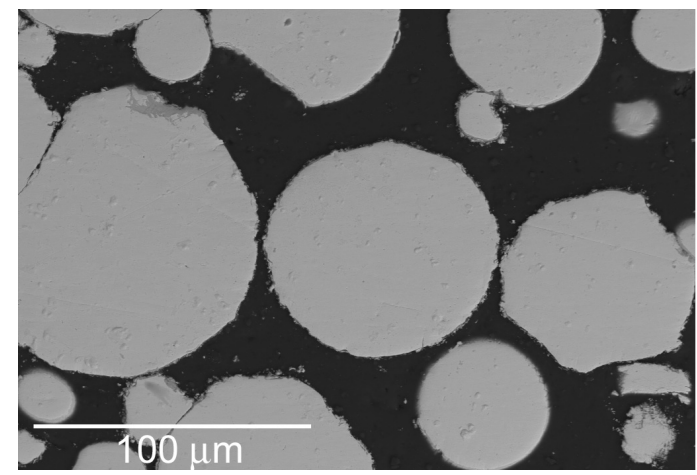

(a)

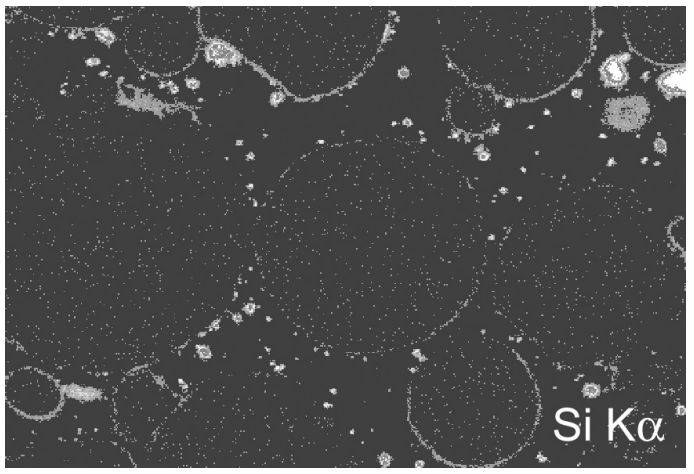

(b)

Figure 18. BSE image (a) and Si x-ray map (b) for the Al-2Si matrix fuel plate annealed for 4 hours at $450^{\circ} \mathrm{C}$

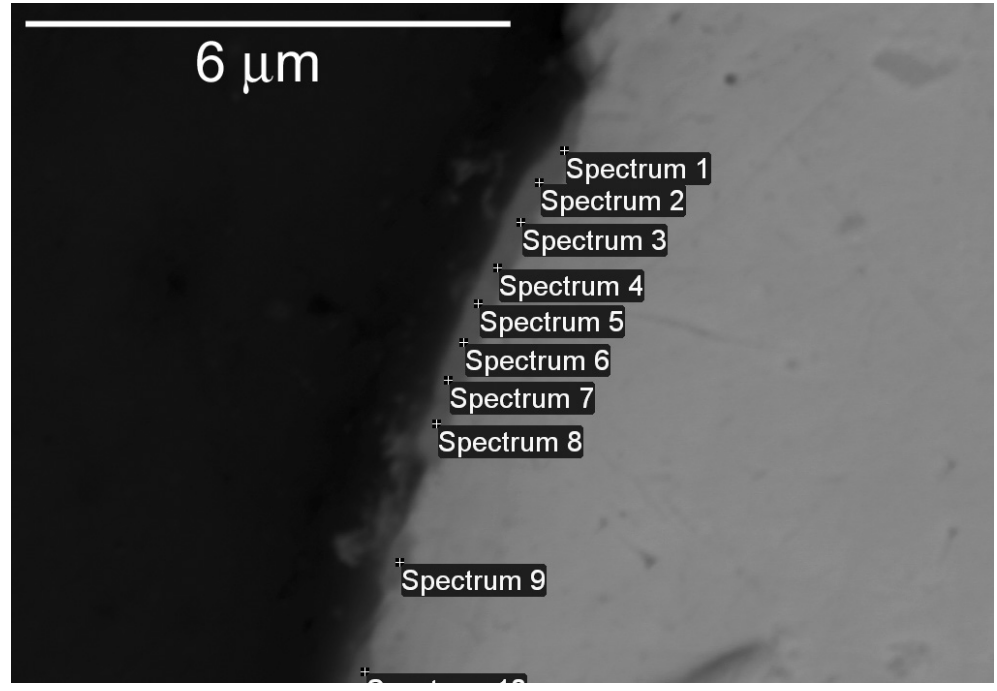

Figure 19. BSE image of the microstructure of a fuel/matrix interaction layer in the Al-2Si matrix fuel plate annealed for 4 hours at $450^{\circ} \mathrm{C}$ and the locations where point-to-point composition analysis was performed (see Table 9 for results). 
Table 9. Results (at \%) of point-to-point composition analysis performed in the interaction layer depicted in Figure 19.

\begin{tabular}{|c|c|c|c|c|}
\hline Spectrum No. & $\mathrm{Al}$ & $\mathrm{Si}$ & $\mathrm{Mo}$ & $\mathrm{U}$ \\
\hline 1 & 47 & 20 & 4 & 29 \\
\hline 2 & 50 & 21 & 3 & 26 \\
\hline 3 & 46 & 22 & 4 & 28 \\
\hline 4 & 52 & 20 & 4 & 24 \\
\hline 5 & 53 & 21 & 3 & 23 \\
\hline 6 & 52 & 21 & 3 & 23 \\
\hline 7 & 59 & 18 & 3 & 20 \\
\hline 8 & 55 & 20 & 3 & 23 \\
\hline 9 & 54 & 18 & 3 & 25 \\
\hline 10 & 58 & 15 & 3 & 23 \\
\hline Mean & 53 & 19 & 3 & 24 \\
\hline
\end{tabular}

\subsubsection{U-7Mo/Al-4Si Fuel Plate}

The microstructure observed for the Al-4Si matrix plate is shown in Figure 20, and a Si X-ray map is presented in Figure 21. Narrow, Si-rich interaction layers are observed around the U-7Mo particles, along with the widely distributed $\mathrm{Si}$-rich powders that constitute the matrix.

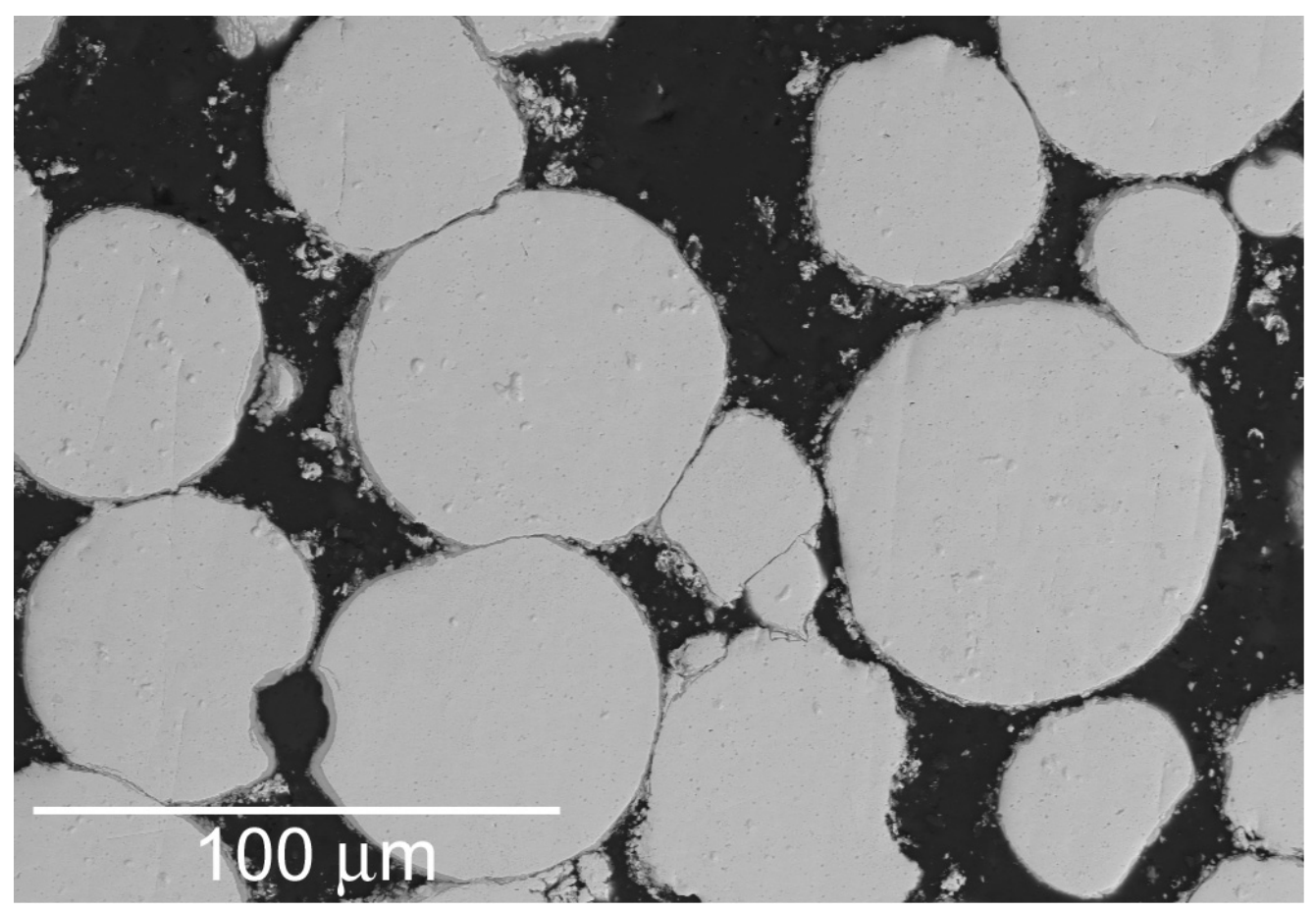

Figure 20. BSE image of the microstructure of the Al-4Si matrix fuel plate annealed for 4 hours at $450^{\circ} \mathrm{C}$. 


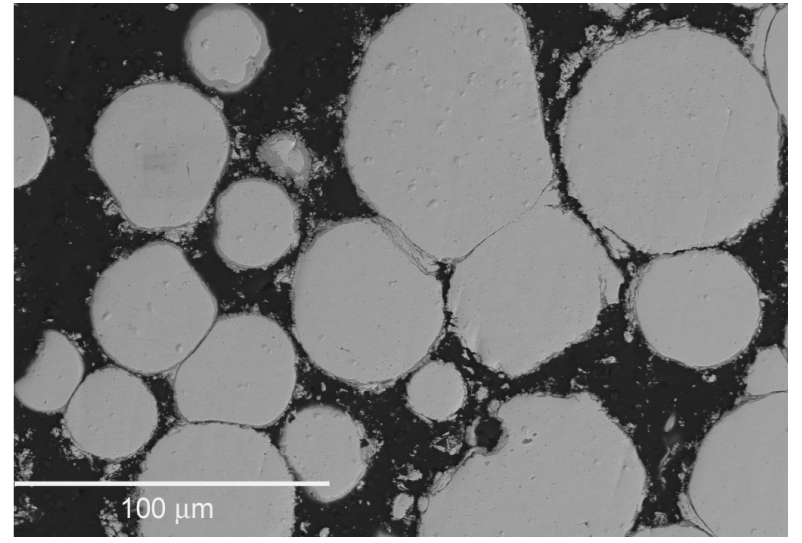

(a)

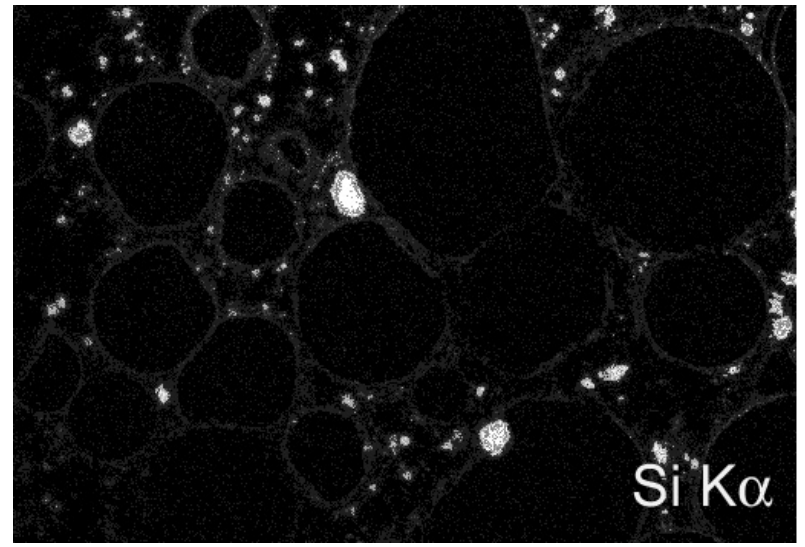

(b)

Figure 21. Backscattered electron image (a) and WDS Si x-ray map (b) for the Al-4Si matrix fuel plate annealed for 4 hours at $450^{\circ} \mathrm{C}$.

\subsubsection{U-7Mo/Al-5Si Fuel Plate}

In Figure 22, a BSE image of the general microstructure of the $\mathrm{Al}-5 \mathrm{Si}$ matrix plate annealed at $450^{\circ} \mathrm{C}$ is presented, and higher magnification images of the interaction layer that was found around the U-7Mo particles are presented in Figure 23. The presence of decomposed regions in the U-7Mo alloy did not appear to have a large impact on the uniformity and thickness of the interaction layers. The locations in an interaction layer where point-to-point composition analysis was conducted are shown in Figure 24, and the results are enumerated in Table 10. The Si concentration in the layer varied between 12 and 42 at $\%$. The layer appeared to be fairly uniform in thickness.

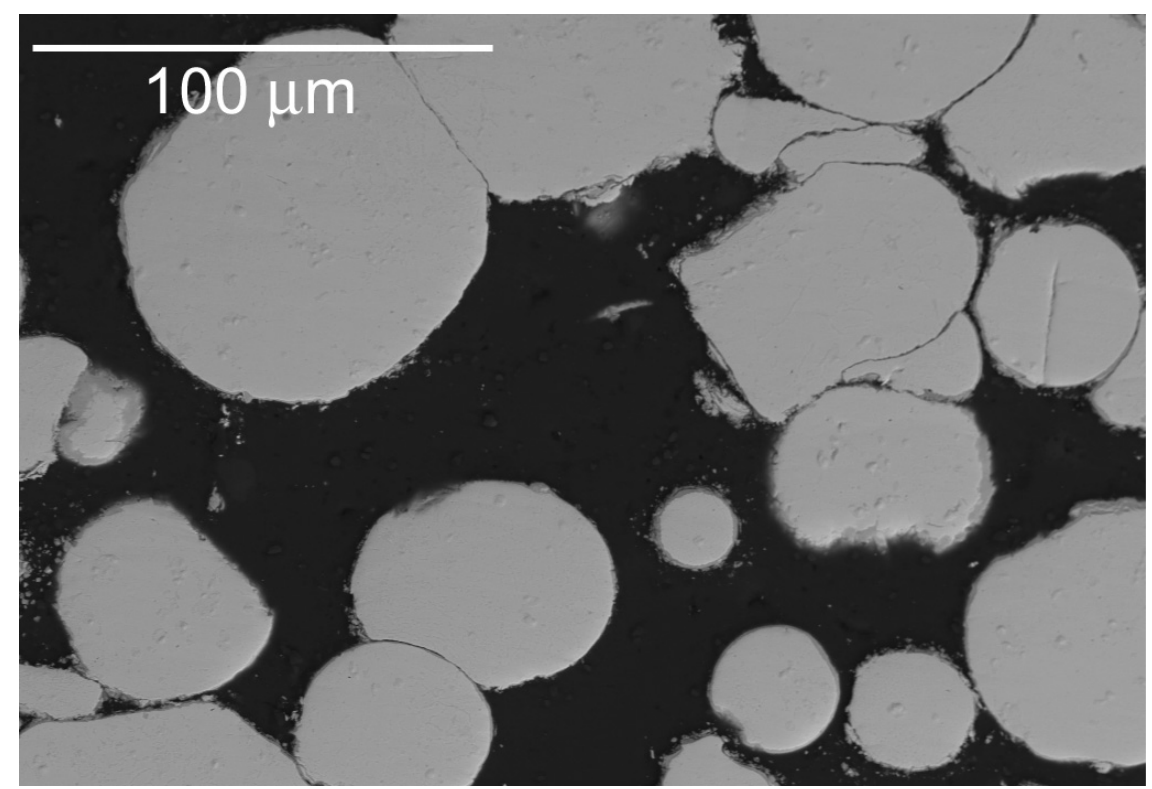

Figure 22. BSE image of the microstructure of the Al-5Si matrix fuel plate annealed for 4 hours at $450^{\circ} \mathrm{C}$. 


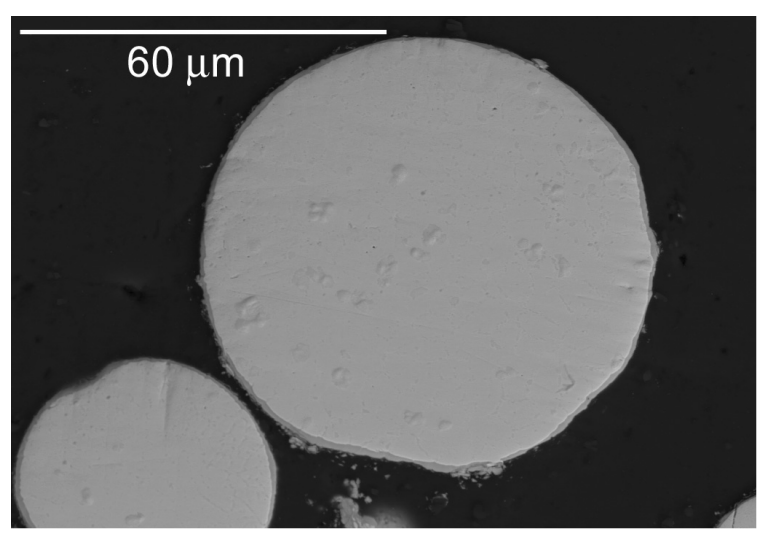

(a)

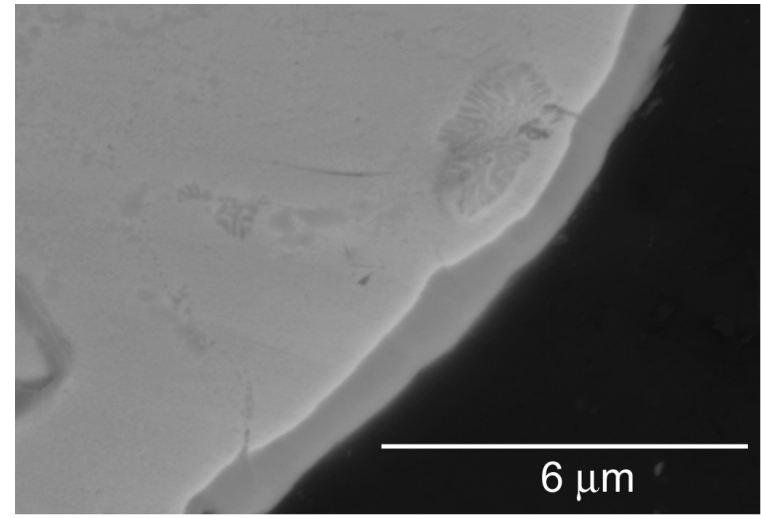

(b)

Figure 23. Backscattered electron images $(\mathrm{a}, \mathrm{b})$ of the microstructure of the Al-5Si matrix fuel plate annealed for 4 hours at $450^{\circ} \mathrm{C}$.

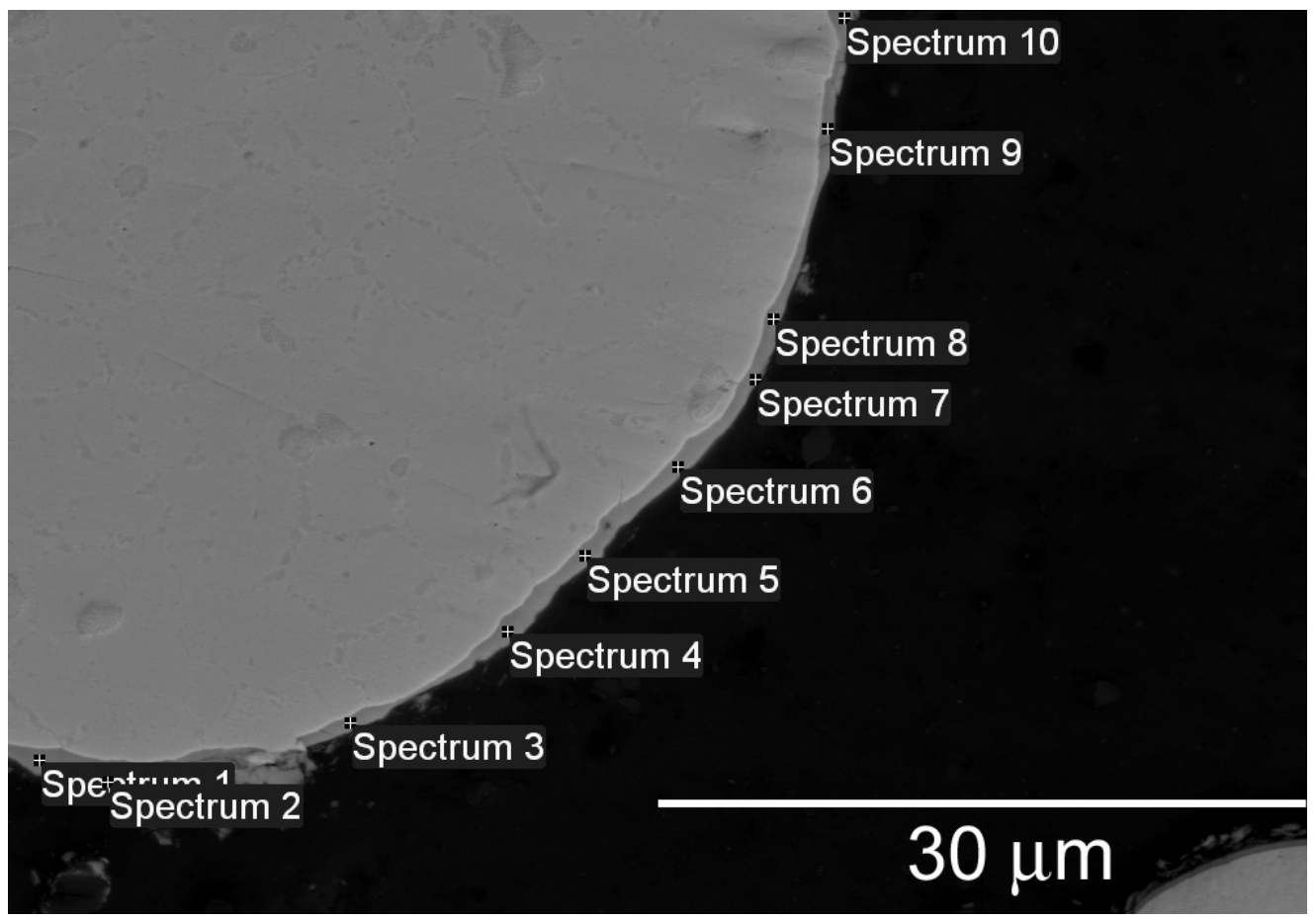

Figure 24. BSE image of the microstructure of a fuel/matrix interaction layer in the Al-5Si matrix fuel plate annealed for 4 hours at $450^{\circ} \mathrm{C}$ and the locations where point-to-point composition analysis was performed (see Table 10 for results). 
Table 10. Results (at\%) of point-to-point composition analysis performed in the interaction layer depicted in Figure 24.

\begin{tabular}{|c|c|c|c|c|}
\hline Spectrum No. & $\mathrm{Al}$ & $\mathrm{Si}$ & Mo & $\mathrm{U}$ \\
\hline 1 & 28 & 42 & 4 & 26 \\
\hline 2 & 57 & 26 & 2 & 15 \\
\hline 3 & 40 & 33 & 4 & 23 \\
\hline 4 & 29 & 41 & 4 & 26 \\
\hline 5 & 23 & 43 & 5 & 30 \\
\hline 6 & 26 & 36 & 6 & 31 \\
\hline 7 & 39 & 31 & 5 & 25 \\
\hline 8 & 15 & 29 & 8 & 47 \\
\hline 9 & 10 & 12 & 13 & 65 \\
\hline 10 & 17 & 45 & 5 & 33 \\
\hline Mean & 28 & 34 & 6 & 32 \\
\hline
\end{tabular}

\subsubsection{U-7Mo/Al-6Si Fuel Plate}

A low and high magnification image of the microstructure observed for the Al-6Si matrix plate annealed at $450^{\circ} \mathrm{C}$ are presented in Figure 25. A Si x-ray map for this sample is presented in Figure 26, and the locations of point-to-point composition analysis of the interaction layer are shown in Figure 27. The results of the analysis are enumerated in Table 11, and the Si concentration values are observed to vary between 24 and 41 at $\%$.

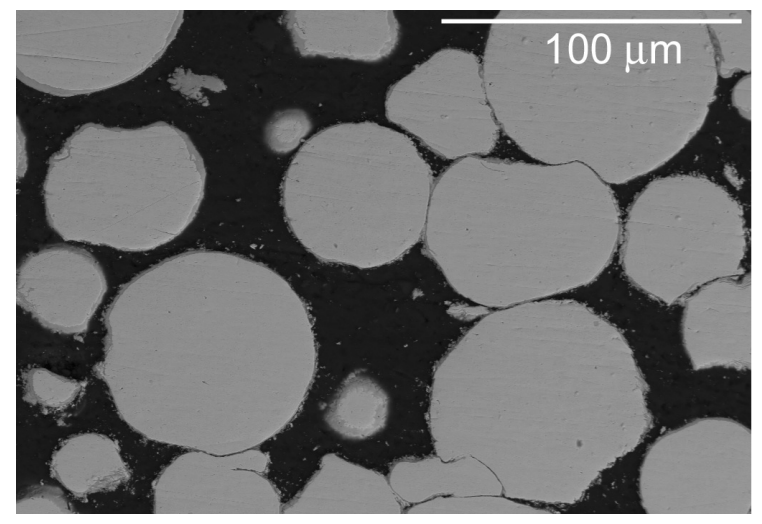

(a)

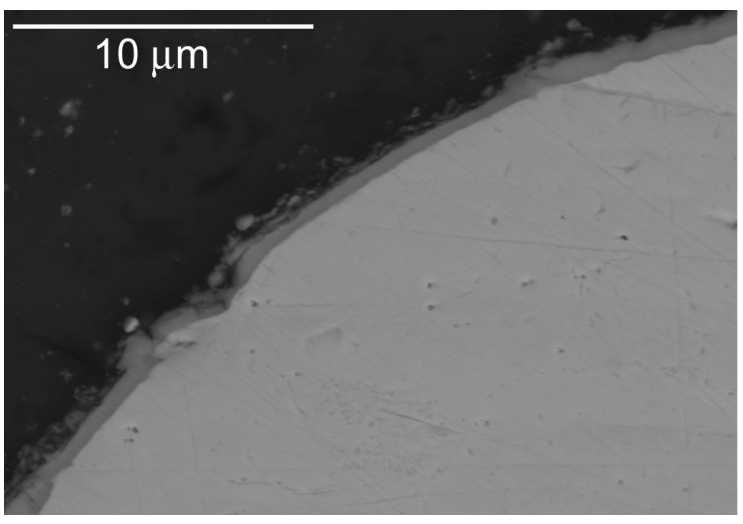

(b)

Figure 25. BSE images $(a, b)$ of the microstructure of the Al-6Si matrix fuel plate annealed for 4 hours at $450^{\circ} \mathrm{C}$. 


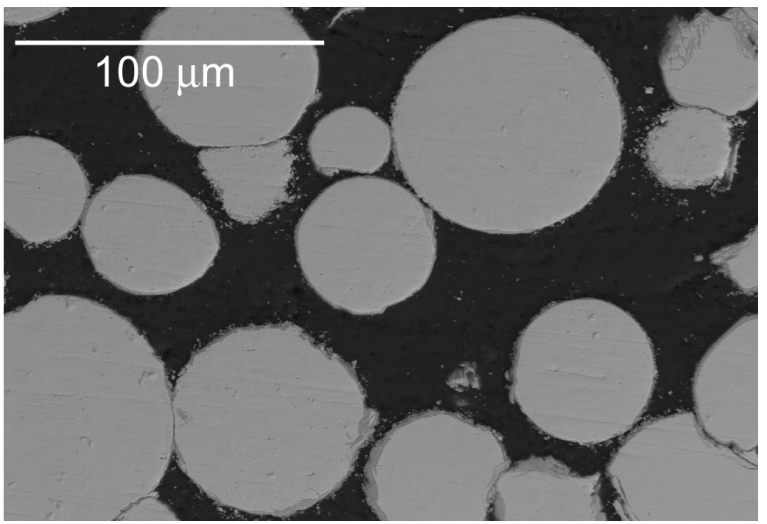

(a)

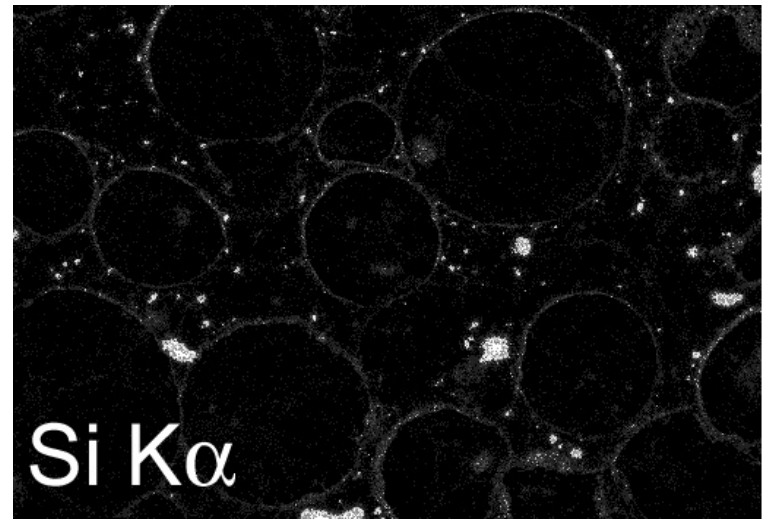

(b)

Figure 26. Backscattered electron image (a) and WDS Si x-ray map (b) for the Al-6Si matrix fuel plate annealed for 4 hours at $450^{\circ} \mathrm{C}$

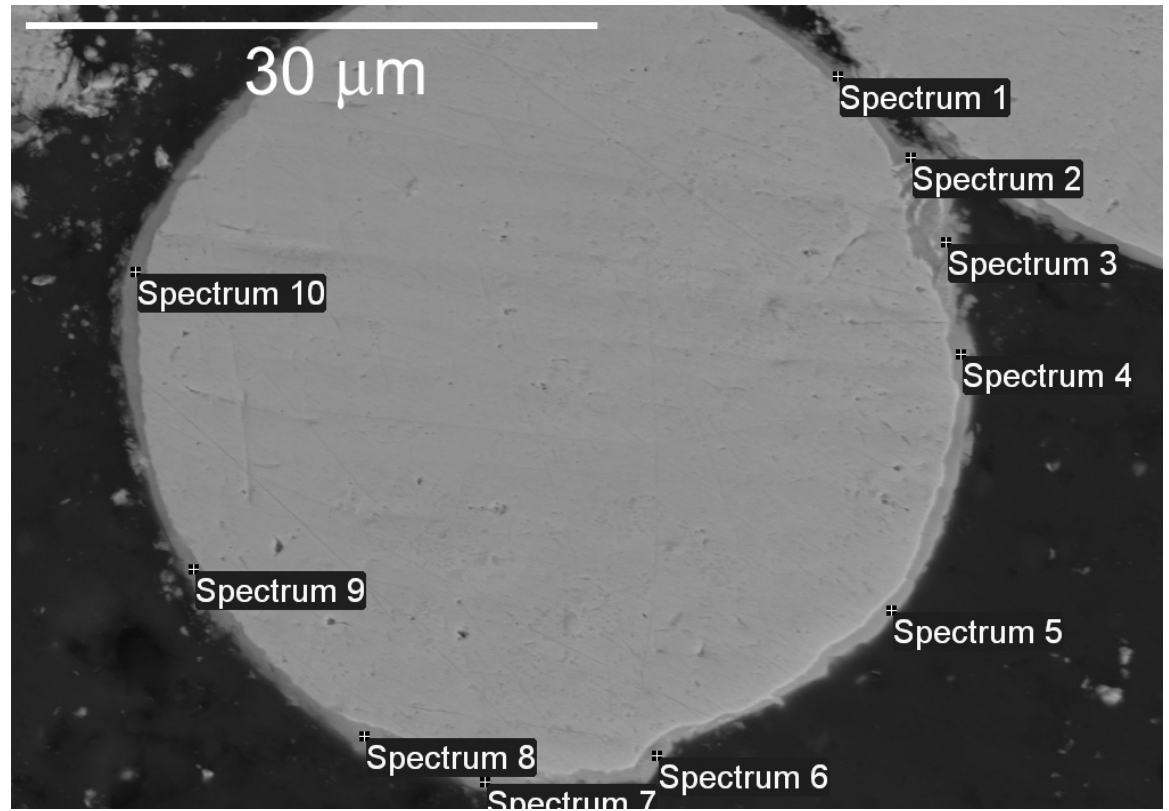

Figure 27. BSE image of the microstructure of a fuel/matrix interaction layer in the Al-6Si matrix fuel plate annealed for 4 hours at $450^{\circ} \mathrm{C}$ and the locations where point-to-point composition analysis was performed (see Table 11 for results). 
Table 11. Results (at\%) of point-to-point composition analysis performed in the interaction layer depicted in Figure 27.

\begin{tabular}{|c|c|c|c|c|}
\hline Spectrum No. & $\mathrm{Al}$ & $\mathrm{Si}$ & $\mathrm{Mo}$ & $\mathrm{U}$ \\
\hline 1 & 34 & 35 & 4 & 27 \\
\hline 2 & 28 & 36 & 5 & 30 \\
\hline 3 & 38 & 32 & 4 & 25 \\
\hline 4 & 32 & 38 & 4 & 26 \\
\hline 5 & 54 & 26 & 3 & 16 \\
\hline 6 & 54 & 24 & 3 & 18 \\
\hline 7 & 45 & 31 & 4 & 20 \\
\hline 8 & 37 & 37 & 4 & 22 \\
\hline 9 & 25 & 41 & 5 & 30 \\
\hline 10 & 28 & 41 & 4 & 28 \\
\hline Mean & 38 & 34 & 4 & 24 \\
\hline
\end{tabular}

\subsection{Interaction Layer Development after Annealing Treatment at $475^{\circ} \mathrm{C}$ for 4 Hours}

\subsubsection{U-7Mo/Al-2Si Fuel Plate}

$\mathrm{BSE}$ images of the microstructure observed for the Al-2Si matrix plate after annealing at $475^{\circ} \mathrm{C}$ for 4 hours are presented in Figure 28. A thin fuel/matrix interaction layer can be found around U-7Mo particles. A Si x-ray map is presented in Figure 29 that indicates that the interaction layer does not provide uniform coverage around the particles. Locations where point-to-point composition analysis was performed are shown in Figure 30, with the results enumerated in Table 12. The Si concentration values varied between 19 and $42 \mathrm{at} \%$. Based on contrast variation in a BSE image, it appeared that the interaction zone was comprised of two different layers with differing Si contents (see Figure 31). Based on point-to-point composition analysis, where, in at $\%$, the measurements at points 1, 2, and 3 in Figure 31 were 19Al-40Si-6Mo-35U, 54Al-20Si-3Mo-24U, and 20Al-38Si-5Mo-37U, respectively, the interaction zone is comprised of at least two different Si-containing phases, where a phase closest to the Al-2Si alloy matrix has higher $\mathrm{Al}$ and less Si than one closer to the U-7Mo. This suggests that for the composition analysis of interaction layers in the different annealing study samples, the values measured will depend on the amount of the different Si-containing phases present at a specific location in the interaction zone.

With the higher annealing temperature of $475^{\circ} \mathrm{C}$ for these samples, it was of interest to see if noticeable "bulk" interaction zone formation could be detected, where a "bulk" interaction is defined as being an interaction zone with negligible Si that is relatively thick and has a lamellar microstructure with a morphology similar to that of decomposed U-7Mo alloy. Overall, there was very limited evidence of any "bulk" interaction zone development in this sample. Figure 32 shows one location where some "bulk" interaction layer did develop. The high magnification image of this region reveals the typical lamellar morphology of a "bulk" interaction zone, where decomposed U-7Mo interacts with the matrix and retains the lamellar microstructure. The results of point-to-point composition analysis performed in this region (see Table 13) indicated the typical low concentrations of Si in the phases. Due to the small size of the phases and the fact that in most areas there is a mixture of phases, the composition numbers are just averages. They show the phases that comprise the mixture all contain negligible $\mathrm{Si}$. 


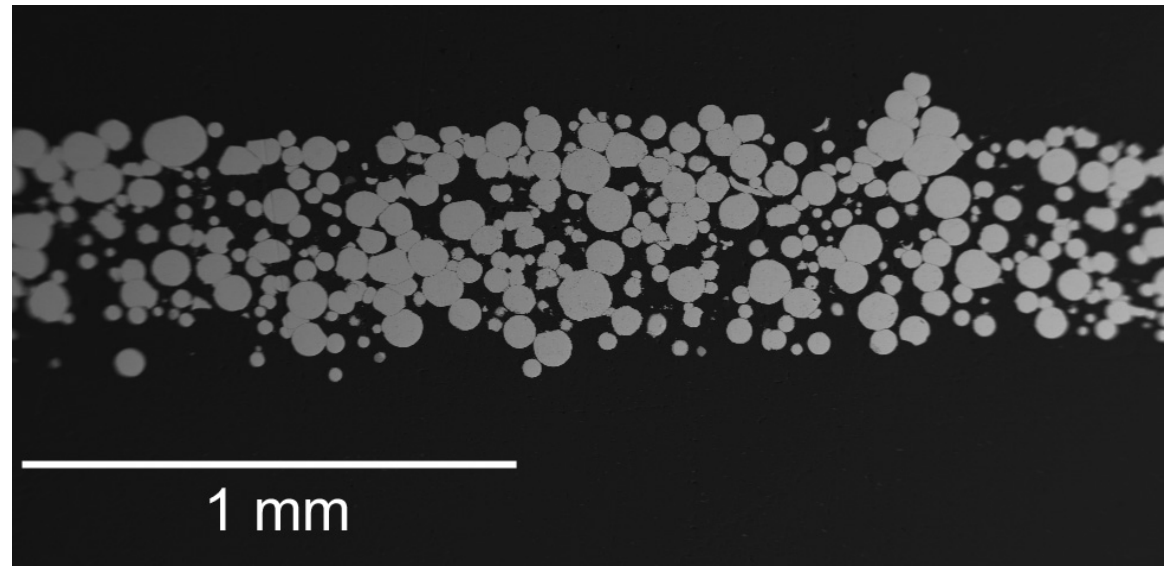

(a)

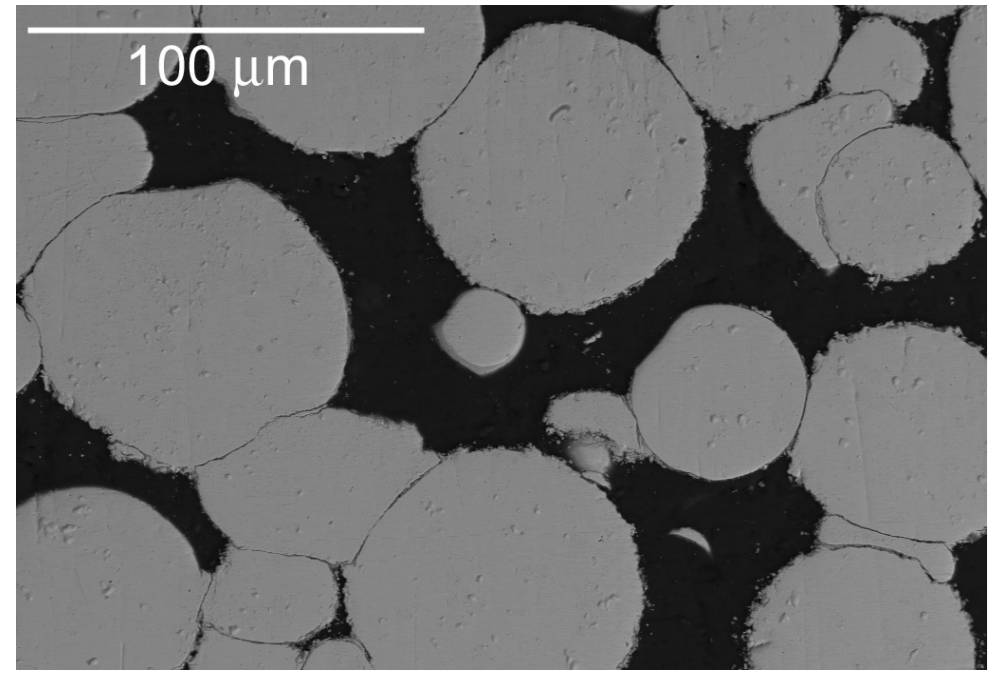

(b)

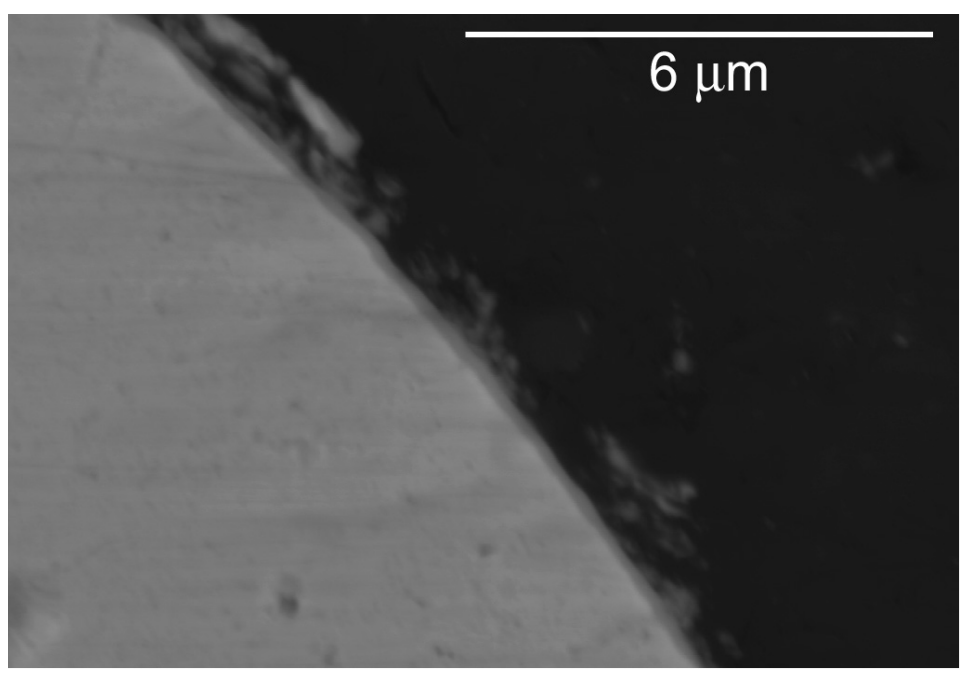

(c)

Figure 28. Backscattered electron images (a-c) of the microstructure of the Al-2Si matrix fuel plate annealed for 4 hours at $475^{\circ} \mathrm{C}$. 


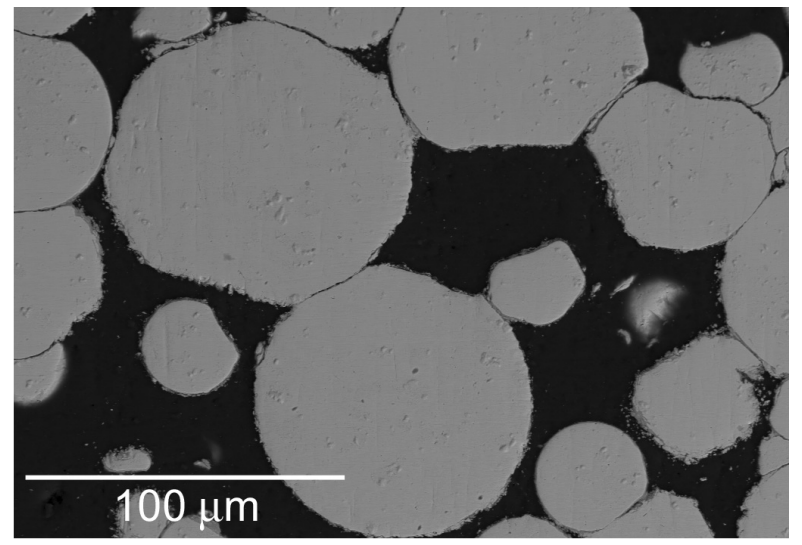

(a)

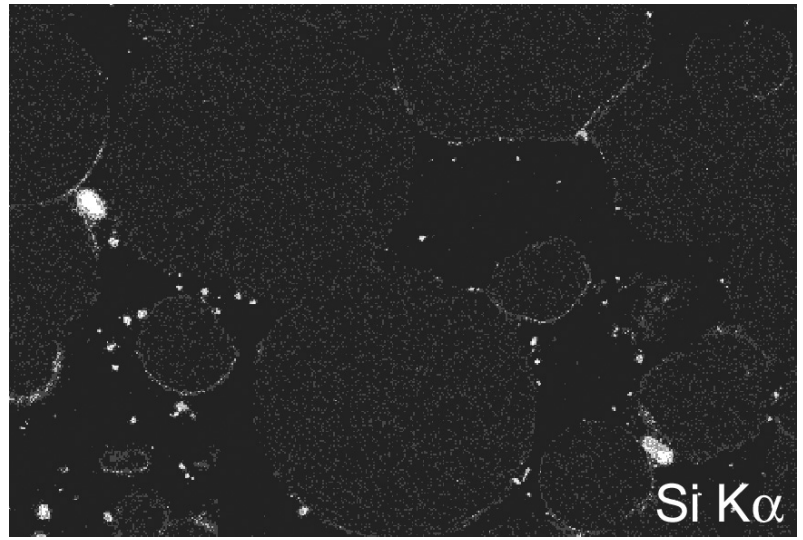

(b)

Figure 29. Backscattered electron image (a) and Si x-ray map (b) for the Al-2Si matrix fuel plate annealed for 4 hours at $475^{\circ} \mathrm{C}$.

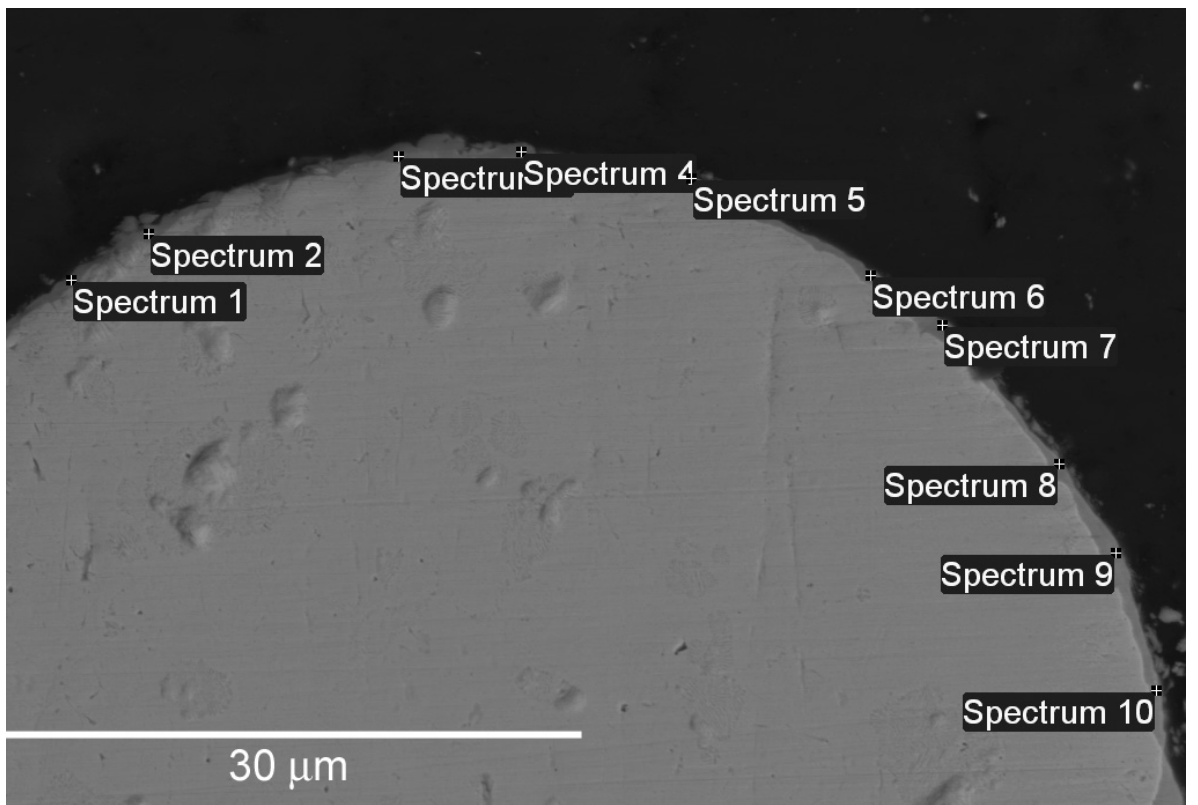

Figure 30. Backscattered electron image of the microstructure of the Al-2Si matrix fuel plate annealed for 4 hours at $475^{\circ} \mathrm{C}$ and the locations where point-to-point composition analysis was performed (see Table 12 for results). 
Table 12. Results of point-to-point composition analysis, in at $\%$, at locations in the interaction layer for the Al-2Si matrix sample annealed at $475^{\circ} \mathrm{C}$ for 4 hours (see Figure 30 ).

\begin{tabular}{|c|c|c|c|c|}
\hline Spectrum No. & Al & Si & Mo & U \\
\hline 1 & 37 & 30 & 4 & 30 \\
\hline 2 & 18 & 42 & 5 & 35 \\
\hline 3 & 20 & 39 & 6 & 35 \\
\hline 4 & 46 & 25 & 3 & 26 \\
\hline 5 & 63 & 19 & 2 & 15 \\
\hline 6 & 42 & 30 & 4 & 24 \\
\hline 7 & 52 & 24 & 3 & 21 \\
\hline 8 & 57 & 23 & 2 & 17 \\
\hline 9 & 53 & 25 & 3 & 19 \\
\hline 10 & 46 & 27 & 5 & 22 \\
\hline Mean & 43 & 29 & 4 & 24 \\
\hline
\end{tabular}

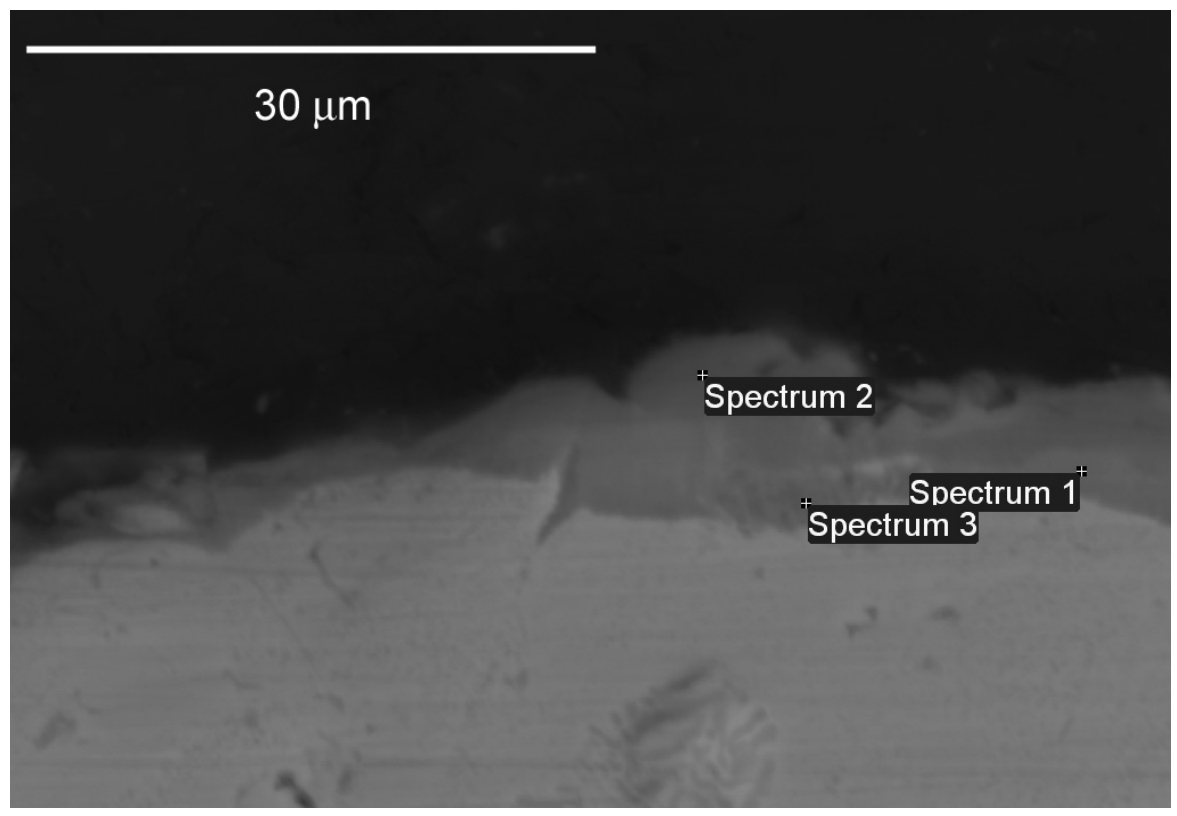

Figure 31. BSE image showing, potentially, two different layers, based on morphology, that constitute the interaction zone in the Al-2Si matrix sample annealed at $475^{\circ} \mathrm{C}$ for 4 hours. Locations where point-topoint composition analysis was performed are identified. 


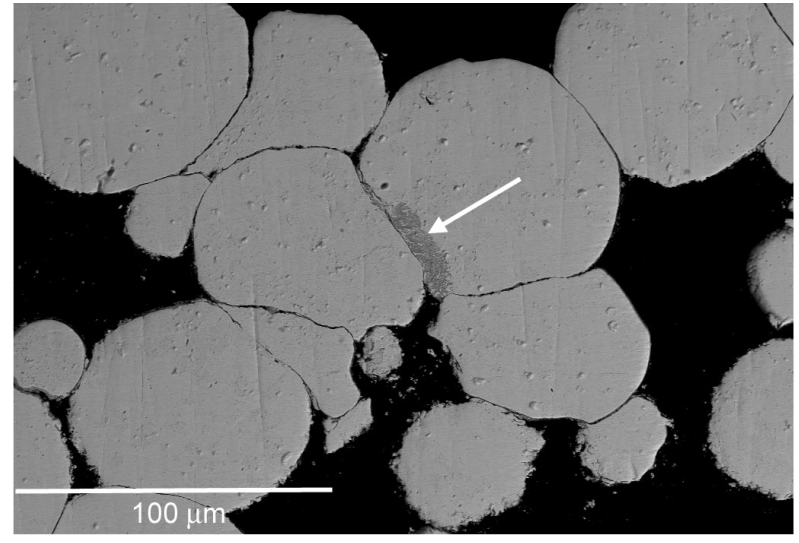

(a)

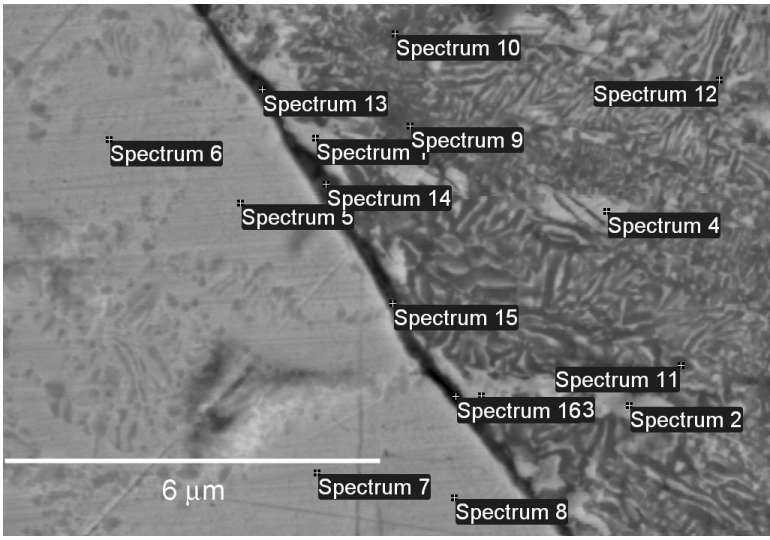

(b)

Figure 32. Low magnification BSE image (a) and high magnification BSE image (b) of a localized area in the microstructure of the Al-2Si matrix fuel plate annealed at $475^{\circ} \mathrm{C}$ for 4 hours where a bulk interaction layer has formed, as indicated by the arrow in (a). The locations where point-to-point composition analysis was performed are identified (see Table 13 for results).

Table 13. Results of point-to-point composition analysis, in at $\%$, conducted near and in some bulk interaction zone in the Al-2Si matrix sample annealed at $475^{\circ} \mathrm{C}$ for 4 hours (see Figure 32).

\begin{tabular}{|c|c|c|c|c|}
\hline Spectrum No. & Al & Si & Mo & U \\
\hline 1 & 29 & 1 & 10 & 61 \\
\hline 2 & 30 & 1 & 10 & 59 \\
\hline 3 & 21 & 1 & 10 & 68 \\
\hline 4 & 24 & 0 & 9 & 66 \\
\hline 5 & 2 & 1 & 17 & 80 \\
\hline 6 & 1 & 0 & 17 & 82 \\
\hline 7 & 1 & 0 & 19 & 81 \\
\hline 8 & 1 & 0 & 19 & 80 \\
\hline 9 & 65 & 1 & 3 & 31 \\
\hline 10 & 64 & 1 & 3 & 32 \\
\hline 11 & 56 & 0 & 6 & 38 \\
\hline 12 & 49 & 0 & 8 & 43 \\
\hline 13 & 55 & 1 & 7 & 37 \\
\hline 14 & 59 & 1 & 7 & 34 \\
\hline 15 & 55 & 2 & 7 & 36 \\
\hline 16 & 54 & 1 & 7 & 38 \\
\hline
\end{tabular}

\subsubsection{U-7Mo/Al-4Si Fuel Plate}

For the Al-4Si matrix plate annealed at $475^{\circ} \mathrm{C}$, the observed microstructures at various magnifications are presented in Figure 33. In the higher magnification images, a thin interaction layer could be identified. In Figure 34, a Si x-ray map is shown indicating the presence of a thin interaction layer. 


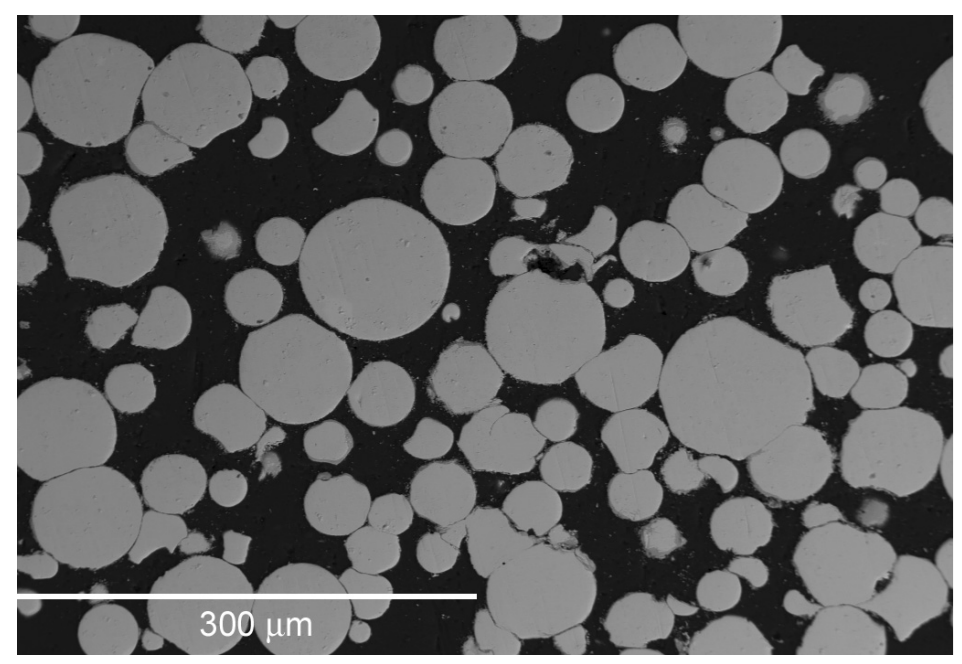

(a)

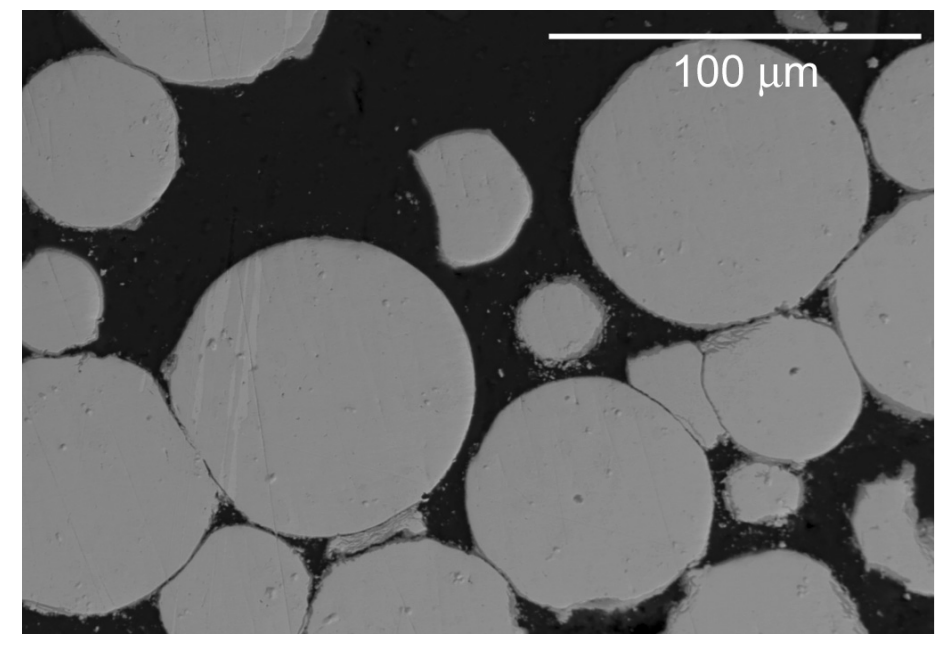

(b)

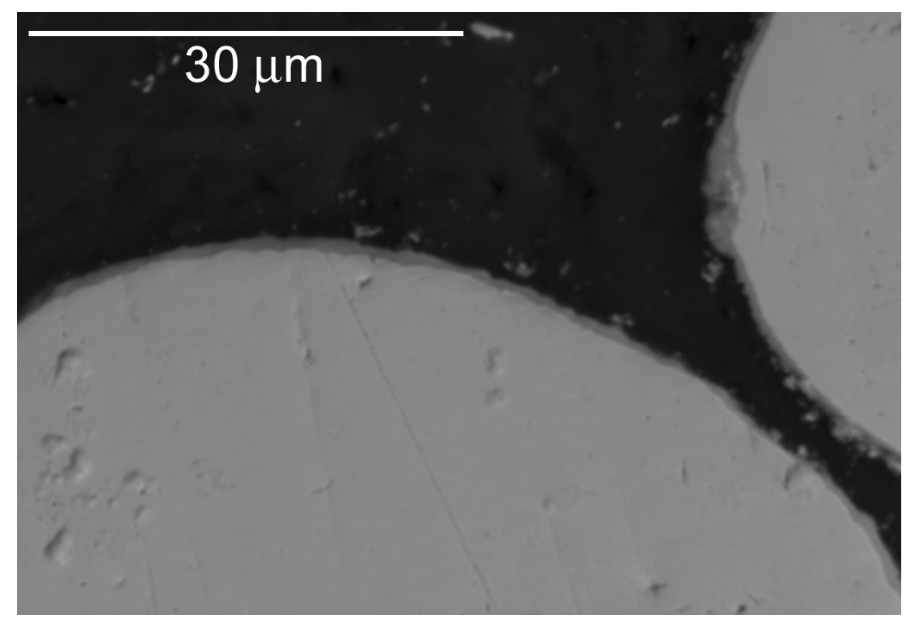

(c)

Figure 33. Backscattered electron images (a-c) of the microstructure of the Al-4Si matrix fuel plate annealed for 4 hours at $475^{\circ} \mathrm{C}$. 


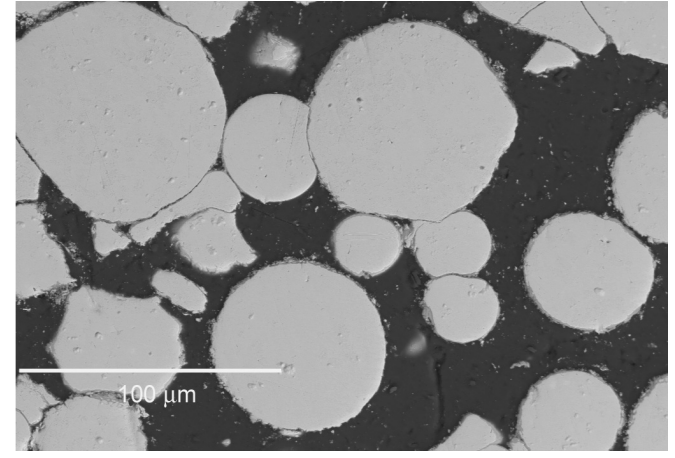

(a)

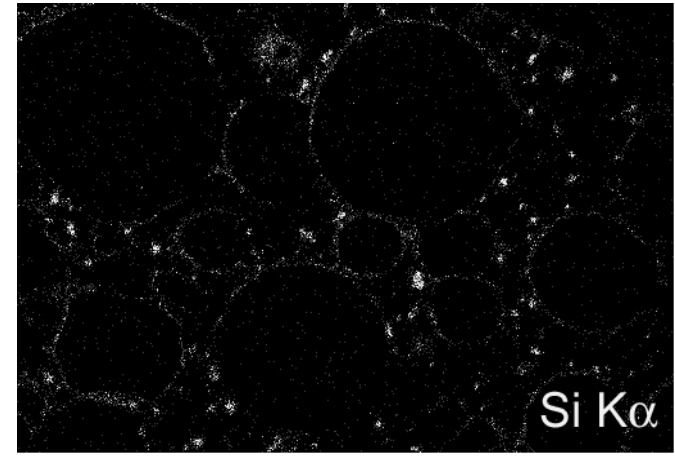

(b)

Figure 34. Backscattered electron image (a) and Si x-ray map (b) of the microstructure of the Al-4Si matrix fuel plate annealed for 4 hours at $475^{\circ} \mathrm{C}$.

\subsubsection{U-7Mo/Al-5Si Fuel Plate}

Low and high magnification images of the microstructure observed for the Al-5Si matrix plate annealed at $475^{\circ} \mathrm{C}$ are presented in Figure 35. These images indicate that a fairly uniform interaction layer is present around the U-7Mo particles, and this layer appears to be more substantial than the one observed for the Al-4Si matrix fuel plate. In Figure 36, locations where point-to-point composition analysis was performed in some interaction layers are identified, and the results are enumerated in Table 14. The measured Si concentrations were observed to vary between 18 and 43 at\%. Even in the thicker interaction layers, which in some cases can contain negligible Si (like in the Al-2Si matrix sample), appreciable Si concentrations were measured.

For this fuel plate, some focus was given to the fuel meat/cladding interface to see if there was any evidence of noticeable formation of Mg-Si precipitates. The Mg and Si x-ray maps shown in Figure 37 indicate that there was no indication of appreciable formation of $\mathrm{Mg}$-Si precipitates at the fuel meat/cladding interface.

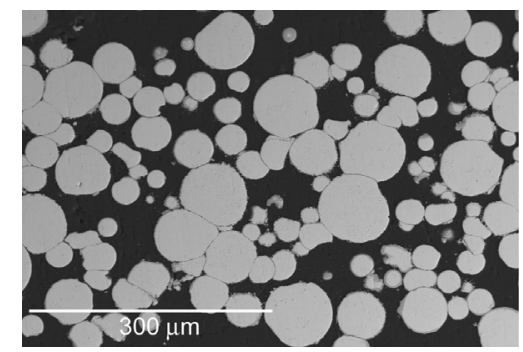

(a)

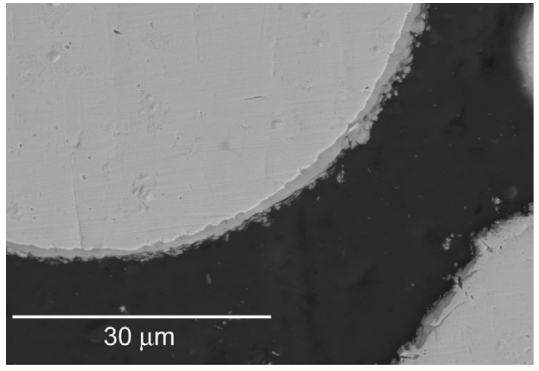

(c)

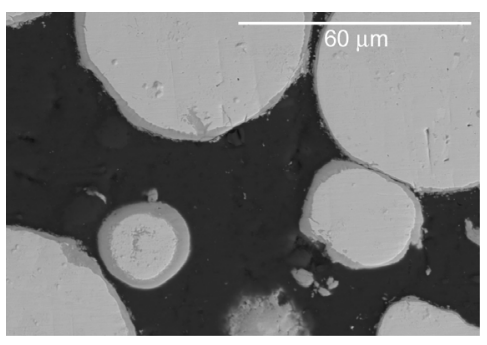

(b)

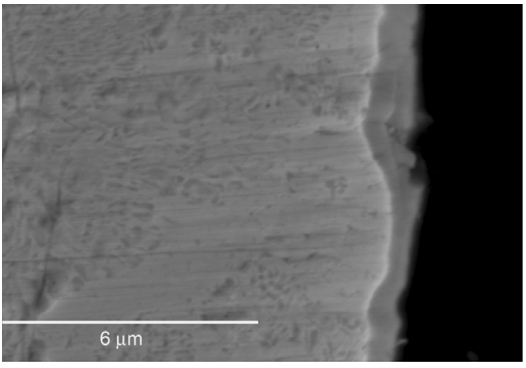

(d)

Figure 35. Backscattered electron images (a-d) of the microstructure of the Al-5Si matrix sample annealed at $475^{\circ} \mathrm{C}$ for 4 hours. 


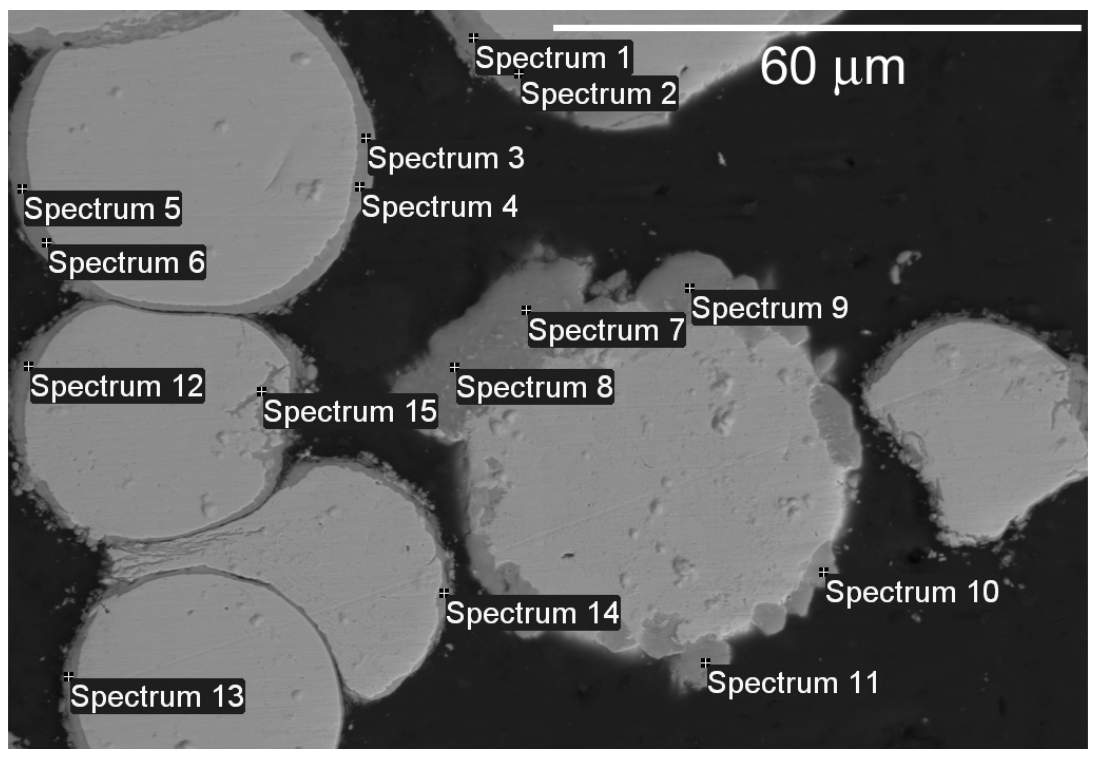

Figure 36. Backscattered electron image of the microstructure of the Al-5Si matrix fuel plate annealed for 4 hours at $475^{\circ} \mathrm{C}$ with the locations in the interaction layers where point-to-point composition analysis was performed (see results in Table 14).

Table 14. Results of point-to-point composition analysis, in at \%, conducted in different interaction layers in the Al-5Si matrix sample annealed at $475^{\circ} \mathrm{C}$ for 4 hours (see Figure 36).

\begin{tabular}{|c|c|c|c|c|}
\hline Spectrum No. & Al & Si & Mo & U \\
\hline 1 & 45 & 27 & 4 & 24 \\
\hline 2 & 47 & 25 & 4 & 24 \\
\hline 3 & 44 & 29 & 4 & 23 \\
\hline 4 & 37 & 34 & 4 & 25 \\
\hline 5 & 40 & 30 & 4 & 26 \\
\hline 6 & 38 & 32 & 4 & 26 \\
\hline 7 & 54 & 20 & 3 & 23 \\
\hline 8 & 58 & 18 & 3 & 21 \\
\hline 9 & 48 & 24 & 4 & 24 \\
\hline 10 & 54 & 22 & 3 & 22 \\
\hline 11 & 56 & 20 & 3 & 21 \\
\hline 12 & 36 & 33 & 5 & 27 \\
\hline 13 & 38 & 35 & 4 & 23 \\
\hline 14 & 50 & 26 & 3 & 21 \\
\hline 15 & 13 & 43 & 6 & 38 \\
\hline Mean & 44 & 28 & 4 & 25 \\
\hline
\end{tabular}




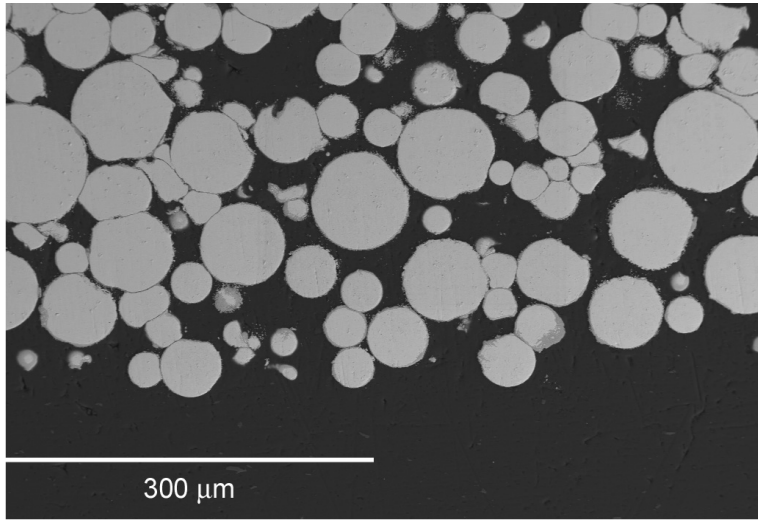

(a)

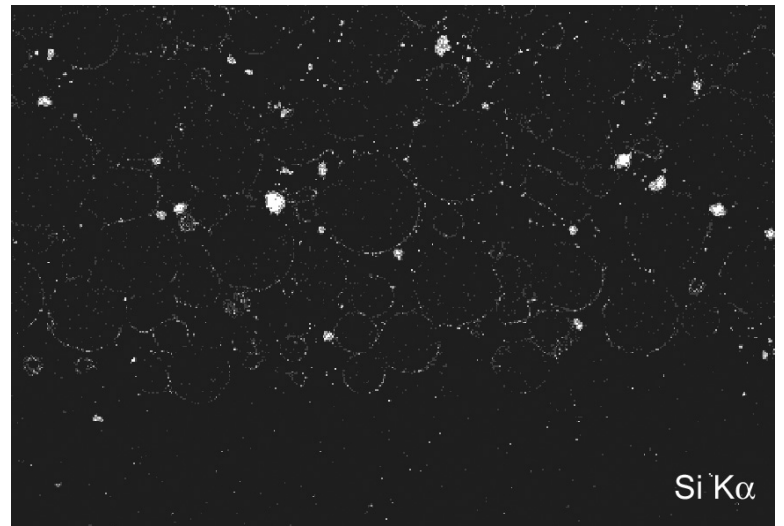

(b)

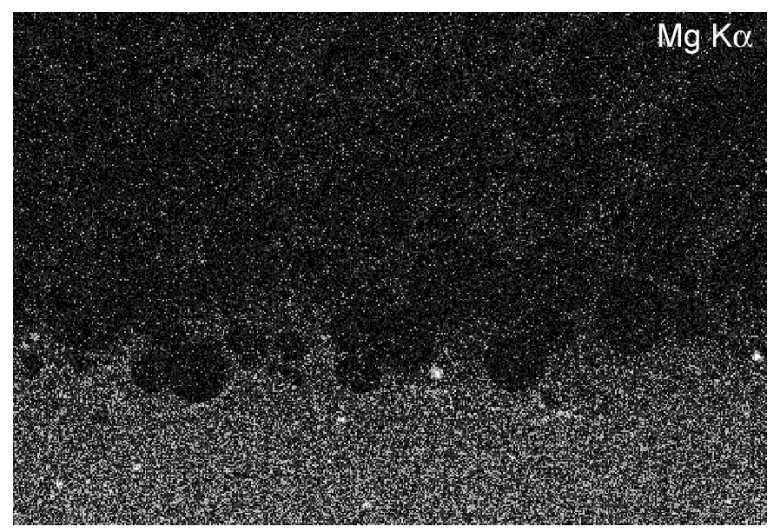

(c)

Figure 37. BSE image (a) and x-ray maps for (b) Si and (c) Mg for the Al-5Si matrix sample annealed at $475^{\circ} \mathrm{C}$ for 4 hours.

\subsubsection{U-7Mo/Al-6Si Fuel Plate}

BSE images of the microstructure for the Al-6Si matrix plate annealed at $475^{\circ} \mathrm{C}$ are presented in Figure 38. A thin interaction layer can be identified around the U-7Mo particles. A Si x-ray map of the microstructure is presented in Figure 39. As was the case for the Al-5Si matrix sample, some relatively thick interaction layers were observed in the sample, and Si x-ray maps were generated at different regions of the sample to see if these layers contained Si (see Figure 40). It was observed that the areas with increased fuel/matrix interaction did contain appreciable Si. Point-to-point composition analysis was performed in a relatively thin interaction layer (see Figure 41 and Table 15), as well as in a relatively thick interaction layer (see Figure 42 and Table 16). Si concentrations that varied between 26 and 41 at $\%$ were measured in the thinner layer, and Si concentrations that varied between 20 and 23 at $\%$ were measured in the thicker layer. 


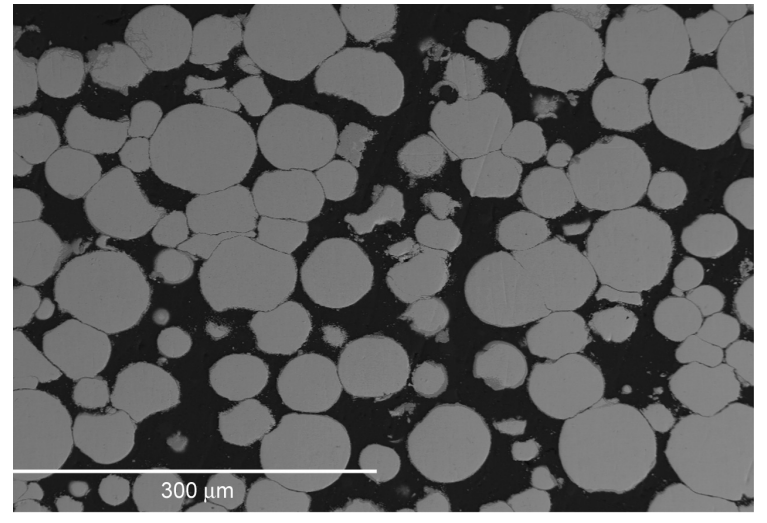

(a)

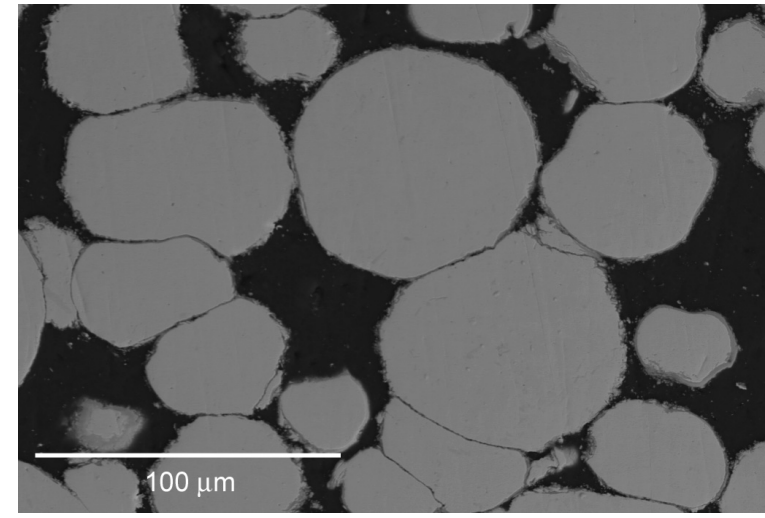

(b)

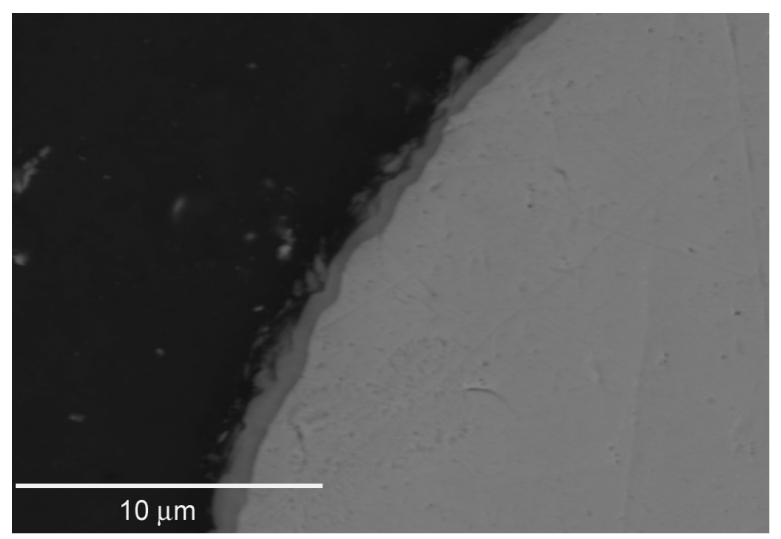

(c)

Figure 38. Backscattered electron images (a-c) of the microstructure of the Al-6Si matrix fuel plate annealed for 4 hours at $475^{\circ} \mathrm{C}$.

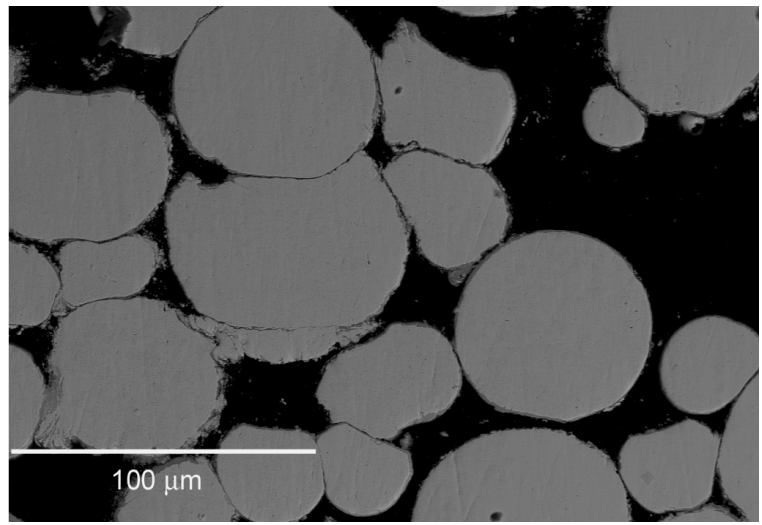

(a)

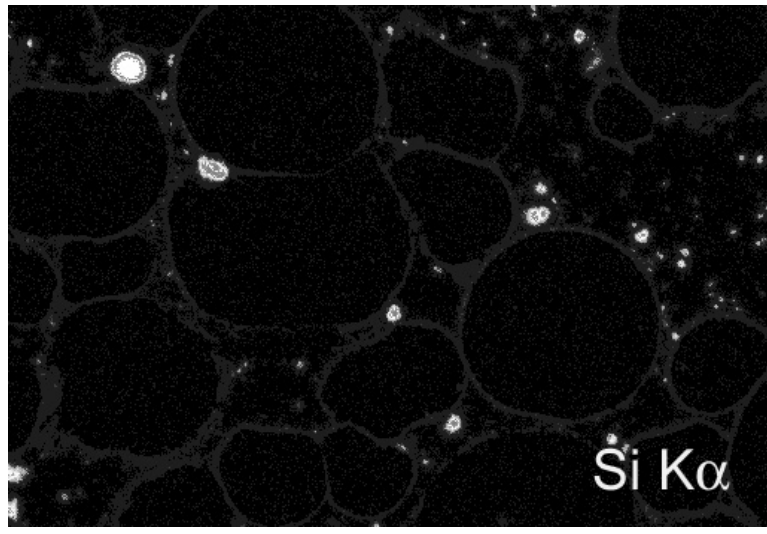

(b)

Figure 39. Backscattered electron image (a) and Si x-ray map (b) of the microstructure for the Al-6Si matrix fuel plate annealed for 4 hours at $475^{\circ} \mathrm{C}$. 


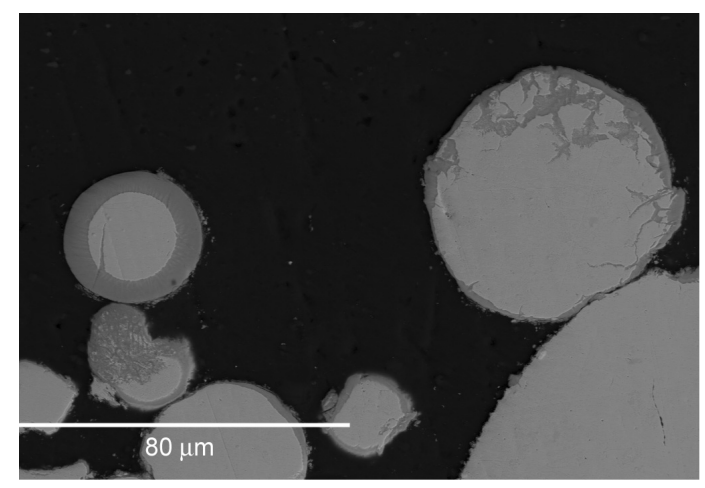

(a)

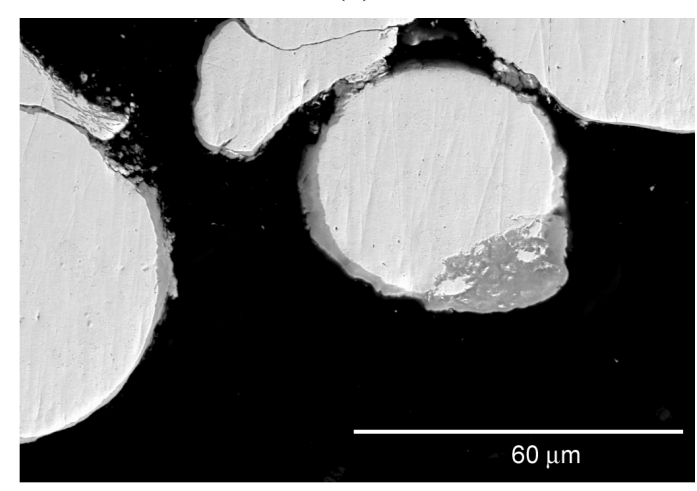

(c)

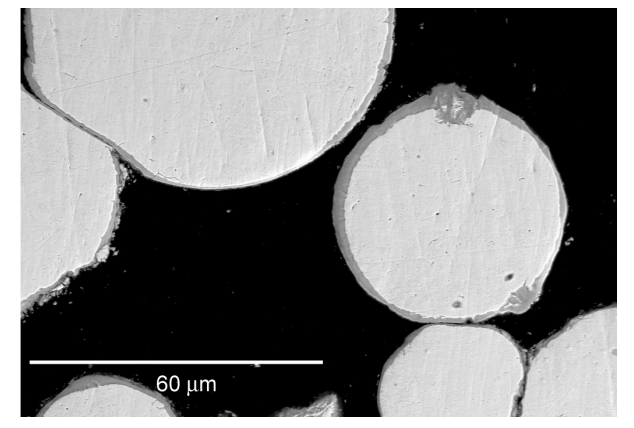

(e)

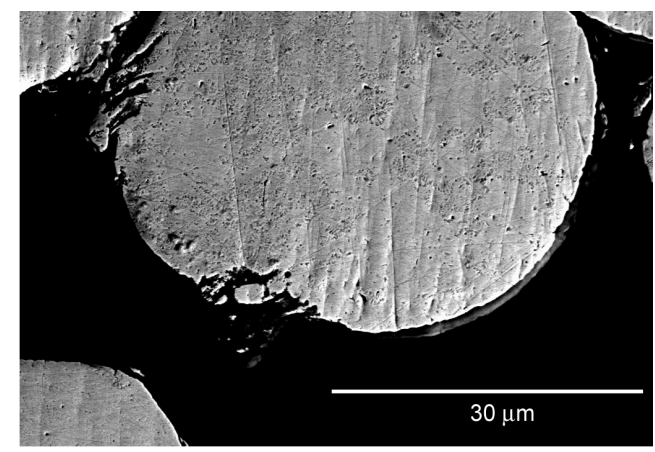

(g)

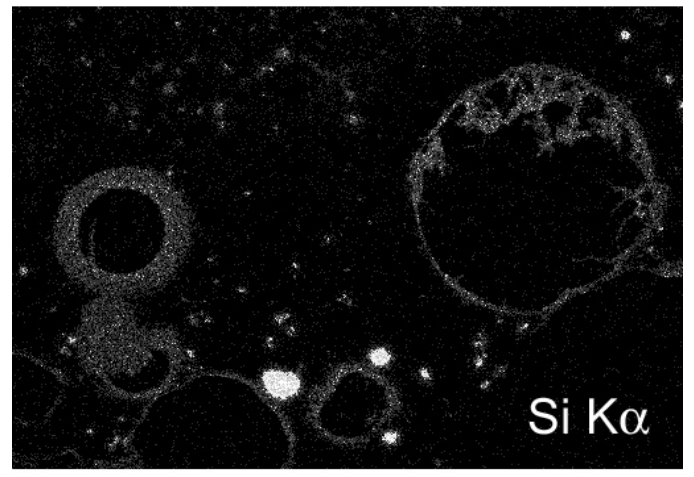

(b)

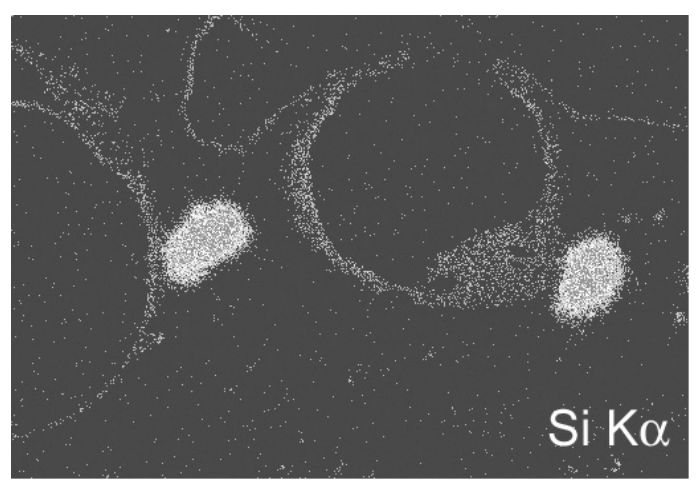

(d)

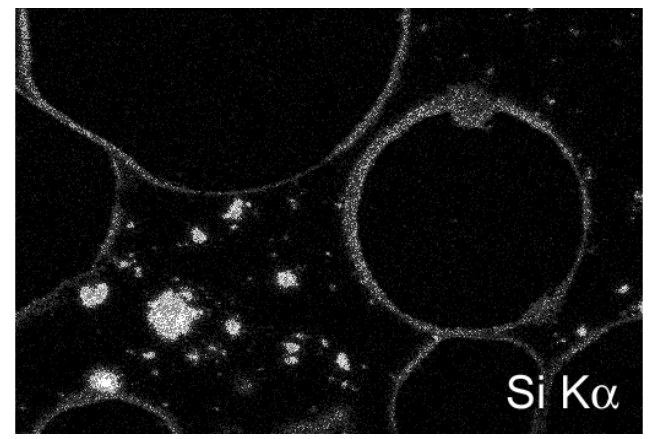

(f)

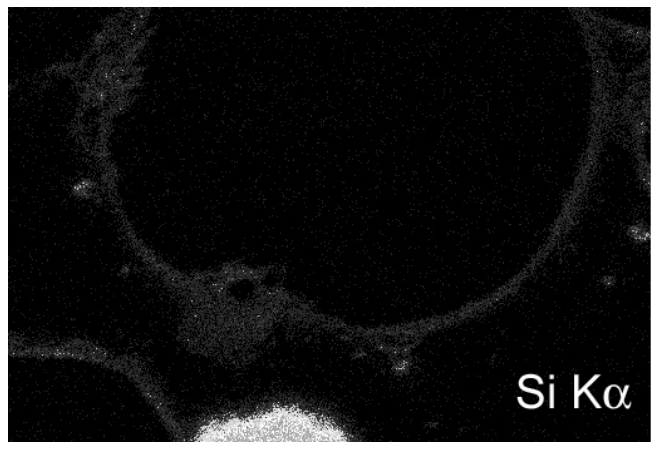

(h)

Figure 40. Backscattered electron images (a, c, e, and g) and Si x-ray maps (b, d, f, and h) at different locations of the microstructure for the Al-6Si matrix fuel plate annealed for 4 hours at $475^{\circ} \mathrm{C}$. 


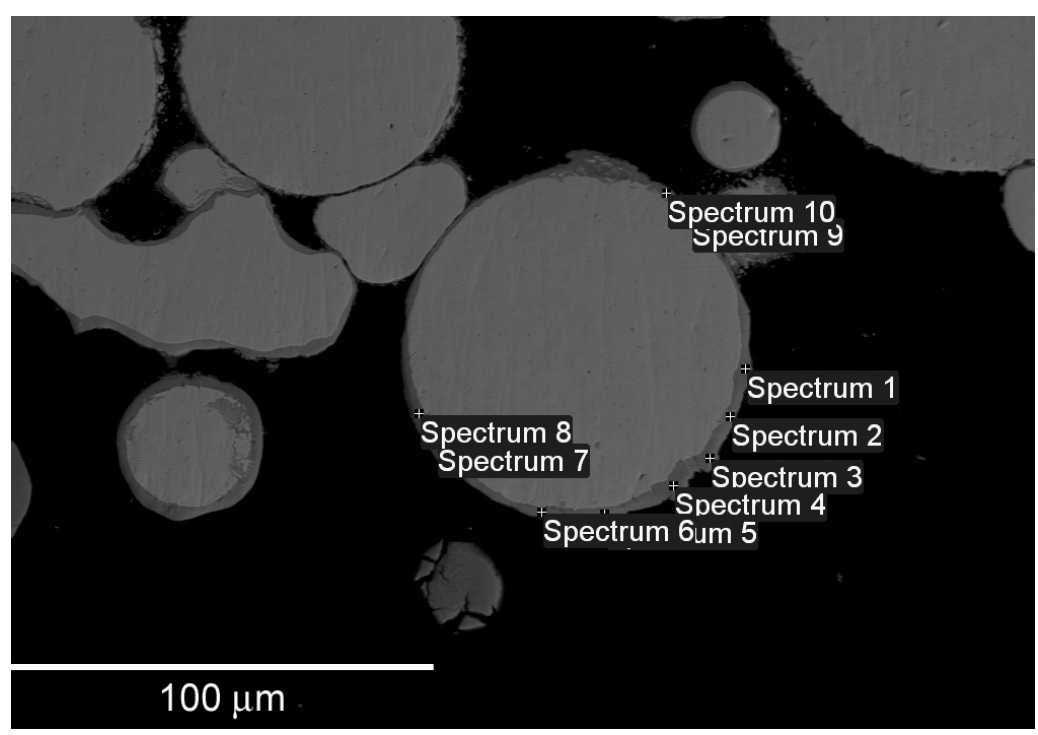

Figure 41. BSE image of an area in the microstructure for the Al-6Si matrix fuel plate annealed at $475^{\circ} \mathrm{C}$ for 4 hours where relatively thick interaction layers were observed. Locations where point-to-point composition analysis was performed are shown (results listed in Table 15).

Table 15. Results of point-to-point composition analysis, in at $\%$, conducted at specific locations in the interaction zone (see Figure 41) in the Al-6Si matrix sample annealed at $475^{\circ} \mathrm{C}$ for 4 hours.

\begin{tabular}{|c|c|c|c|c|}
\hline Spectrum No. & Al & Si & Mo & U \\
\hline 1 & 46 & 26 & 3 & 25 \\
\hline 2 & 41 & 32 & 4 & 23 \\
\hline 3 & 49 & 26 & 4 & 22 \\
\hline 4 & 47 & 26 & 4 & 23 \\
\hline 5 & 32 & 38 & 5 & 25 \\
\hline 6 & 27 & 41 & 5 & 27 \\
\hline 7 & 35 & 34 & 5 & 27 \\
\hline 8 & 22 & 44 & 5 & 29 \\
\hline 9 & 39 & 31 & 3 & 26 \\
\hline 10 & 32 & 36 & 4 & 28 \\
\hline Mean & 40 & 34 & 4 & 26 \\
\hline
\end{tabular}




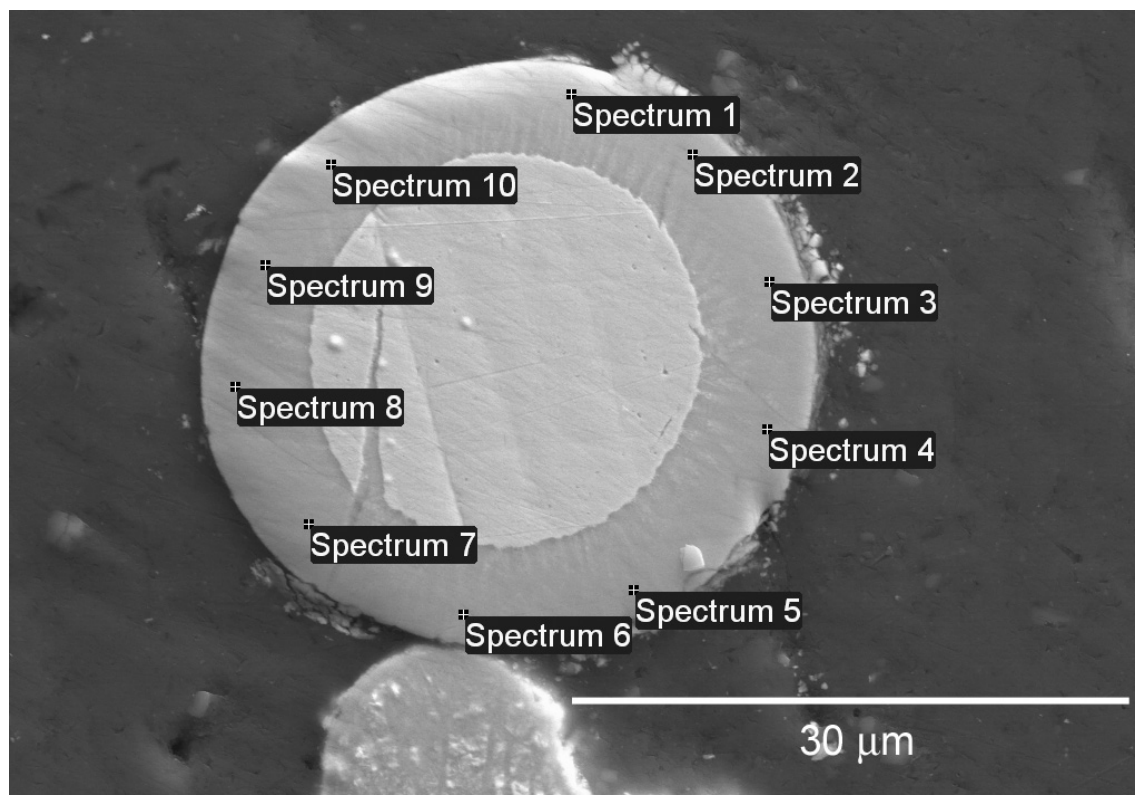

Figure 42. BSE image of a particle in the Al-6Si matrix plate annealed at $475^{\circ} \mathrm{C}$ for 4 hours with a relatively thick interaction layer. Locations where point-to-point composition analysis was performed are shown (results listed in Table 16).

Table 16. Results of point-to-point composition analysis, in at $\%$, conducted at specific locations in the interaction zone (see Figure 42) in the Al-6Si matrix sample annealed at $475^{\circ} \mathrm{C}$ for 4 hours.

\begin{tabular}{|c|c|c|c|c|}
\hline Spectrum No. & $\mathrm{Al}$ & $\mathrm{Si}$ & $\mathrm{Mo}$ & $\mathrm{U}$ \\
\hline 1 & 52 & 22 & 4 & 22 \\
\hline 2 & 53 & 23 & 4 & 21 \\
\hline 3 & 53 & 22 & 4 & 21 \\
\hline 4 & 56 & 21 & 3 & 20 \\
\hline 5 & 57 & 20 & 3 & 20 \\
\hline 6 & 57 & 20 & 3 & 20 \\
\hline 7 & 56 & 20 & 3 & 21 \\
\hline 8 & 56 & 20 & 3 & 20 \\
\hline 9 & 54 & 21 & 3 & 21 \\
\hline 10 & 52 & 22 & 4 & 22 \\
\hline Mean & 55 & 21 & 3 & 21 \\
\hline
\end{tabular}

\subsection{Interaction Layer Development after Annealing Treatment at $500^{\circ} \mathrm{C}$ for 2 Hours}

The annealing treatments performed at $500^{\circ} \mathrm{C}$ for 2 hours are of particular interest since the microstructures of these samples should be very similar to what is observed for actual as-fabricated U-7Mo dispersion fuel plates that have AA6061 cladding, which are rolled and blister annealed at temperatures near $500^{\circ} \mathrm{C}$ with a total exposure time near 2 hours. An actual U-7Mo dispersion fuel plate with AA6061 cladding and with a matrix comprised of a powder mixture of pure $\mathrm{Al}$ and pure Si powders has been tested in ATR. The final matrix Si content of the tested plate was $2 \mathrm{wt} \% \mathrm{Si}^{6}$ 


\subsubsection{U-7Mo/Al-2Si Fuel Plate}

BSE images of the microstructure observed in the Al-2Si matrix fuel plate annealed at $500^{\circ} \mathrm{C}$ are presented in Figure 43. Areas where, based on the morphology of the layer, a "bulk" interaction layer has appeared to form are identified with arrows. The majority of the microstructure was comprised of U-7Mo fuel particles with a relatively thin layer around the surface of the fuel particles. A Si x-ray map of the microstructure is presented in Figure 44. Point-to-point composition analysis was performed in some fuel meat matrix and interaction layer locations (see Figure 45) and the results are listed in Table 17. The measured Si concentration values in the interaction layer varied between 10 and 18 at $\%$. BSE images of a "bulk" interaction zone are presented in Figure 46. The morphology of this layer is very similar to the lamellar microstructure of decomposed U-7Mo alloy. Point-to-point composition analysis was performed in some "bulk" interaction zones (see Figure 47), and the results are shown in Table 18. The readings from the "bulk" interaction zones indicated negligible Si.

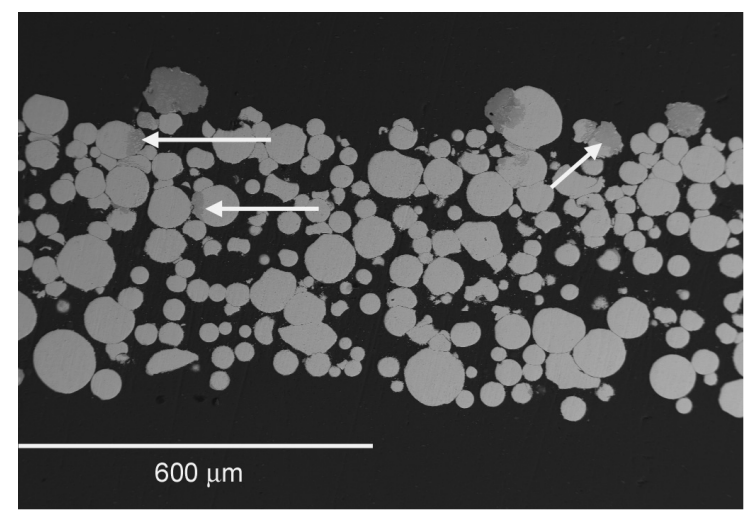

(a)

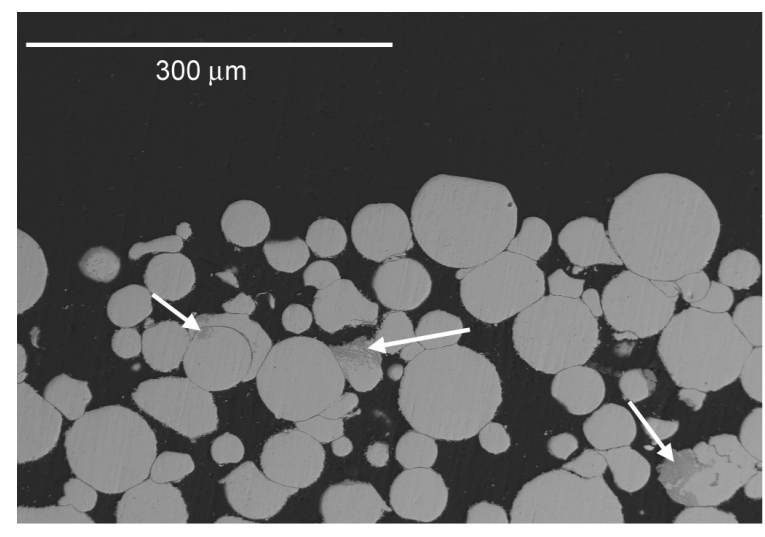

(b)

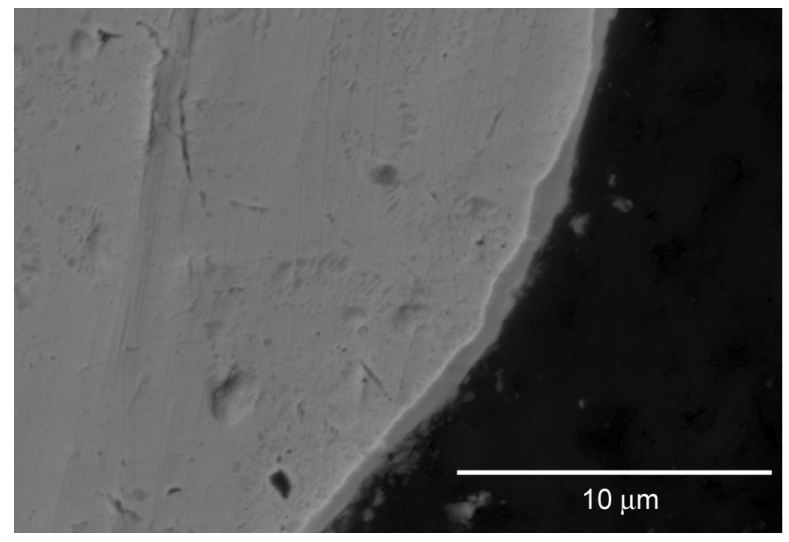

(c)

Figure 43. BSE images (a-c) of the microstructure of the as-fabricated Al-2Si matrix fuel plate annealed at $500^{\circ} \mathrm{C}$ for 2 hours. The arrows in (a) and (b) identify regions where relatively thick interaction layers are present. The image in (c) shows the presence of a relatively uniform interaction layer around a U-7Mo fuel particle. 


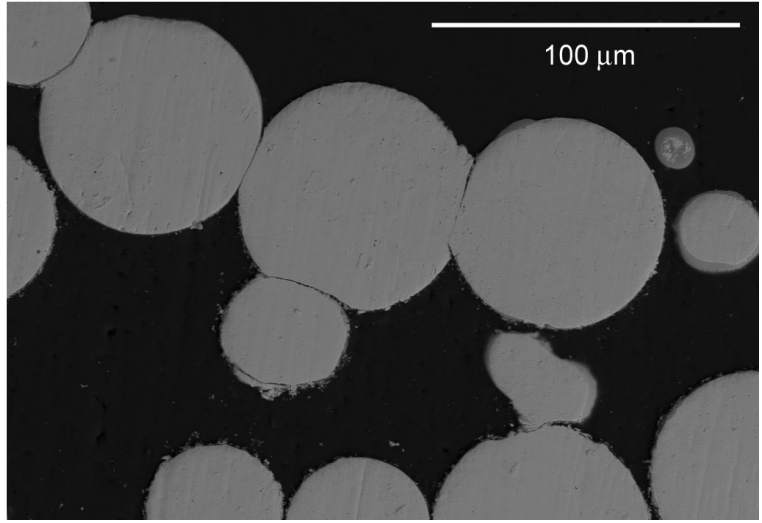

(a)

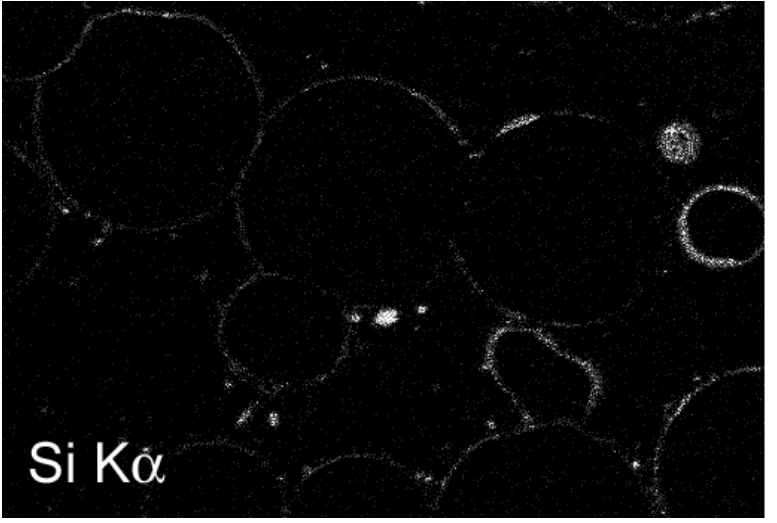

(b)

Figure 44. BSE image (a) and Si x-ray map (b) in the Al-2Si matrix sample annealed at $500^{\circ} \mathrm{C}$ for 2 hours.

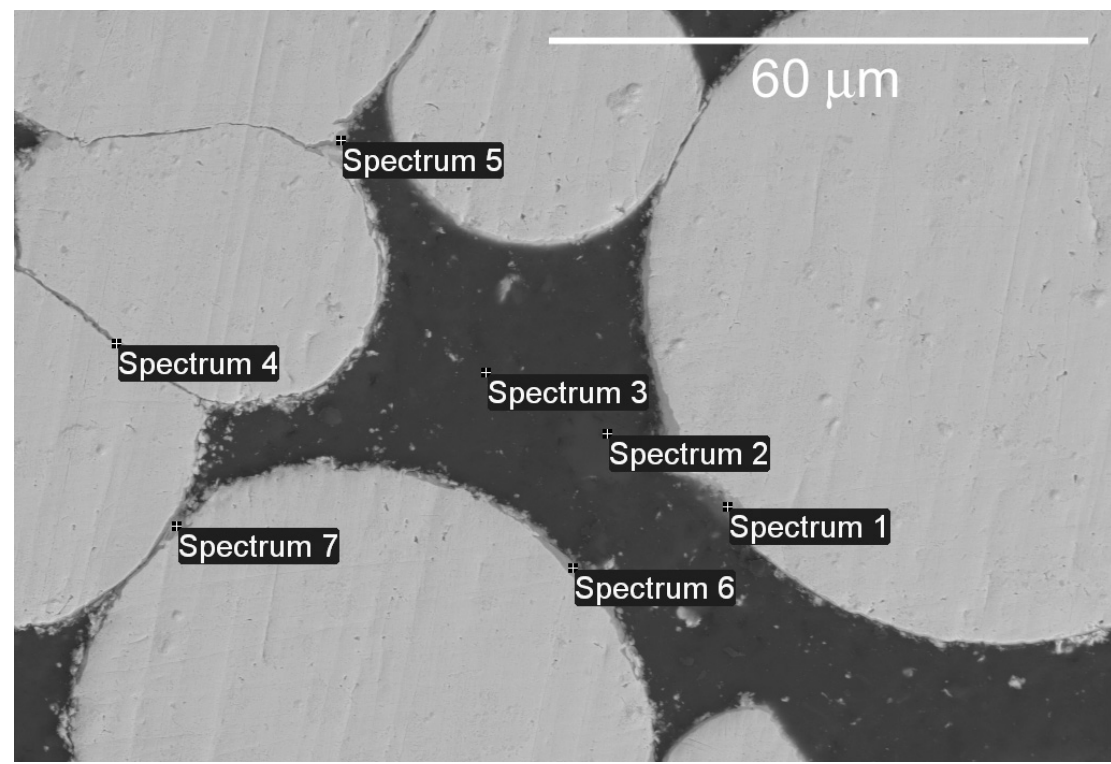

Figure 45. BSE image showing where point-to-point composition analysis was performed on the Al-2Si matrix sample annealed at $500^{\circ} \mathrm{C}$ for 2 hours (results listed in Table 17).

Table 17. Results of point-to-point composition analysis, in at $\%$, conducted at specific locations in the interaction zone (see Figure 45) in the Al-2Si matrix sample annealed at $500^{\circ} \mathrm{C}$ for 2 hours.

\begin{tabular}{|c|c|c|c|c|}
\hline Spectrum No. & $\mathrm{Al}$ & $\mathrm{Si}$ & Mo & $\mathrm{U}$ \\
\hline 1 & 74 & 10 & 3 & 13 \\
\hline 2 & 6 & 94 & 0 & 0 \\
\hline 3 & 100 & 0 & 0 & 0 \\
\hline 4 & 49 & 15 & 6 & 31 \\
\hline 5 & 75 & 12 & 2 & 10 \\
\hline 6 & 65 & 18 & 2 & 16 \\
\hline 7 & 69 & 13 & 3 & 15 \\
\hline
\end{tabular}




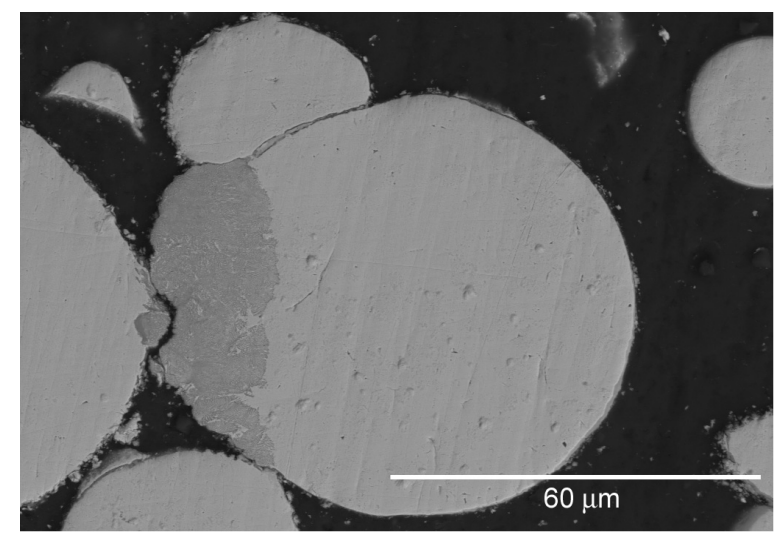

(a)

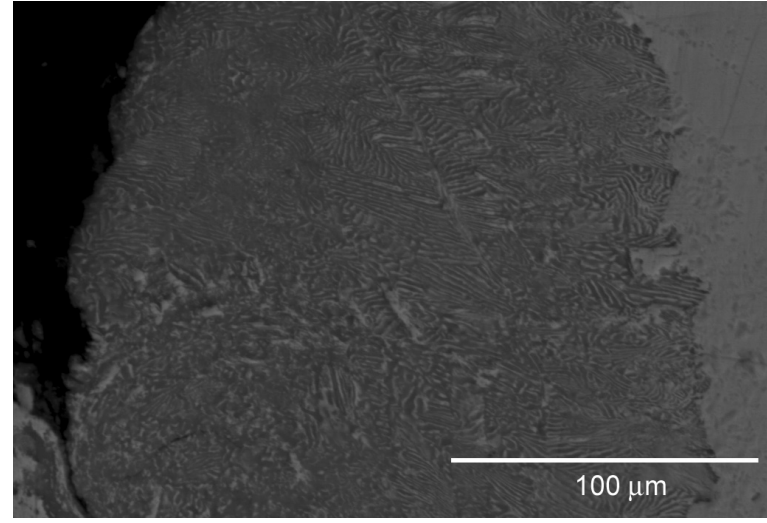

(b)

Figure 46. BSE images $(\mathrm{a}, \mathrm{b})$ of an interaction layer in the Al-2Si sample annealed at $500^{\circ} \mathrm{C}$ for 2 hours with negligible Si (medium contrast) that reveals the lamellar microstructure of decomposed U-7Mo alloy.

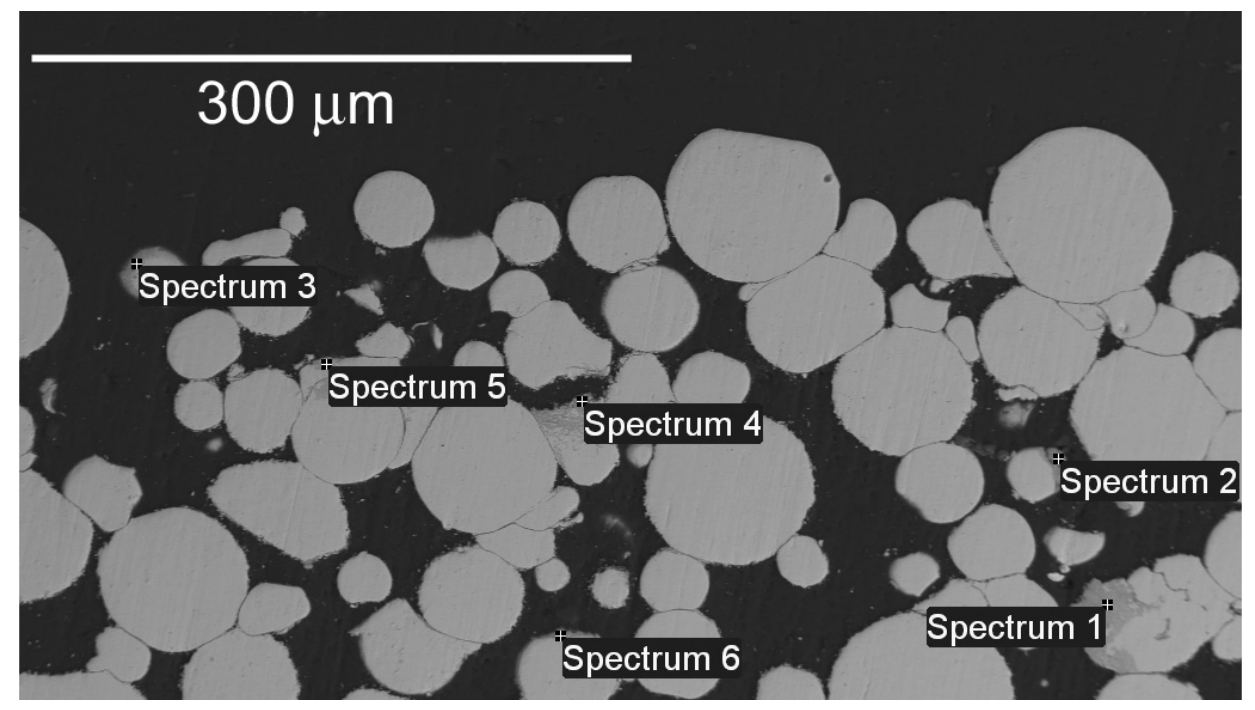

Figure 47. BSE image showing where point-to-point composition analysis was performed on the Al-2Si matrix sample annealed at $500^{\circ} \mathrm{C}$ for 2 hours (results listed in Table 18).

Table 18. Results of point-to-point composition analysis, in at $\%$, conducted at specific locations in the interaction zone (see Figure 47) in the Al-2Si matrix sample annealed at $500^{\circ} \mathrm{C}$ for 2 hours.

\begin{tabular}{|c|c|c|c|c|}
\hline Spectrum No. & $\mathrm{Al}$ & $\mathrm{Si}$ & Mo & $\mathrm{U}$ \\
\hline 1 & 64 & 0 & 6 & 31 \\
\hline 2 & 66 & 14 & 3 & 17 \\
\hline 3 & 27 & 34 & 5 & 33 \\
\hline 4 & 74 & 0 & 3 & 22 \\
\hline 5 & 42 & 2 & 9 & 47 \\
\hline 6 & 52 & 23 & 4 & 21 \\
\hline
\end{tabular}




\subsubsection{U-7Mo/Al-4Si Fuel Plate}

A BSE image of the microstructure observed for the Al-4Si matrix fuel plate annealed at $500^{\circ} \mathrm{C}$ is presented in Figure 48. A Si x-ray map of the microstructure is presented in Figure 49 that shows the presence of Si-rich interaction layers around the U-7Mo particles. In Figure 50, a BSE image is presented where a decomposed region of $\mathrm{U}-7 \mathrm{Mo}$ is present adjacent to a Si-rich interaction layer, and there is no evidence that the morphology of the layer has been impacted. X-ray maps for $\mathrm{U}, \mathrm{Mo}, \mathrm{Al}$, and Si that were generated in this same region are presented in Figure 51, and they show the presence of the Mo-deficient grain boundaries around the decomposed area and high Si concentrations in the interaction layer.

Whereas, in Figure 52, a BSE image is presented that shows how the decomposition of the U-7Mo alloy has resulted in the growth of a "bulk" interaction zone in this area of the sample near a Si-rich interaction layer. Results of point-to-point composition analysis that was performed in this region of the Al-4Si matrix sample (see Figure 52) are presented in Table 19, and they show that the "bulk" interaction zone contains negligible Si. The Si-rich layer contains between 18 and 23 at $\% \mathrm{Si}$.

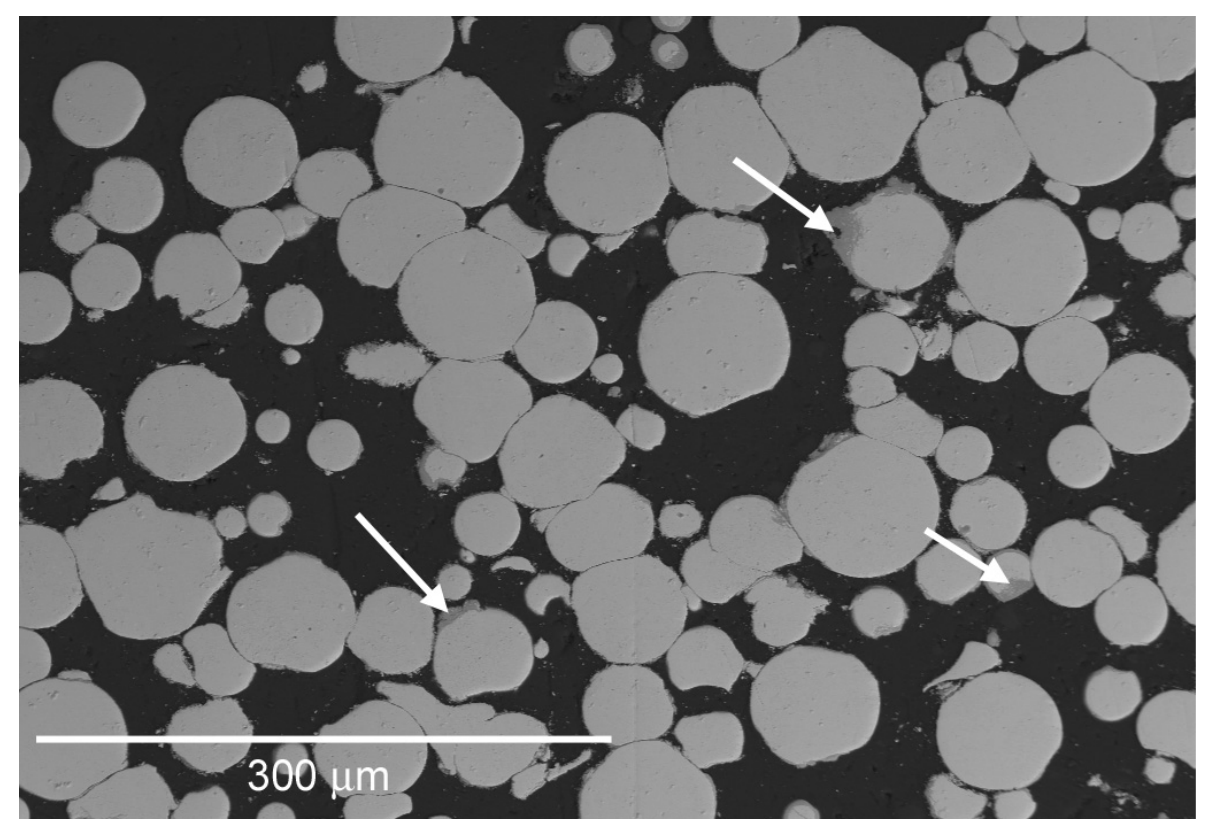

Figure 48. Backscattered electron image of the microstructure of the as-fabricated Al-4Si matrix fuel plate annealed at $500^{\circ} \mathrm{C}$ for 2 hours. The arrows identify where increased fuel/matrix interaction has occurred at areas of decomposed U-7Mo alloy. 


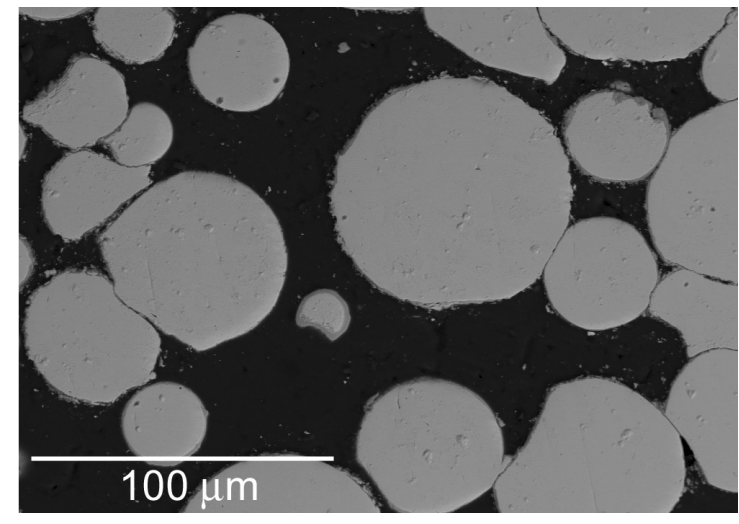

(a)

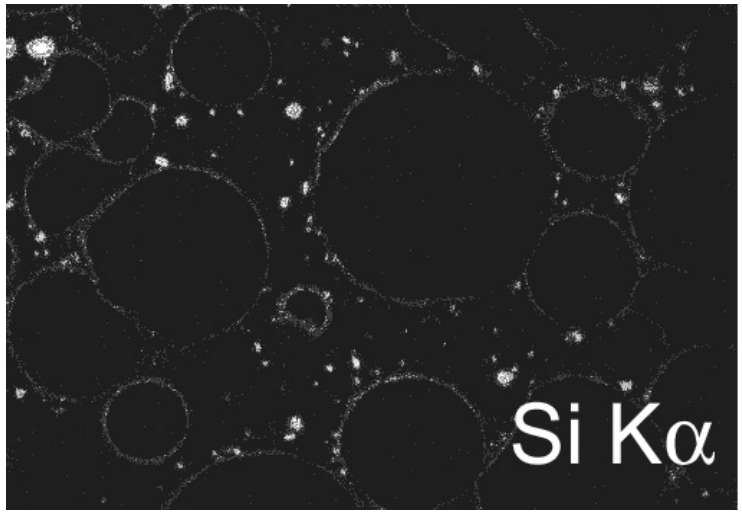

(b)

Figure 49. BSE image (a) of the microstructure of the as-fabricated Al-4Si matrix fuel plate annealed at $500^{\circ} \mathrm{C}$ for 2 hours, and (b) a Si x-ray map.

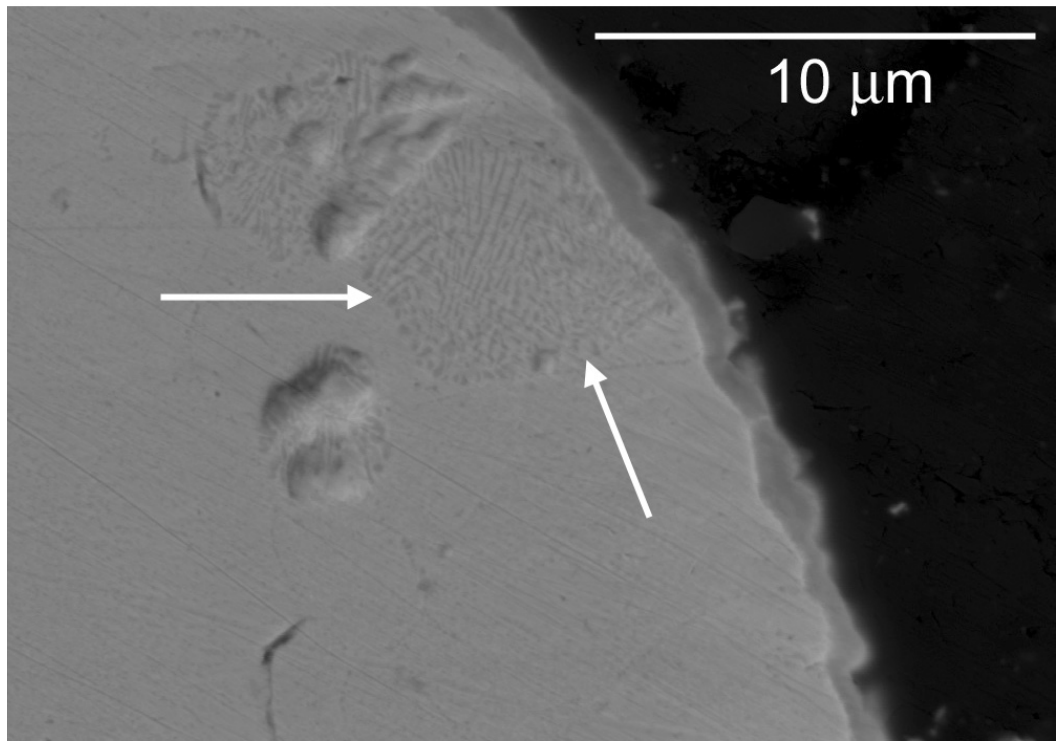

Figure 50. Backscattered electron image of the microstructure of the as-fabricated Al-4Si matrix fuel plate annealed at $500^{\circ} \mathrm{C}$ for 2 hours. The arrows indicate a location in the U-7Mo alloy where fuel decomposition has occurred. 


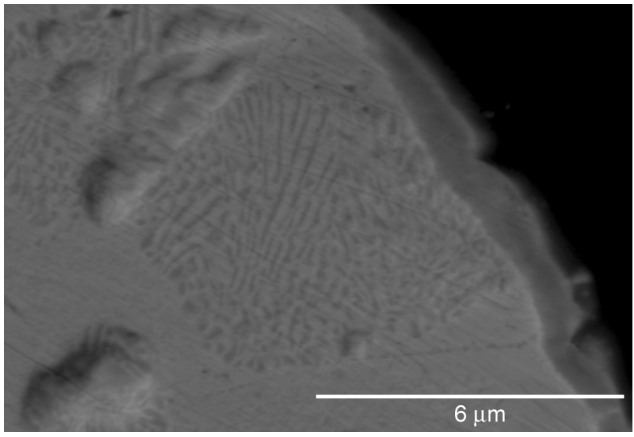

(a)

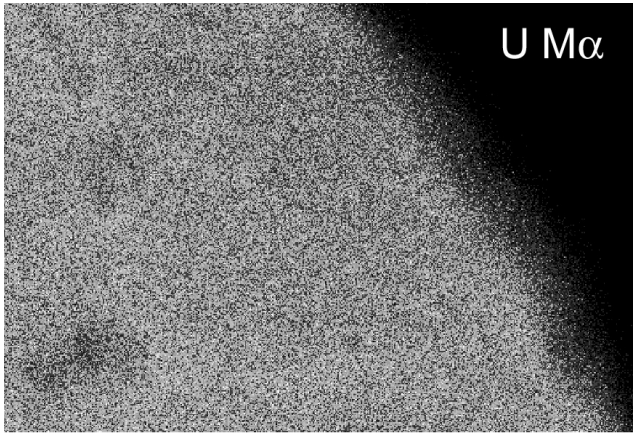

(c)

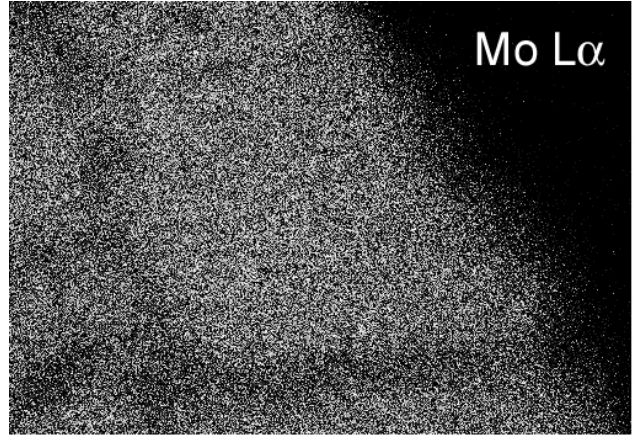

(b)

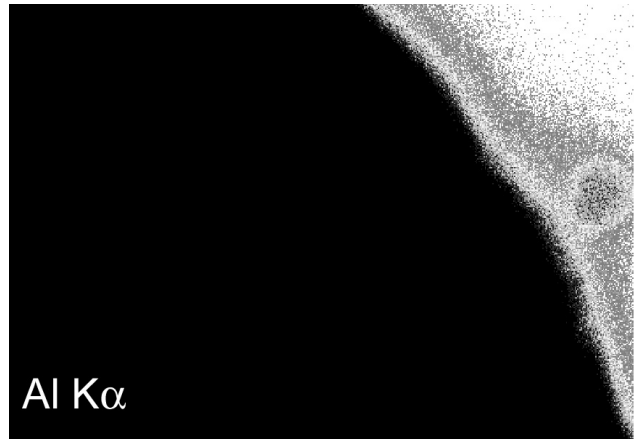

(d)

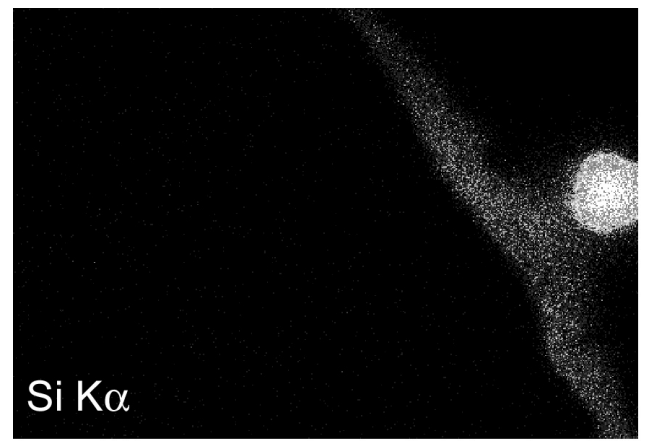

(e)

Figure 51. BSE image (a) of the microstructure of the as-fabricated Al-4Si matrix fuel plate annealed at $500^{\circ} \mathrm{C}$ for 2 hours, and x-ray maps for (b) Mo, (c) U, (d) Al, and (e) Si. 


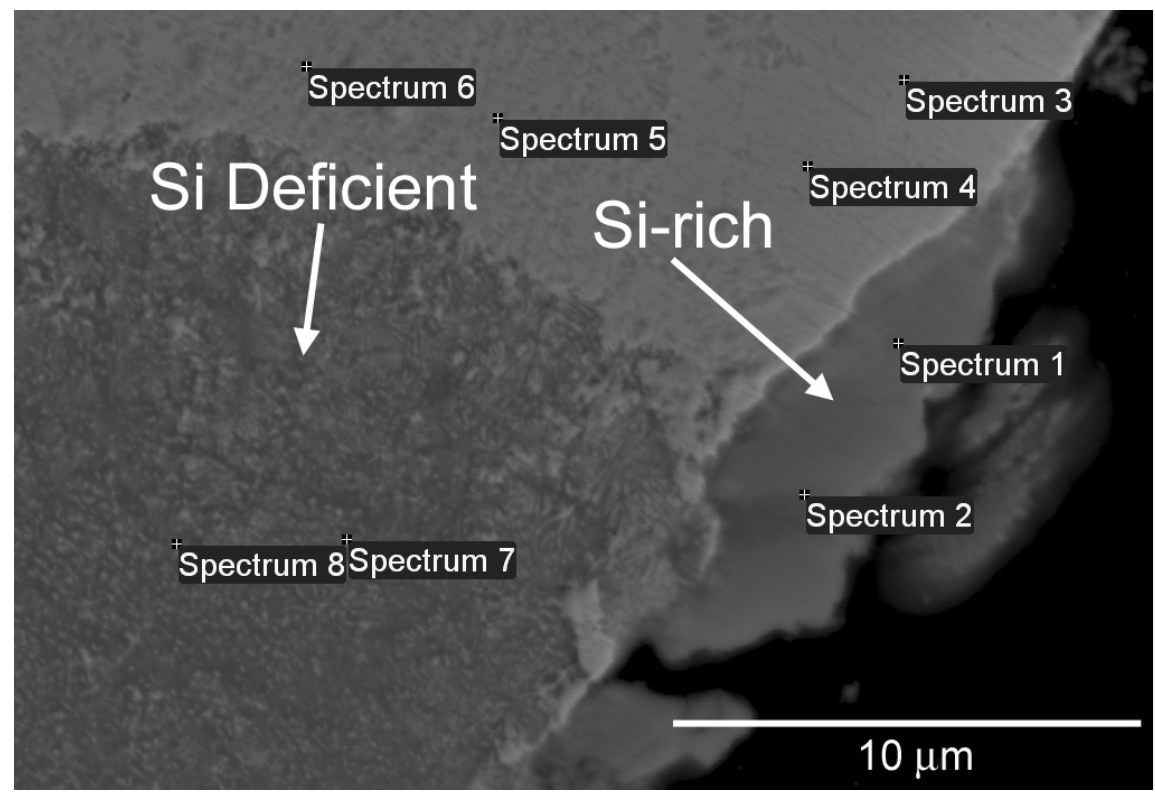

Figure 52. BSE image showing an area where Si-deficient interaction layer has developed near a Si-rich interaction layer. Points where composition analysis was performed (see Table 19) are identified.

Table 19. Results of point-to-point composition analysis, in at $\%$, conducted at specific locations in the interaction zone (see Figure 52) in the Al-4Si matrix sample annealed at $500^{\circ} \mathrm{C}$ for 2 hours.

\begin{tabular}{|c|c|c|c|c|}
\hline Spectrum No. & $\mathrm{Al}$ & $\mathrm{Si}$ & Mo & $\mathrm{U}$ \\
\hline 1 & 51 & 23 & 3 & 23 \\
\hline 2 & 58 & 18 & 3 & 21 \\
\hline 3 & 1 & 0 & 12 & 87 \\
\hline 4 & 2 & 0 & 12 & 85 \\
\hline 5 & 1 & 0 & 12 & 88 \\
\hline 6 & 2 & 0 & 13 & 85 \\
\hline 7 & 60 & 0 & 5 & 34 \\
\hline 8 & 63 & 0 & 5 & 33 \\
\hline
\end{tabular}

\subsubsection{U-7Mo/Al-5Si Fuel Plate}

BSE images of the microstructure observed for the Al-5Si matrix plate annealed at $500^{\circ} \mathrm{C}$ are presented in Figure 53. The presence of an interaction layer can be observed around the U-7Mo particles. The Si x-ray map in Figure 54 shows that the interaction layers are enriched in Si. Based on the BSE images produced for this sample, there was little indication of "bulk" interaction layer development. Point-to-point composition analysis performed in some interaction layers (see Figure 55 for the locations and Table 20 for the results) confirmed the fact that the layers were enriched in Si. The measured Si concentration values varied between 15 and 32 at $\%$. 


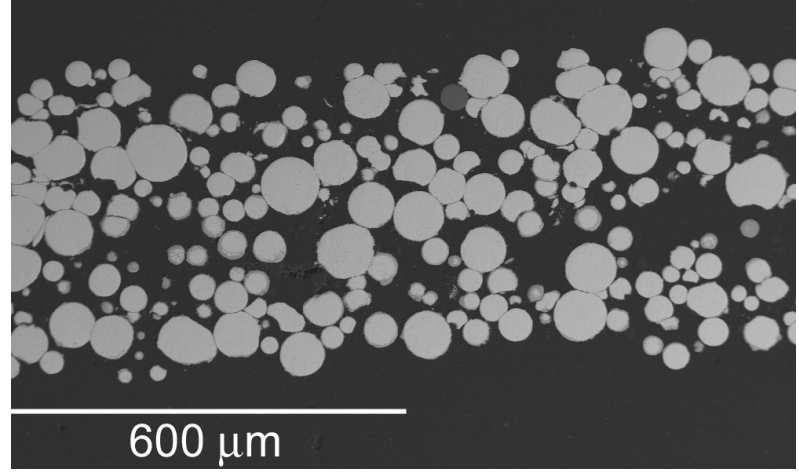

(a)

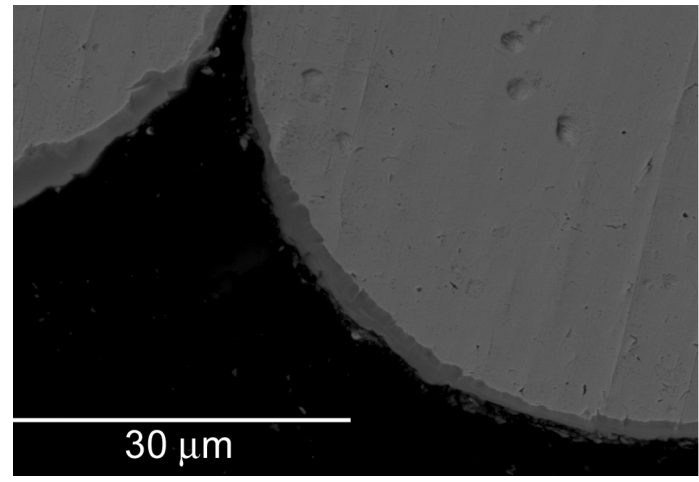

(b)

Figure 53. Backscattered electron images $(a, b)$ of the microstructure of the Al-5Si matrix fuel plate annealed at $500^{\circ} \mathrm{C}$ for 2 hours.

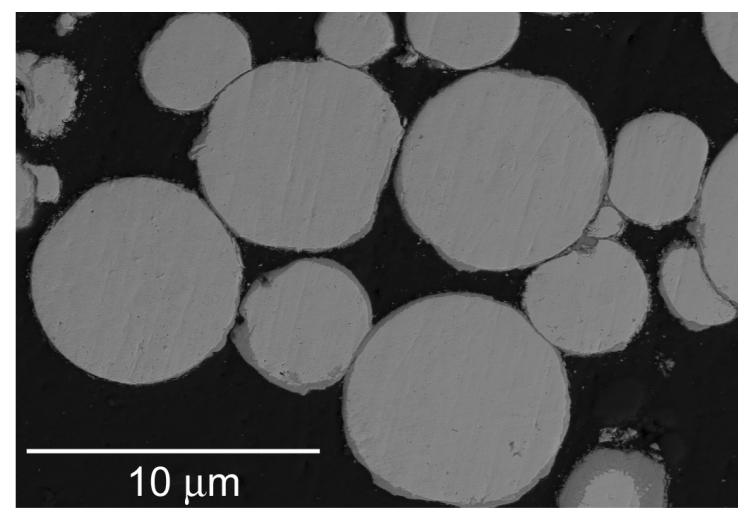

(a)

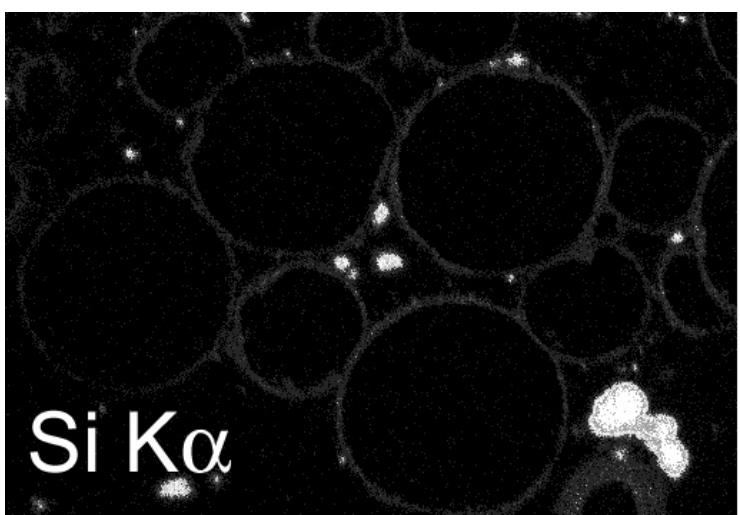

(b)

Figure 54. Backscattered electron image (a) and Si x-ray map (b) of the microstructure of the Al-5Si matrix fuel plate annealed at $500^{\circ} \mathrm{C}$ for 2 hours.

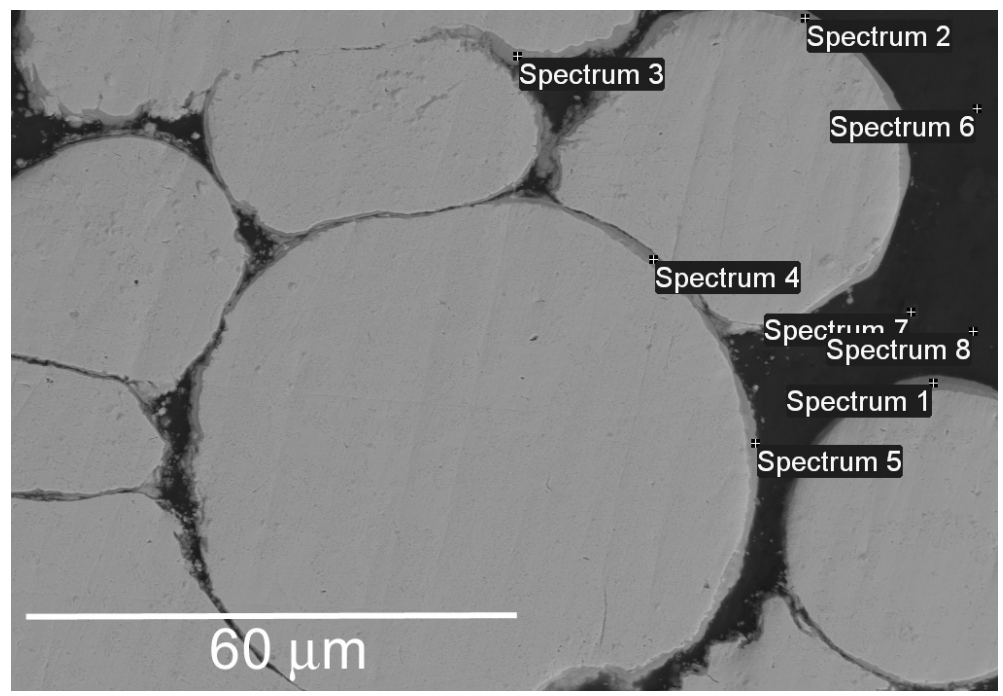

Figure 55. Backscattered electron image of locations in the microstructure of the Al-5Si matrix fuel plate annealed at $500^{\circ} \mathrm{C}$ for 2 hours where point-to-point composition analysis was performed (see Table 20 for results). 
Table 20. Results of point-to-point composition analysis, in at $\%$, conducted at specific locations in the interaction zone (see Figure 55) in the Al-5Si matrix sample annealed at $500^{\circ} \mathrm{C}$ for 2 hours.

\begin{tabular}{|c|c|c|c|c|}
\hline Spectrum No. & $\mathrm{Al}$ & $\mathrm{Si}$ & Mo & $\mathrm{U}$ \\
\hline 1 & 48 & 23 & 4 & 25 \\
\hline 2 & 47 & 25 & 4 & 24 \\
\hline 3 & 44 & 32 & 4 & 20 \\
\hline 4 & 50 & 22 & 4 & 24 \\
\hline 5 & 68 & 15 & 2 & 15 \\
\hline 6 & 100 & 0 & 0 & 0 \\
\hline 7 & 44 & 56 & 0 & 0 \\
\hline 8 & 100 & 0 & 0 & 0 \\
\hline
\end{tabular}

\subsubsection{U-7Mo/Al-6Si Fuel Plate}

Like was the case for the Al-5Si matrix sample, the BSE images produced for the Al-6Si matrix sample annealed at $500^{\circ} \mathrm{C}$ for 2 hours (see Figure 56) showed little indication of "bulk" interaction layer development. A Si x-ray map for this sample is presented in Figure 57 to show the presence of Si-rich interaction layers around the U-7Mo particles. The locations where point-to-point composition analysis was performed in interaction layers are shown in Figure 58, and the results are enumerated in Table 21. The Si concentration values varied between 19 and 37 at\%. Point-to-point composition analysis was also performed on an interaction layer that appeared to penetrate into the U-7Mo (see Figure 59) to look for evidence of "bulk" interaction layer formation. The results (see Table 22) indicated that this particular relatively thick interaction layer is enriched in $\mathrm{Si}$, where the Si concentration value varied between 21 and 37 at \%. It appears that even the thicker interaction layers in this sample are enriched in $\mathrm{Si}$.

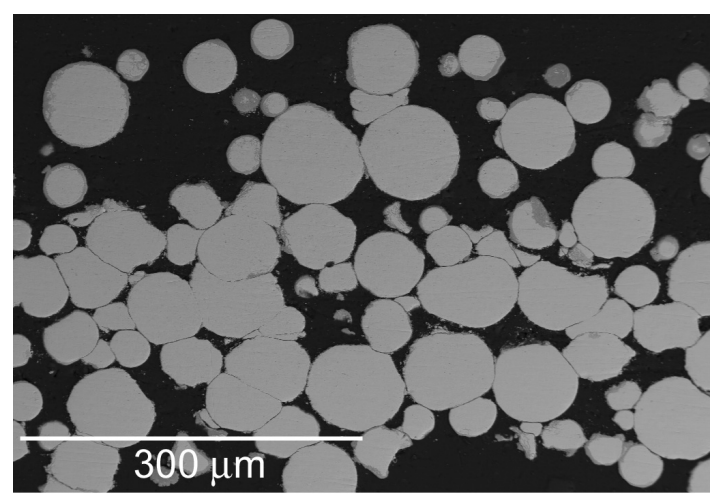

(a)

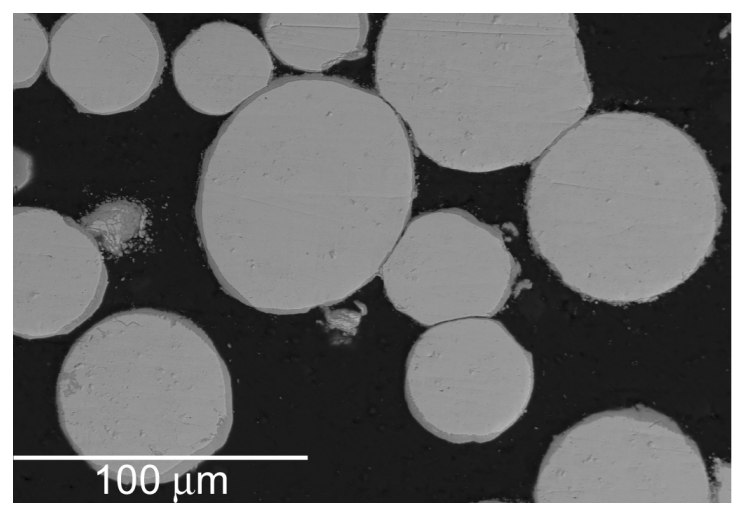

(b)

Figure 56. Backscattered electron images $(a, b)$ of the microstructure of the Al-6Si matrix fuel plate annealed at $500^{\circ} \mathrm{C}$ for 2 hours. 


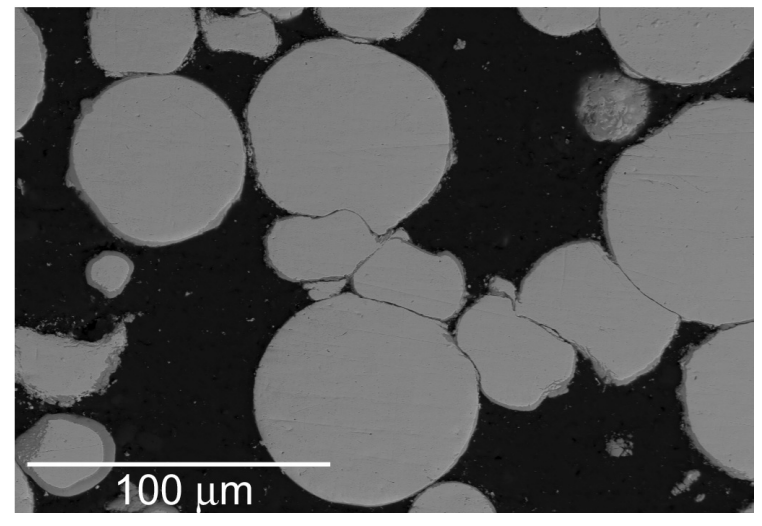

(a)

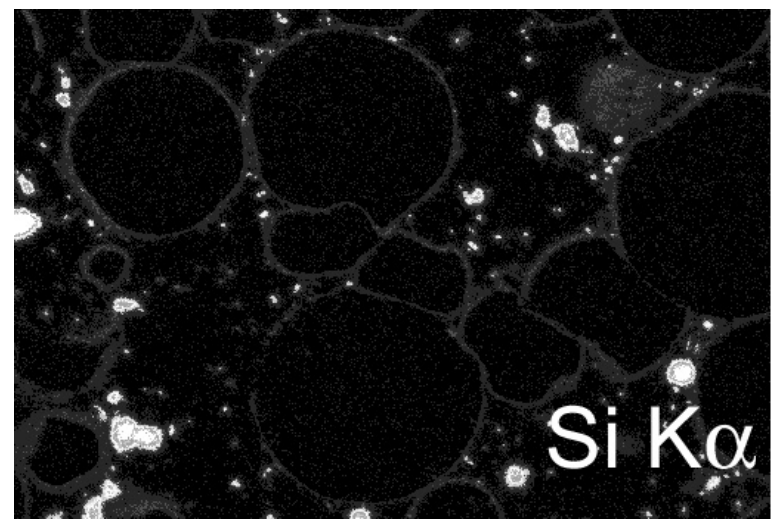

(b)

Figure 57. Backscattered electron image (a) and (b) Si x-ray map of the microstructure of the Al-6Si matrix fuel plate annealed at $500^{\circ} \mathrm{C}$ for 2 hours.

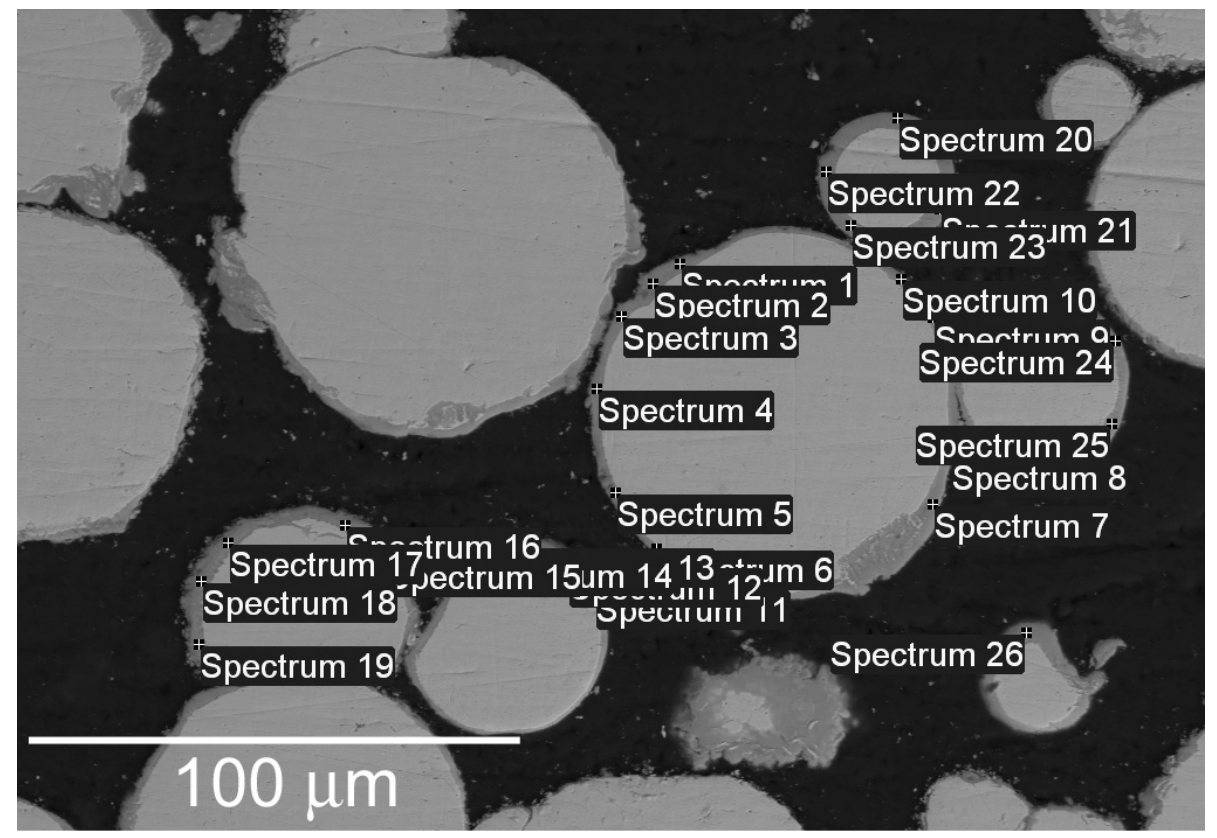

Figure 58. Backscattered electron image of locations in the microstructure of the Al-6Si matrix fuel plate annealed at $500^{\circ} \mathrm{C}$ for 2 hours where point-to-point composition analysis was performed (see Table 21 for results). 
Table 21. Results of point-to-point composition analysis, in at $\%$, conducted at specific locations in the interaction zone (see Figure 58) in the Al-6Si matrix sample annealed at $500^{\circ} \mathrm{C}$ for 2 hours.

\begin{tabular}{|c|c|c|c|c|}
\hline Spectrum No. & $\mathrm{Al}$ & $\mathrm{Si}$ & Mo & $\mathrm{U}$ \\
\hline 1 & 47 & 25 & 4 & 24 \\
\hline 2 & 50 & 23 & 4 & 23 \\
\hline 3 & 44 & 27 & 4 & 25 \\
\hline 4 & 33 & 35 & 4 & 28 \\
\hline 5 & 30 & 37 & 4 & 28 \\
\hline 6 & 40 & 30 & 4 & 25 \\
\hline 7 & 53 & 21 & 3 & 22 \\
\hline 8 & 56 & 24 & 3 & 28 \\
\hline 9 & 56 & 20 & 3 & 21 \\
\hline 10 & 51 & 21 & 4 & 24 \\
\hline 11 & 50 & 24 & 4 & 23 \\
\hline 12 & 41 & 30 & 4 & 25 \\
\hline 13 & 43 & 28 & 4 & 25 \\
\hline 14 & 46 & 26 & 4 & 24 \\
\hline 15 & 39 & 31 & 5 & 25 \\
\hline 16 & 34 & 35 & 5 & 26 \\
\hline 17 & 34 & 35 & 5 & 26 \\
\hline 18 & 46 & 26 & 4 & 24 \\
\hline 19 & 32 & 37 & 5 & 26 \\
\hline 20 & 56 & 19 & 3 & 22 \\
\hline 21 & 57 & 20 & 3 & 21 \\
\hline 22 & 54 & 20 & 3 & 23 \\
\hline 23 & 52 & 22 & 3 & 23 \\
\hline 24 & 52 & 22 & 4 & 22 \\
\hline 25 & 48 & 25 & 4 & 23 \\
\hline 26 & 44 & 27 & 4 & 25 \\
\hline Mean & 46 & 27 & 4 & 24 \\
\hline
\end{tabular}




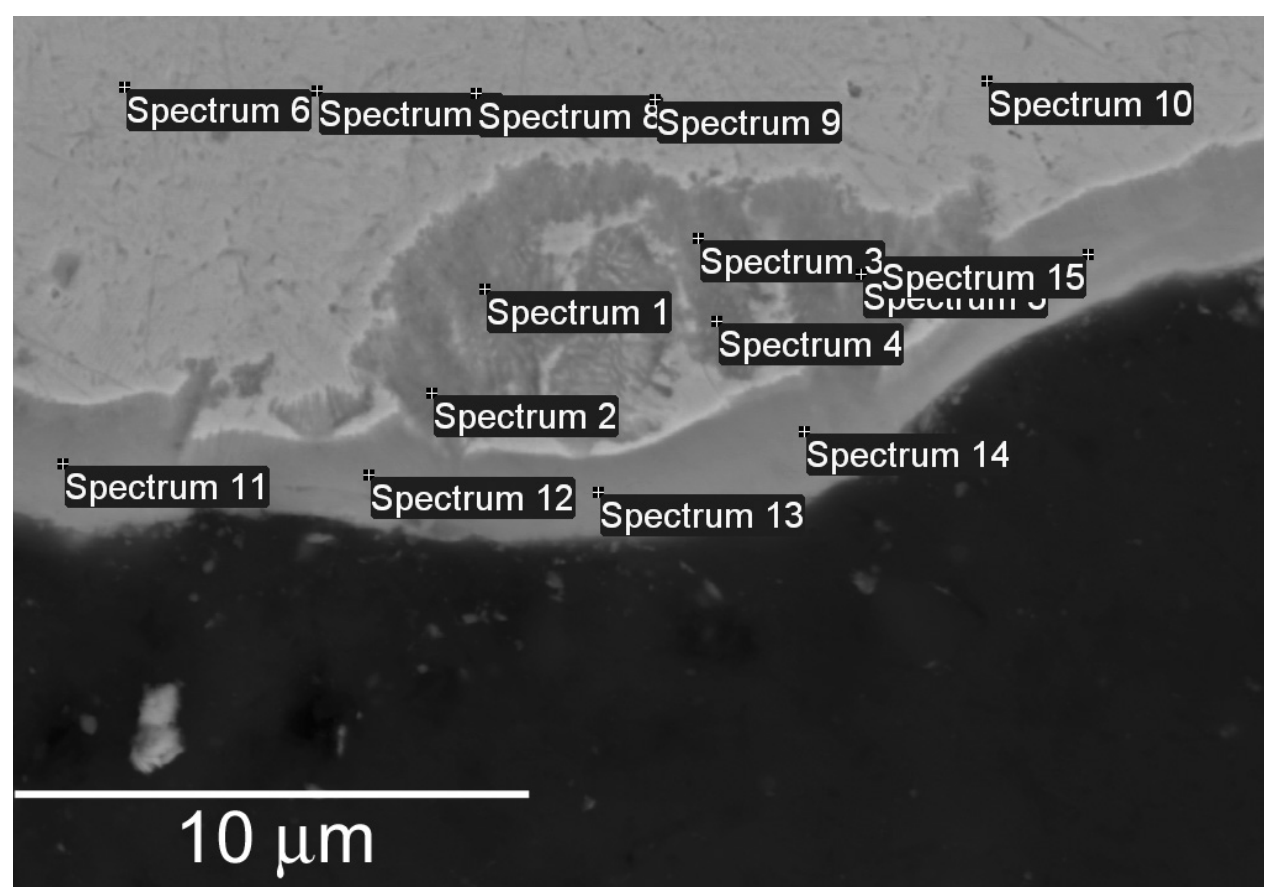

Figure 59. Backscattered electron image of locations in the microstructure of the Al-6Si matrix fuel plate annealed at $500^{\circ} \mathrm{C}$ for 2 hours where point-to-point composition analysis was performed (see Table 22 for results).

Table 22. Results of point-to-point composition analysis, in at $\%$, conducted at specific locations in the interaction zone (see Figure 59) in the Al-6Si matrix sample annealed at $500^{\circ} \mathrm{C}$ for 2 hours.

\begin{tabular}{|c|c|c|c|c|}
\hline Spectrum No. & $\mathrm{Al}$ & $\mathrm{Si}$ & Mo & $\mathrm{U}$ \\
\hline 1 & 39 & 30 & 3 & 27 \\
\hline 2 & 49 & 24 & 3 & 24 \\
\hline 3 & 37 & 33 & 3 & 27 \\
\hline 4 & 45 & 25 & 4 & 26 \\
\hline 5 & 43 & 28 & 4 & 25 \\
\hline 6 & 1 & 1 & 15 & 83 \\
\hline 7 & 2 & 0 & 15 & 85 \\
\hline 8 & 2 & 0 & 12 & 82 \\
\hline 9 & 1 & 0 & 12 & 87 \\
\hline 10 & 1 & 0 & 14 & 84 \\
\hline 11 & 52 & 24 & 4 & 21 \\
\hline 12 & 54 & 23 & 4 & 19 \\
\hline 13 & 56 & 21 & 4 & 19 \\
\hline 14 & 54 & 22 & 4 & 21 \\
\hline 15 & 35 & 37 & 4 & 24 \\
\hline
\end{tabular}




\subsection{Interaction Layer Development after Annealing Treatment at $525^{\circ} \mathrm{C}$ for 1 Hour}

\subsubsection{U-7Mo/Al-4Si Fuel Plate}

$\mathrm{BSE}$ images of the microstructure of the Al-4Si matrix sample annealed at $525^{\circ} \mathrm{C}$ are presented in Figure 60. Narrow interaction layers were observed around the U-7Mo particles. Si x-ray maps showing that the interaction layers are enriched in Si are presented in Figure 61. It was observed that the interaction layers are slightly thicker when a Si particle is in close proximity. Locations where point-topoint composition analysis was performed are shown in Figure 62, and the results are enumerated in Table 23. The Si content in the layers varied between 12 and 33 at $\%$.

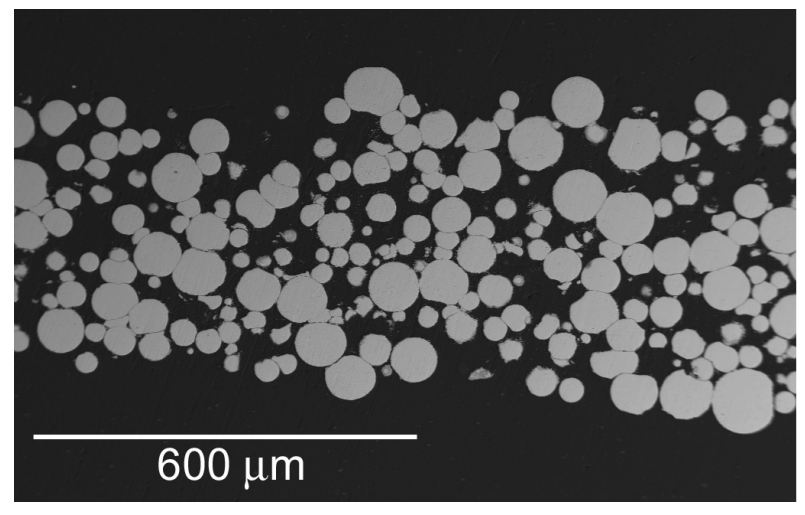

(a)

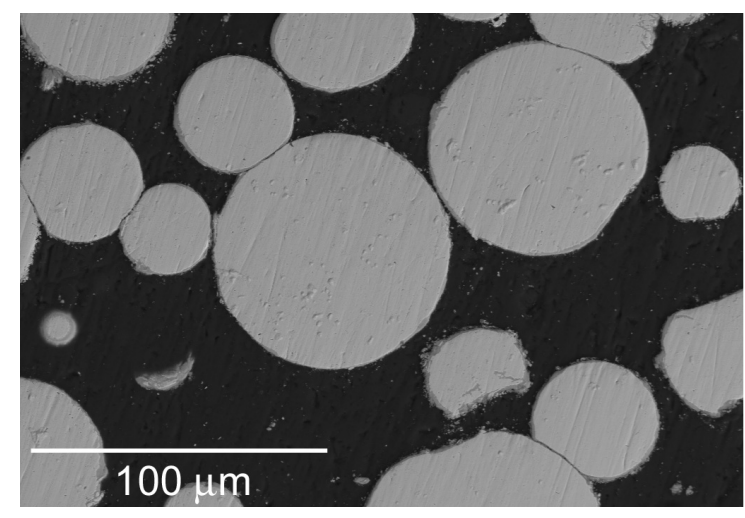

(b)

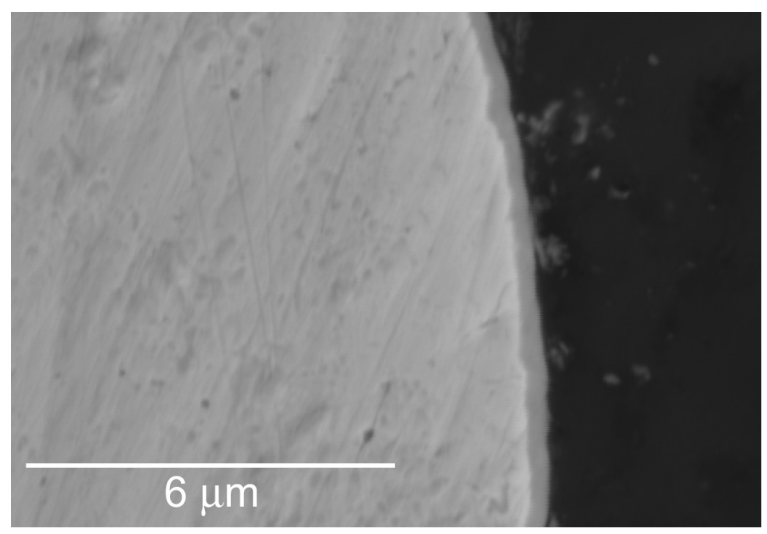

(c)

Figure 60. BSE images (a-c) of the microstructure of the Al-4Si matrix fuel plate annealed at $525^{\circ} \mathrm{C}$ for 1 hour. 


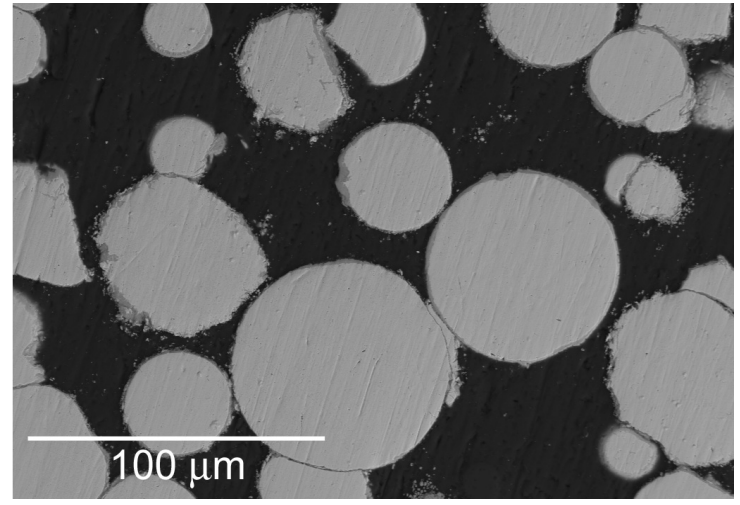

(a)

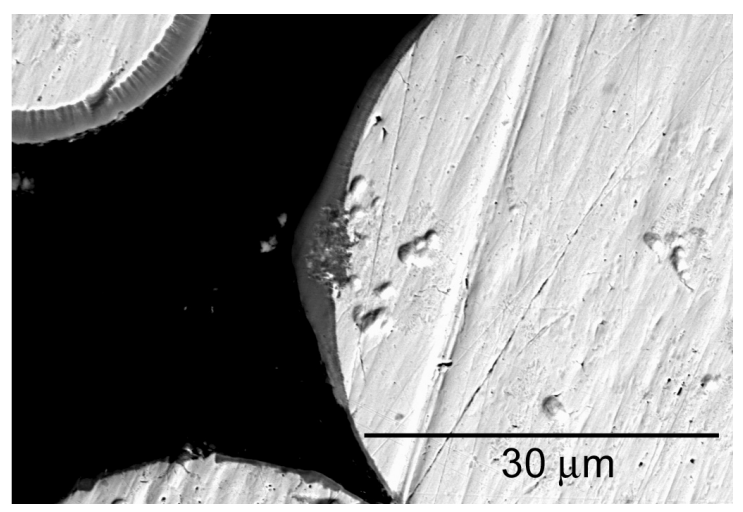

(c)

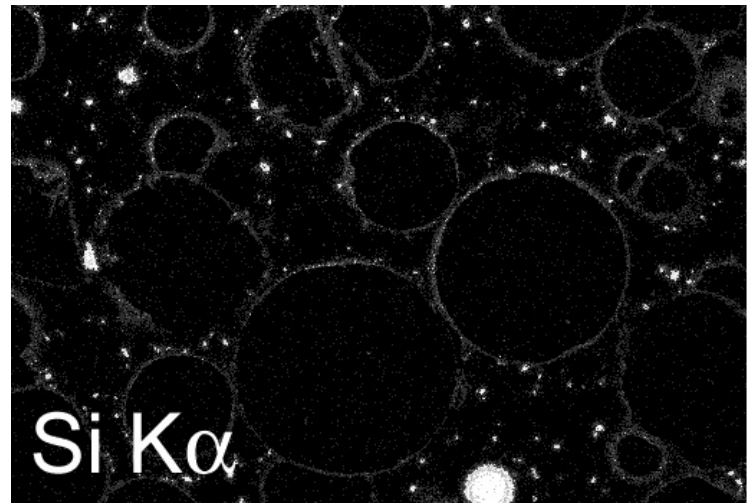

(b)

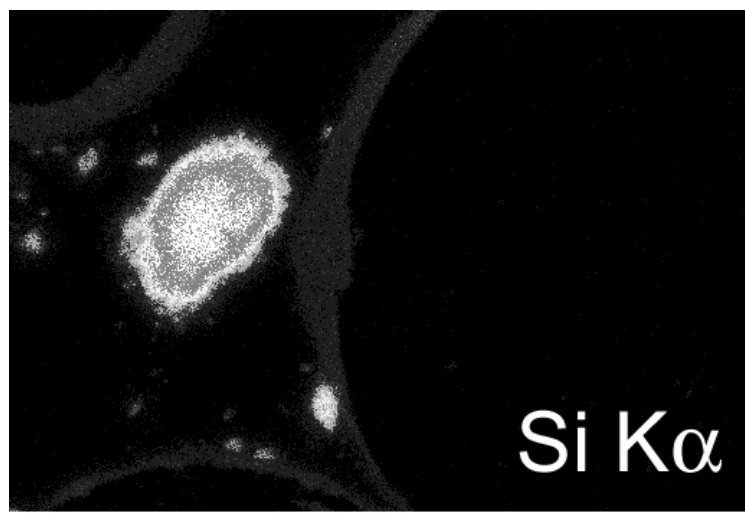

(d)

Figure 61. Backscattered electron images $(a, c)$ and Si x-ray maps $(b, d)$ of the microstructure for the Al-4Si matrix fuel plate annealed for 1 hour at $525^{\circ} \mathrm{C}$.

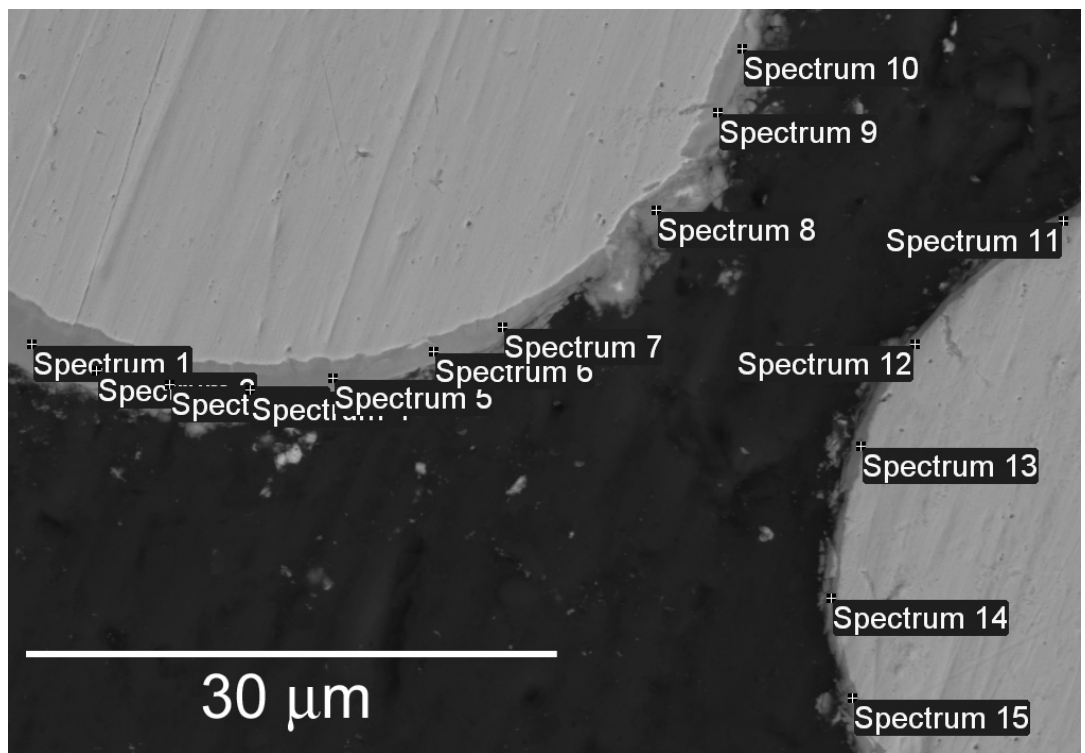

Figure 62. Backscattered electron image of locations in the microstructure of the as-fabricated Al-4Si matrix fuel plate annealed at $525^{\circ} \mathrm{C}$ for 1 hour where point-to-point composition analysis was performed (see Table 23 for results). 
Table 23. Results of point-to-point composition analysis, in at $\%$, conducted at specific locations in the interaction zone (see Figure 62) in the Al-4Si matrix sample annealed at $525^{\circ} \mathrm{C}$ for 1 hour.

\begin{tabular}{|c|c|c|c|c|}
\hline Spectrum No. & Al & Si & Mo & U \\
\hline 1 & 51 & 23 & 3 & 23 \\
\hline 2 & 52 & 22 & 3 & 22 \\
\hline 3 & 55 & 21 & 3 & 21 \\
\hline 4 & 59 & 20 & 2 & 19 \\
\hline 5 & 53 & 23 & 3 & 21 \\
\hline 6 & 47 & 29 & 3 & 21 \\
\hline 7 & 67 & 17 & 2 & 13 \\
\hline 8 & 60 & 19 & 3 & 19 \\
\hline 9 & 62 & 19 & 3 & 17 \\
\hline 10 & 62 & 18 & 3 & 17 \\
\hline 11 & 16 & 12 & 11 & 60 \\
\hline 12 & 17 & 13 & 11 & 59 \\
\hline 13 & 29 & 33 & 6 & 32 \\
\hline 14 & 63 & 16 & 4 & 17 \\
\hline 15 & 60 & 20 & 3 & 17 \\
\hline Mean & 50 & 20 & 4 & 25 \\
\hline
\end{tabular}

\subsubsection{U-7Mo/Al-6Si Fuel Plate}

Figure 63 shows the narrow interaction layers present around the U-7Mo particles in the Al-6Si matrix sample annealed at $525^{\circ} \mathrm{C}$. The Si x-ray map in Figure 64 indicates that the interaction layers are enriched in Si. Point-to-point composition analysis was performed at different locations in the interaction layers (see Figure 65) and the results are listed in Table 24. The Si concentration values varied between 9 and 39 at \%. Point-to-point composition analysis was also performed in another region of the sample (see Figure 66 and Table 25), and the results indicated that the Si concentration varied between 22 and 38 at $\%$.

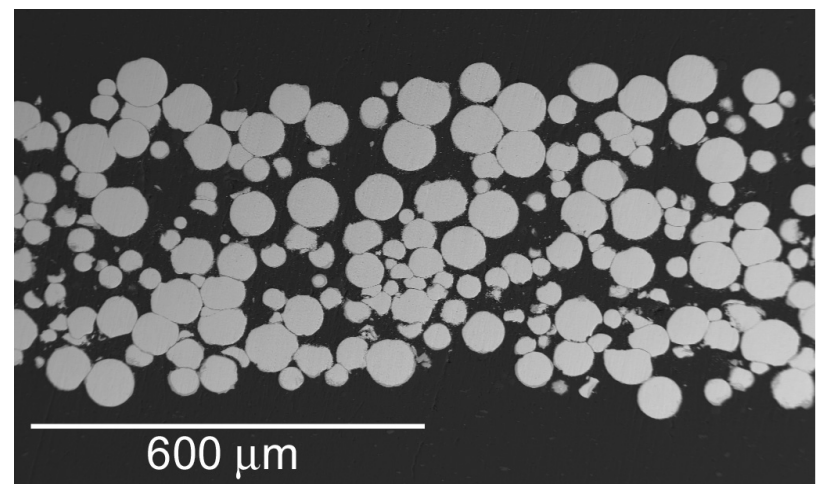

(a)

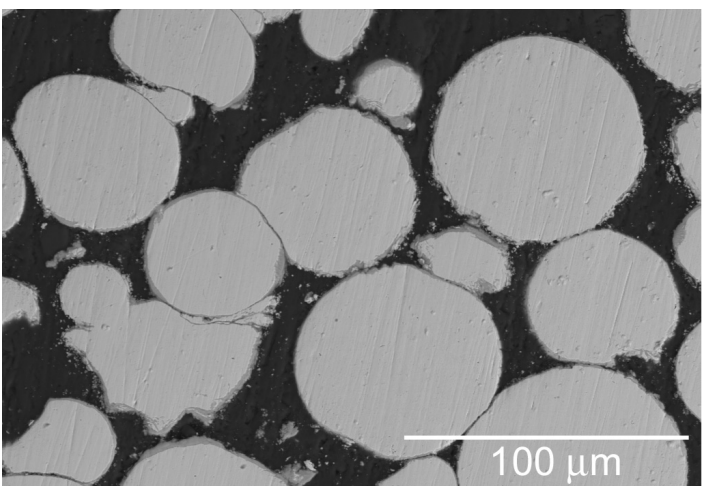

(b)

Figure 63. Backscattered electron images $(a, b)$ of the microstructure of the Al-6Si matrix fuel plate annealed at $525^{\circ} \mathrm{C}$ for 1 hour. 


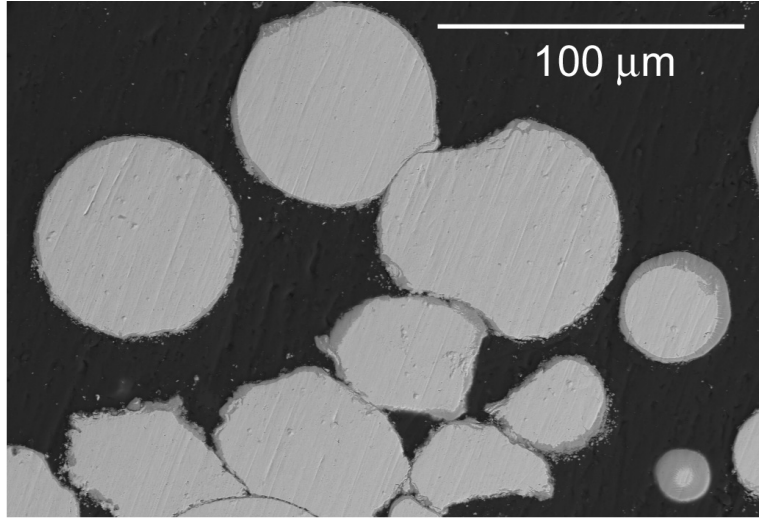

(a)

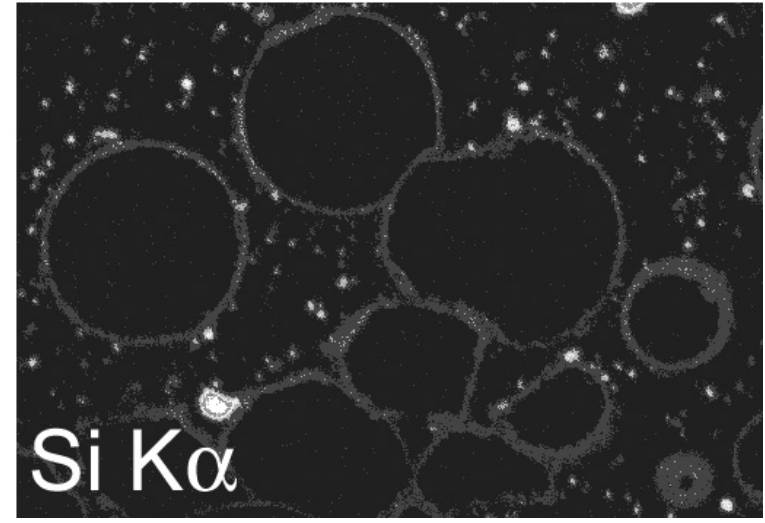

(b)

Figure 64. Backscattered electron image (a) and Si x-ray map (b) of the microstructure for the Al-6Si matrix fuel plate annealed for 1 hour at $525^{\circ} \mathrm{C}$.

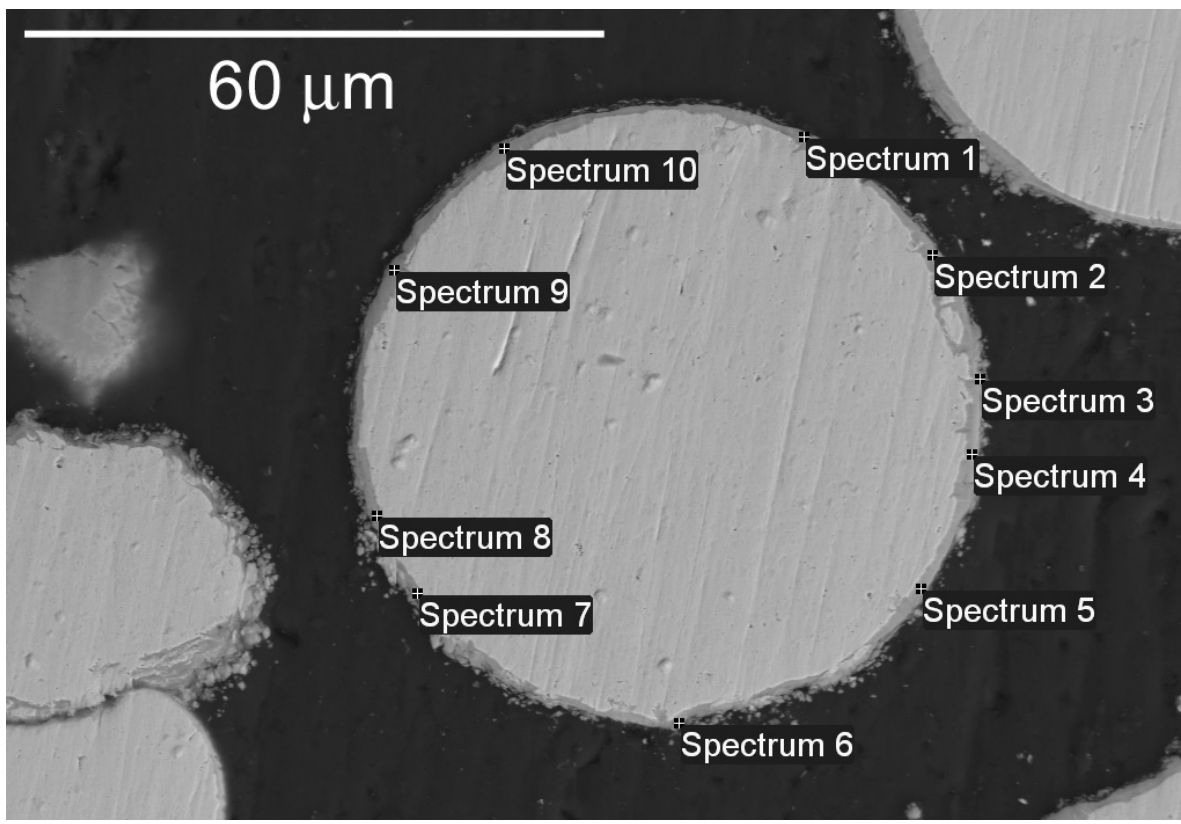

Figure 65. Backscattered electron image of locations in the microstructure of the as-fabricated Al-6Si matrix fuel plate annealed at $525^{\circ} \mathrm{C}$ for 1 hour where point-to-point composition analysis was performed (see Table 24 for results). 
Table 24. Results of point-to-point composition analysis, in at $\%$, conducted at specific locations in the interaction zone (see Figure 65) in the Al-6Si matrix sample annealed at $525^{\circ} \mathrm{C}$ for 1 hour.

\begin{tabular}{|c|c|c|c|c|}
\hline Spectrum No. & $\mathrm{Al}$ & $\mathrm{Si}$ & $\mathrm{Mo}$ & $\mathrm{U}$ \\
\hline 1 & 51 & 25 & 3 & 21 \\
\hline 2 & 33 & 38 & 4 & 25 \\
\hline 3 & 70 & 17 & 2 & 11 \\
\hline 4 & 46 & 30 & 4 & 20 \\
\hline 5 & 62 & 20 & 3 & 16 \\
\hline 6 & 82 & 9 & 2 & 7 \\
\hline 7 & 40 & 29 & 5 & 26 \\
\hline 8 & 21 & 39 & 6 & 34 \\
\hline 9 & 40 & 29 & 4 & 27 \\
\hline 10 & 51 & 33 & 3 & 23 \\
\hline Mean & 50 & 26 & 4 & 21 \\
\hline
\end{tabular}

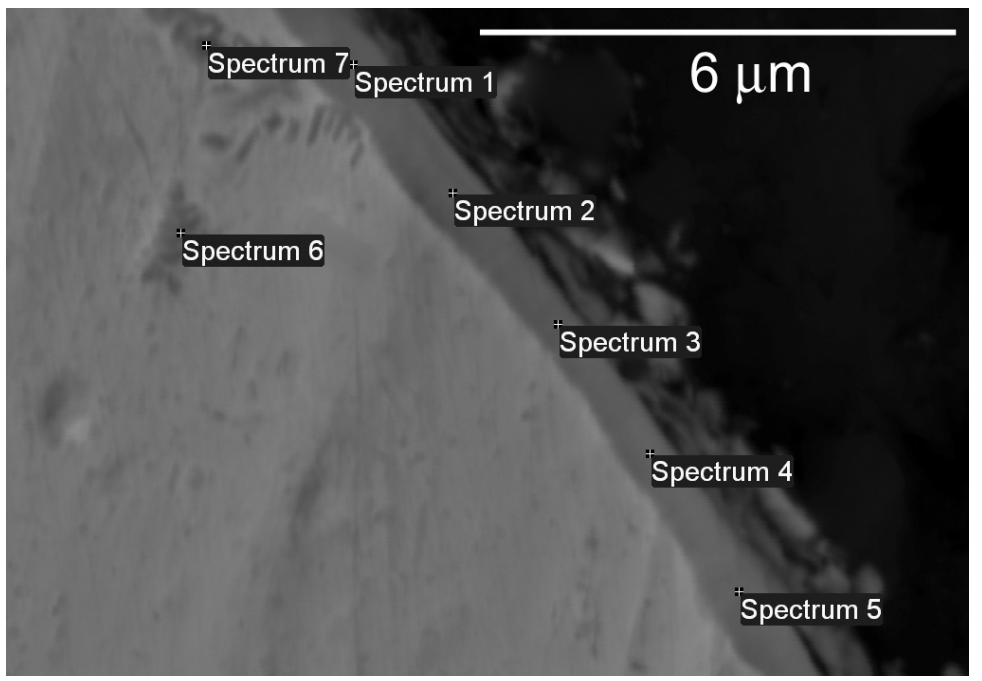

Figure 66. Backscattered electron image of locations in the microstructure of the Al-6Si matrix fuel plate annealed at $525^{\circ} \mathrm{C}$ for 1 hour where point-to-point composition analysis was performed (see Table 25 for results).

Table 25. Results of point-to-point composition analysis, in at $\%$, conducted at specific locations in the interaction zone (see Figure 66) in the Al-6Si matrix sample annealed at $525^{\circ} \mathrm{C}$ for 1 hour.

\begin{tabular}{|c|c|c|c|c|}
\hline Spectrum No. & $\mathrm{Al}$ & $\mathrm{Si}$ & $\mathrm{Mo}$ & $\mathrm{U}$ \\
\hline 1 & 56 & 22 & 3 & 19 \\
\hline 2 & 46 & 29 & 4 & 22 \\
\hline 3 & 47 & 28 & 4 & 21 \\
\hline 4 & 42 & 31 & 4 & 22 \\
\hline 5 & 35 & 36 & 5 & 25 \\
\hline 6 & 5 & 38 & 8 & 50 \\
\hline 7 & 24 & 25 & 7 & 45 \\
\hline
\end{tabular}




\subsection{Image Analysis of Microstructures}

The values of average thickness, minimum thickness, maximum thickness, maximum to minimum thickness ratio, average fuel area fraction, average IL area fraction, and IL to fuel area fraction ratios were obtained using image analysis and the generated SEM images, and the results are listed in Table 26. Based on these values, plots were created to determine whether or not there is a correlation between $\mathrm{Si}$ content and IL thickness or Si content and IL area fraction (see Figure 67). Based on these results, the relationship between Si content and both IL thickness and IL area fraction do not appear to be strong. Because the samples were annealed for different times, a plot of $\lambda$ vs. Si content was developed where $\lambda=\frac{x}{\sqrt{t}}$

$\mathrm{x}$ is the thickness, and $\mathrm{t}$ is the time in seconds. This equation factors in the varying annealing times for a more appropriate comparison. This plot is shown in Figure 68. A strong correlation was not observed between Si content and $\lambda$, but there was a trend of increasing $\lambda$ (and IL thickness and IL area fraction) with increasing matrix Si content.

Table 26. FMI Layer Attributes.

\begin{tabular}{|c|c|c|c|c|c|c|c|c|c|}
\hline Matrix & $\begin{array}{c}\text { Temp. } \\
\left({ }^{\circ} \mathrm{C}\right)\end{array}$ & $\begin{array}{c}\text { Time } \\
(\mathrm{Hr})\end{array}$ & $\begin{array}{c}\text { Ave. } \\
\text { Thickness } \\
(\mu \mathrm{m})\end{array}$ & $\begin{array}{c}\text { Min. } \\
\text { Thickness } \\
(\mu \mathrm{m})\end{array}$ & $\begin{array}{l}\text { Max. } \\
\text { Thickness } \\
(\mu \mathrm{m})\end{array}$ & $\begin{array}{c}\text { Max/Min } \\
\text { Thickness } \\
\text { Ratio } \\
\end{array}$ & $\begin{array}{l}\text { Ave. Fuel } \\
\text { Area } \\
\text { Fraction } \\
(\%)\end{array}$ & $\begin{array}{c}\text { Ave. IL } \\
\text { Area } \\
\text { Fraction } \\
(\%)\end{array}$ & $\begin{array}{l}\text { Ave. } \\
\text { IL/Fuel } \\
\text { Area } \\
\text { Fraction } \\
\text { Ratio }\end{array}$ \\
\hline $\mathrm{Al}-2 \mathrm{Si}$ & 450 & 4 & $0.6(0.25)^{*}$ & 0.2 & 0.9 & 4.5 & $59(6)$ & $4(1)$ & $0.07(0.01)$ \\
\hline Al-2Si & 475 & 4 & $0.7(0.30)$ & 0.4 & 1.4 & 3.5 & $62(7)$ & $6(2)$ & $0.10(0.02)$ \\
\hline Al-2Si & 500 & 2 & $1.3(0.33)$ & 0.7 & 1.8 & 2.6 & $55(7)$ & $8(2)$ & $0.14(0.03)$ \\
\hline Al-4Si & 450 & 4 & ND & ND & ND & ND & ND & ND & ND \\
\hline Al-4Si & 475 & 4 & $1.4(0.51)$ & 0.7 & 3.0 & 4.3 & $59(7)$ & $7(1)$ & $0.12(0.03)$ \\
\hline Al-4Si & 500 & 2 & $1.3(0.37)$ & 0.7 & 2.6 & 3.7 & $55(8)$ & $7(1)$ & $0.12(0.02)$ \\
\hline $\mathrm{Al}-4 \mathrm{Si}$ & 525 & 1 & $1.3(0.30)$ & 0.8 & 2.2 & 2.8 & $52(5)$ & $7(1)$ & $0.12(0.01)$ \\
\hline $\mathrm{Al}-5 \mathrm{Si}$ & 450 & 4 & $1.0(0.41)$ & 0.7 & 2.2 & 3.1 & $53(7)$ & $5(2)$ & $0.09(0.02)$ \\
\hline $\mathrm{Al}-5 \mathrm{Si}$ & 475 & 4 & $1.3(0.41)$ & 0.8 & 2.3 & 2.9 & $56(5)$ & $7(1)$ & $0.13(0.02)$ \\
\hline $\mathrm{Al}-5 \mathrm{Si}$ & 500 & 2 & $1.9(0.53)$ & 1.3 & 3.0 & 2.3 & $59(5)$ & $9(2)$ & $0.15(0.04)$ \\
\hline Al-6Si & 450 & 4 & $2.0(1.17)$ & 1.0 & 5.9 & 5.9 & $53(9)$ & $7(1)$ & $0.14(0.04)$ \\
\hline Al-6Si & 475 & 4 & $1.5(0.49)$ & 1.0 & 2.9 & 2.9 & $65(2)$ & $8(1)$ & $0.13(0.02)$ \\
\hline Al-6Si & 500 & 2 & $1.8(0.69)$ & 0.9 & 3.6 & 4 & $57(3)$ & $8(1)$ & $0.13(0.02)$ \\
\hline Al-6Si & 525 & 1 & $1.8(0.77)$ & 0.8 & 4.1 & 5.1 & $51(8)$ & $7(1)$ & $0.15(0.03)$ \\
\hline
\end{tabular}




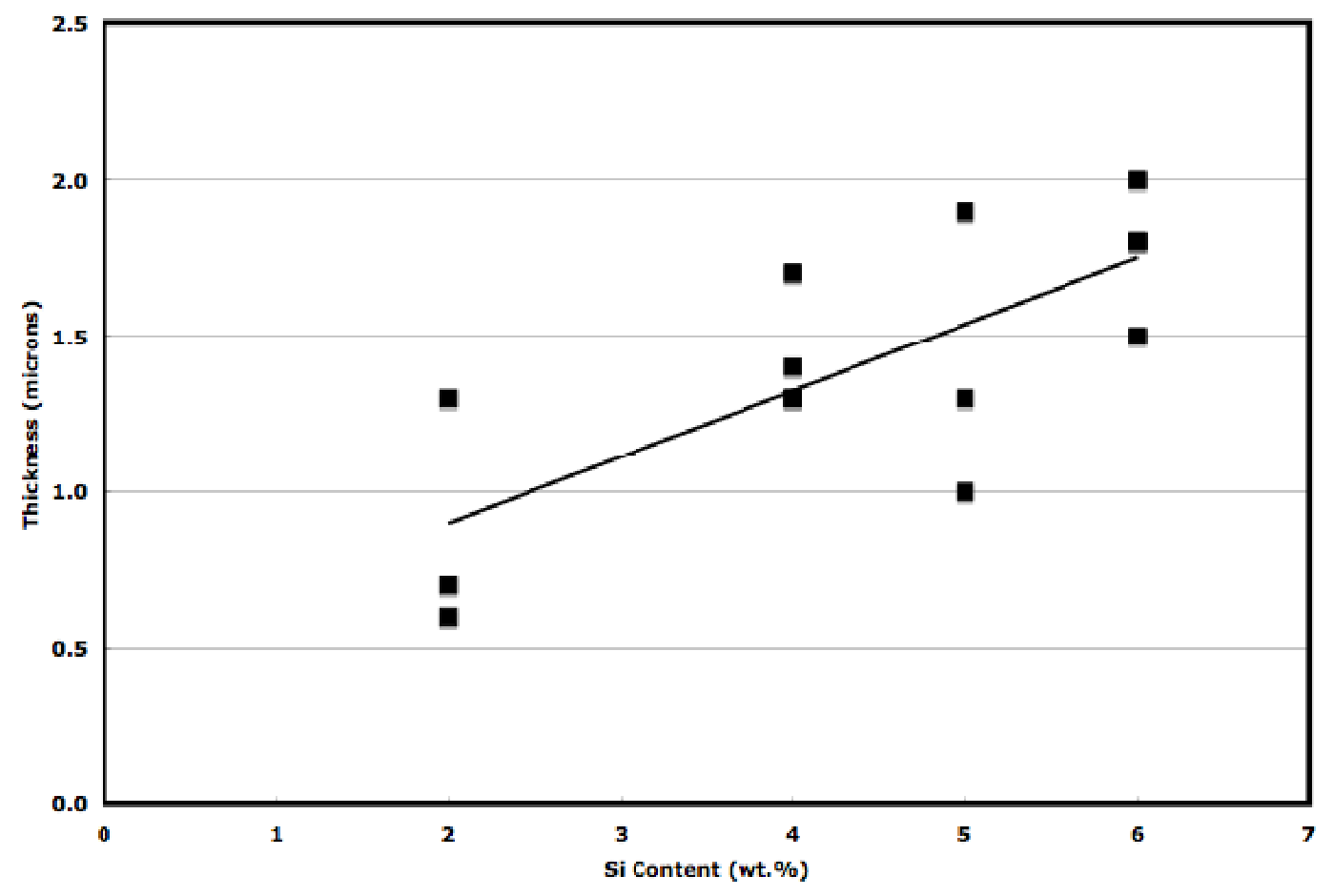

(a)

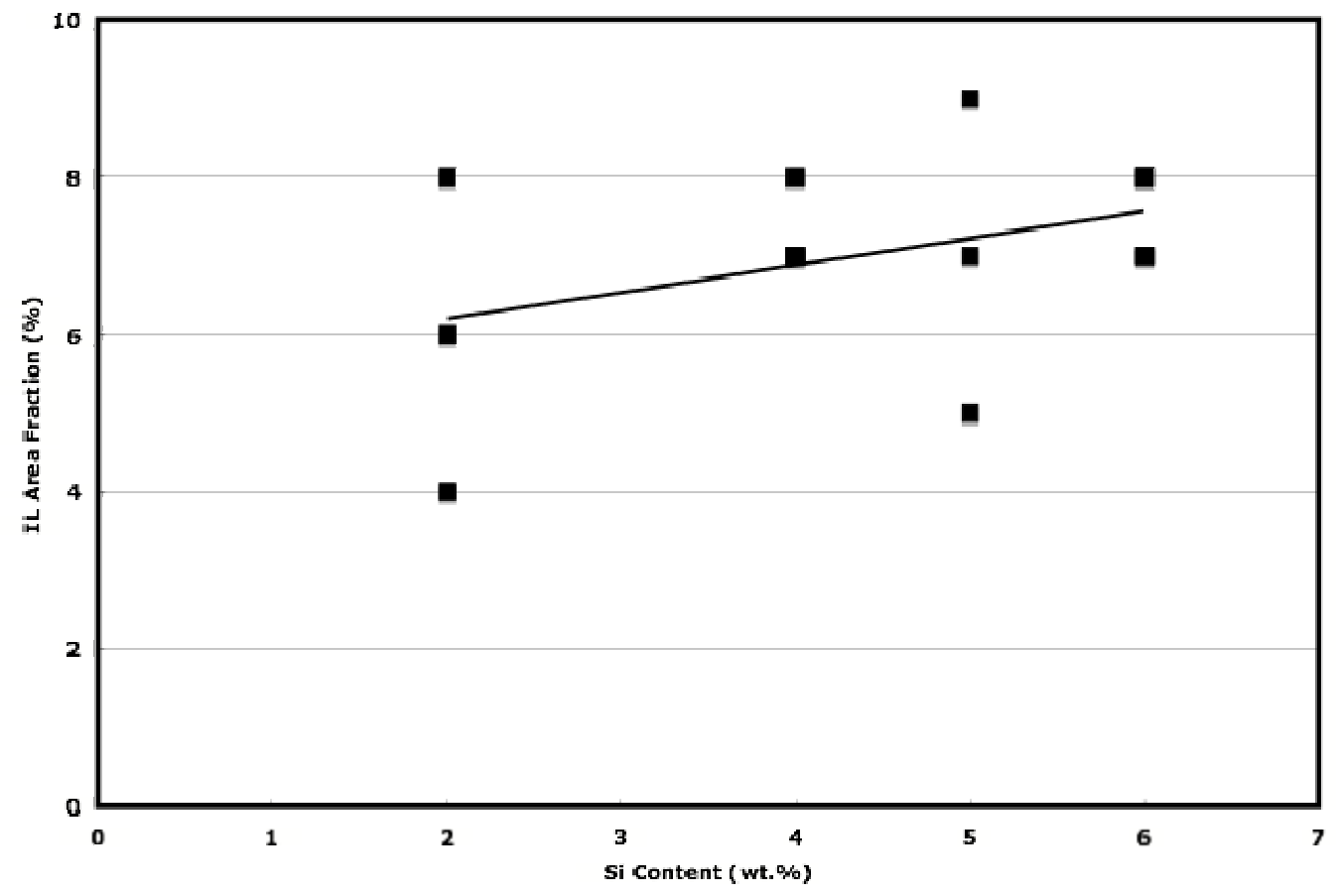

(b)

Figure 67. Plots of (a) IL thickness vs. Si content, and (b) IL area fraction vs. Si content. 


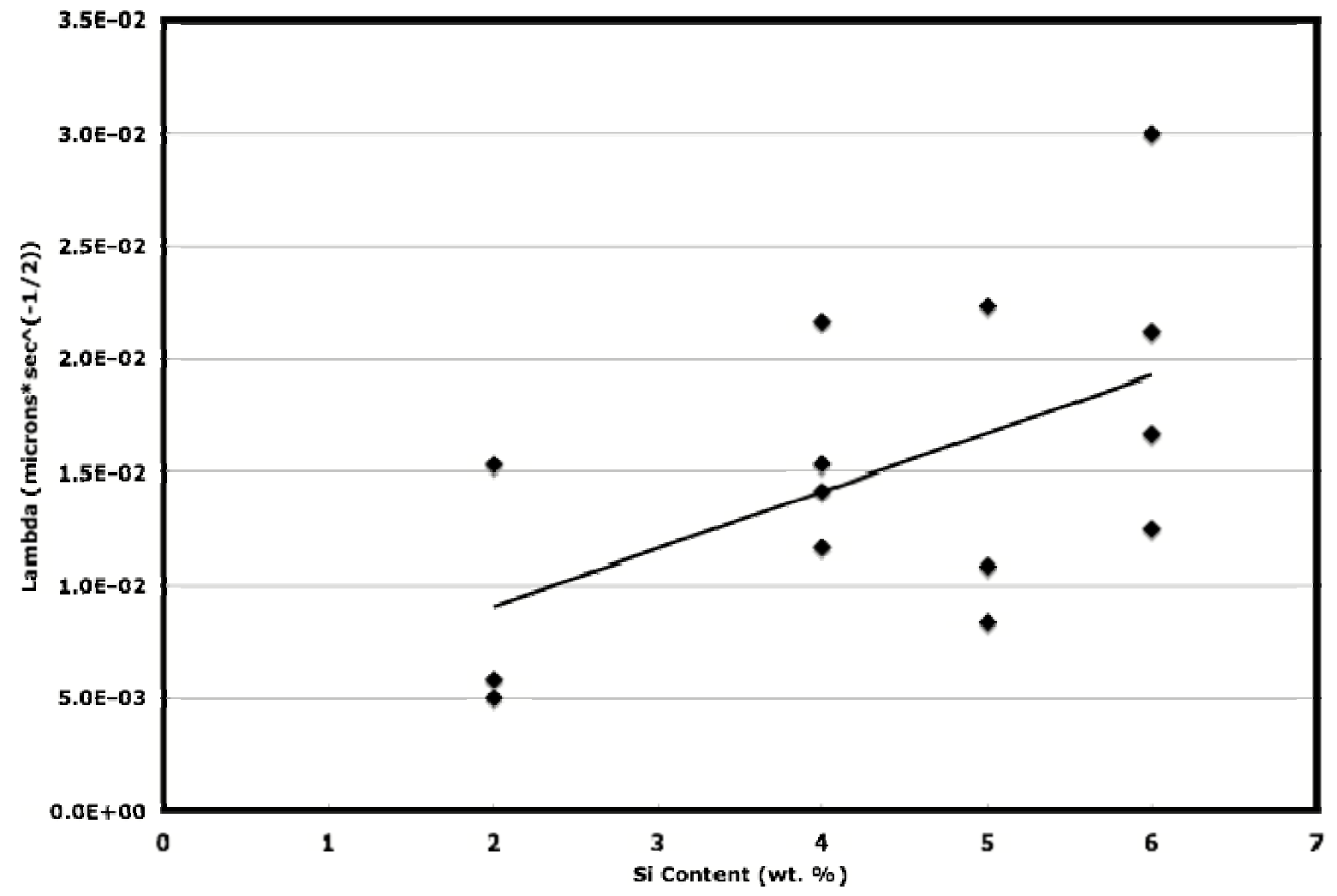

Figure 68. Plot of $\lambda$ vs. Si content. 


\section{DISCUSSION}

\subsection{Development of FMI Layers in Annealing Study Samples}

As described earlier in this report, all of the as-fabricated fuel plate samples had FMI layers. This means that the starting microstructure for all of the annealing study samples was one where the fuel/matrix interface already had a very thin interaction layer (less than one $\mu \mathrm{m}$ thick) that varied in thickness around the surface of the U-7Mo particles. In some locations, an interaction layer could not be resolved. It is believed that the thickness of this layer depended on the quality of contact at the $\mathrm{U}-7 \mathrm{Mo} / \mathrm{matrix}$ interface during fuel plate fabrication, the amount of uranium-oxide and aluminum-oxide at the interface, and the local compositions, temperature, and pressure that provided the driving force for interdiffusion between $\mathrm{U}, \mathrm{Mo}, \mathrm{Al}$, and $\mathrm{Si}$. As a result, fuel plates fabricated using different U-7Mo alloy, $\mathrm{Al}$, and Si powders, rolling schedules, or heating schemes than were used for these plates could have different amounts of interaction layers for a certain matrix composition after fabrication at $425^{\circ} \mathrm{C}$. In terms of the effect of the Si content of the matrix on the development of interaction layers during fabrication, it seemed that the narrowest layers were present in the Al-2Si matrix sample, and the Al-4Si, Al-5Si, and Al-6Si matrix samples all had more substantial layer formation. In terms of composition of the interaction layers that developed, the layer compositions described in Tables 5-8 for the Al-2Si, Al-5Si, or Al-6Si matrix samples show that the interaction layers had a Si content of at least 13 at $\%$ and a maximum Si content of 47 at $\%$. Due to the narrowness of these layers, these numbers are just qualitative, but it is clear that after fabrication at temperatures near $425^{\circ} \mathrm{C}$, the layers that developed in the annealing study samples were enriched in Si.

With respect to the growth of the existing interaction layers during a heat treatment, specifically the treatment at $450^{\circ} \mathrm{C}$ for 4 hours, the interaction layers for the Al-2Si sample did not increase much in thickness over what had been observed after fabrication. As shown in Table 26, the layer had an average thickness value of a few tenths of a micron. The Al-4Si sample was also observed to contain relatively thin interaction layers. For the Al-5Si sample, the interaction layers exceeded 1 micron in thickness, and the Al-6Si matrix sample layer approached 2 microns in thickness. These results suggest that for the samples annealed at $450^{\circ} \mathrm{C}$, there was a slight effect on interaction layer thickness of the Si content in the matrix (larger thicknesses resulted from higher Si contents). A similar effect of the matrix Si content on the interaction layer thickness seemed to apply to the samples annealed at $475^{\circ} \mathrm{C}$. The Al-2Si matrix sample had an average interaction layer thickness below 1 micron, and the Al-4Si, Al-5Si, and Al-6Si matrix samples had thicknesses between 1 and 1.5 microns. For the annealing tests conducted at $500^{\circ} \mathrm{C}$, the thickest interaction layers (around 2 microns thick) were observed for the samples with Al-5Si and Al-6Si samples, and thinner layers were observed for the Al-2Si and Al-4Si samples (between 1 and 1.5 microns thick). The final heat treatment temperature of $525^{\circ} \mathrm{C}$ produced layers about 2 microns thick in an Al-6Si matrix sample and between 1 and 1.5 microns thick in an Al-4Si matrix sample. Overall, these results for the samples exposed to different annealing treatments suggest there is only a slight effect on interaction layer thickness of the Si content in the matrix. Remembering that the matrix was produced by mixing pure Si powders with pure Al powders, the ultimate source of the Si comes from the pure $\mathrm{Si}$ powders, and the kinetics of how fast Si gets to the U-Mo/Al-Si matrix interface depends on Si diffusing through the pure $\mathrm{Al}$ or along surfaces or grain boundaries. The solid solubility of $\mathrm{Si}$ in $\mathrm{Al}$ is low $\left(0.008 \mathrm{wt} \%\right.$ at $250^{\circ} \mathrm{C}$ and $1.3 \mathrm{wt} \%$ at $\left.540^{\circ} \mathrm{C}^{7}\right)$. This means that even when the Si content of the matrix is increased, causing an increase in the amount of Si precipitates, only a limited amount of Si can still get to the $\mathrm{U}-7 \mathrm{Mo} /$ matrix interface to contribute to the growth of the interaction layer due to the limited $\mathrm{Si}$ solubility in Al. Having more Si powders may increase the amount of Si that gets to the U-7Mo/matrix interface via diffusion along surfaces. The result is that increasing the Si content in the matrix does not appear to have a large impact on interaction layer growth (after at least $4 \%$ has been added), and so the growth is very similar when comparing the different samples and there is only a slight increase in thickness for the samples with matrices that have higher Si contents. 
With respect to the Si contents observed in the interaction layers of the annealed samples, there was great similarity to what was observed for the as-fabricated samples. This suggests that the interaction layers that form during fabrication grow in thickness and uniformity during a particular heat treatment, but change little in composition regardless of the Si content in the matrix. Basically, the same types of phases seem to constitute the interaction layer, and the composition measured will depend on how much of a particular phase is present at that location. In the Al-2Si matrix sample annealed at $475^{\circ} \mathrm{C}$ for 4 hours (see Figure 31), at least two different phases, one with around 20 at $\%$ Si and another with almost 40 at $\%$ $\mathrm{Si}$, were identified in the interaction layer. If the interaction layers in the other annealed samples also contained these types of phases then when performing point-to-point composition analysis of interaction layers the Si content values should vary between 20 and 40 at $\%$, depending on how much of each phase was present at a particular location. Looking at the IL composition data that is included in this report, many of the Si measurements do fall within this range. Due to the narrowness of many interaction layers, there can be contributions to the final composition reading from the surrounding matrix or fuel phase that will affect the final readings, and this has to be considered.

Decomposition of the U-7Mo alloy from single-phase $\gamma-(\mathrm{U}, \mathrm{Mo})$ to $\alpha-\mathrm{U}$ and $\gamma-\mathrm{U}$ or $\gamma^{\prime}\left(\mathrm{U}_{2} \mathrm{Mo}\right)$ can potentially have a large impact on the nature of the interaction layers that develop. The main effect is the development of a relatively thick interaction layer with negligible Si. This effect has been observed in dispersion fuel samples fabricated as part of the RERTR-9A experiment. ${ }^{8}$ In these samples, it was shown that the U-7Mo dispersion fuel samples that were fabricated for extended time periods at high temperatures (i.e., around $500^{\circ} \mathrm{C}$ ) produced interaction layers depleted in $\mathrm{Si}$ and those exposed to a high temperature for shorter time frames produced only layers that were Si-rich. The development of the layers with negligible Si was connected to having decomposed U-7Mo regions in close proximity. ${ }^{9}$ The development of this type of interaction layer that contains only $\mathrm{U}$, Mo, and $\mathrm{Al}$ is unfavorable since the layer does not behave well during irradiation. ${ }^{1}$ Due to the lack of development of Si-depleted phases in the interaction zones in this study, it can be concluded that the times at the various temperatures are not excessive such that the decomposition of U-7Mo could impact the development of the interaction zones in terms of causing formation of Si-depleted phases. Clearly, decomposed regions were present in the U-7Mo alloy in all the samples. Yet, in most cases, negligible impact was observed on the stability of the Si-rich interaction layer (i.e., there was no increase in thickness with a significant decrease in Si content), and in the cases where there was an effect, it was only very limited. In the Al-2Si matrix sample annealed at $475^{\circ} \mathrm{C}$ for 4 hours, the $\mathrm{Al}-2 \mathrm{Si}$ matrix sample annealed at $500^{\circ} \mathrm{C}$ for 2 hours; and the Al-4Si matrix sample annealed at $500^{\circ} \mathrm{C}$ for 2 hours only very isolated formation of a "bulk" interaction zone could be observed, and even in these cases, the vast majority of the interaction layers remained thin and enriched in Si. This suggests that there is some time threshold at a particular temperature where, if the threshold is not exceeded, the decomposition of the U-7Mo alloy will not result in the degradation of the Si-rich interaction layers, which continues to act as a diffusion barrier to relatively fast diffusion between fuel and matrix constituents. This is consistent with what was reported for the fabricated RERTR-9 fuel plates. ${ }^{8}$ Clearly, exposure to too long of times at high temperatures will eventually have an adverse effect on the integrity of the thin, Si-rich interaction layers. This may be related to the fact that decomposition results in the formation of $\alpha-\mathrm{U}$, and $\alpha-\mathrm{U}$ interdiffuses rapidly with $\mathrm{Al},{ }^{10}$ or that the presence of the lamellar microstructure of a decomposed region, which has many boundaries between $\alpha$ and $\gamma$ or $\gamma$ ' phases, can act as short circuit diffusion paths and affect the interdiffusion kinetics. Over time the increased interdiffusion rates of fuel and matrix constituents can lead to the development of the phase(s) found in the "bulk" interaction zone. Based on the annealing experiments discussed in this report, during fabrication of plates with AA6061 cladding at $500^{\circ} \mathrm{C}$, there is an exposure time threshold in excess of 2 hours for fuel plates with Al-2Si or Al-4Si matrices before "bulk" interaction layers will start to form in relatively large amounts. The time seems to be a little longer for fuel plates with Al-5Si or Al-6Si matrices. 


\subsection{Comparison of FMI Layer Development in Annealing Study Samples to Diffusion Experiment Results Reported in the Literature}

Much work has been performed studying interactions between U-Mo and Al-Si alloys out-of-pile, and the different experiments that have been performed are compared in Reference 11. The majority of the studies have employed bulk diffusion couples, where polished pieces of U-Mo alloy are mated with polished pieces of Al-Si alloys and then annealed at a specific temperature. The result of using polished samples that are held together under pressure in some sort of jig or capsule is that the size of the interdiffusion zones that develop during a particular annealing treatment are larger than if an actual dispersion fuel comprised of the same U-Mo and Al-Si alloy had been exposed to that same annealing treatment. In a dispersion fuel, there is imperfect contact between the U-Mo particles and Al-Si matrix, and oxide layers can be present at the U-Mo/Al-Si alloy matrix that can affect interdiffusion rates. As a result, it is not very useful to compare results of diffusion tests using actual dispersion fuels with those generated using diffusion couples in terms of the kinetics of the interactions. However, for increasing the understanding of how phase development changes in dispersion fuel FMI layers as function of changes in the matrix Si content, it can be useful to compare the phases that develop in annealed diffusion couples with those that form in annealed dispersion fuel samples.

With respect to comparing the kinetic results of this current study with those obtained from some other diffusion experiments using actual dispersion fuels, some data is available in the literature for dispersion fuel samples comprised of U-7Mo particles dispersed in some Al-Si alloy matrices. ${ }^{12}$ Park et al. have reported results for samples that were hot extruded at $400^{\circ} \mathrm{C}$ and were annealed at $550^{\circ} \mathrm{C}-600^{\circ} \mathrm{C}$ for up to 50 hours in a vacuum and were comprised of 10.0 volume $\% \mathrm{U}-7 \mathrm{Mo}$ particles and $\mathrm{Al}-\mathrm{xSi}(\mathrm{x}=0$, $0.4,2$, or $5 \mathrm{wt} \%$ ) alloy matrix. However, it must be kept in mind that these results are for rod-type samples that were fabricated differently than the samples used in this study, which were rolled at $425^{\circ} \mathrm{C}$. It is not known what interaction layers were present, if at all, after fabrication of the rod-type samples, how the amount of oxide at the fuel particle/matrix interface may be different than for the samples in this study, how the microstructure of the U-Mo powders may be different, how the Al-Si alloy powders may result in different behavior compared to using blends of pure Si and pure Al powders (like in this study), and how the contact between the U-Mo particles and matrix may be different. All these factors can conceivably play a role in how the interdiffusion process will take place, which results in the development of interaction layers. Park et al. report that a U-7Mo/Al-5Si dispersion sample that was annealed at $600^{\circ} \mathrm{C}$ for 3 hours showed the development of a fairly uniform Si-containing interaction layer around the U-7Mo particles. It was observed that for the dispersion samples annealed for relatively long times at the different temperatures interaction layers with a wide range of thicknesses developed. This suggests that the couples annealed for longer times, as part of the work of Park et al. may have exceeded a time threshold at the different test temperatures, and if shorter annealing times had been consistently used the interaction layers may have remained thin and uniform. ${ }^{12}$

As was mentioned earlier, it can be useful to compare the phases that develop in the interdiffusion zones in typical diffusion couples with those that develop in the interdiffusion zones in annealed dispersion fuel samples. In many cases the $(\mathrm{Al}+\mathrm{Si}) /(\mathrm{U}+\mathrm{Mo})$ ratio has been used to compare the composition of interaction layers. ${ }^{11}$ For the studies performed in this report, the $(\mathrm{Al}+\mathrm{Si}) /(\mathrm{U}+\mathrm{Mo})$ ratio was found to vary tremendously when all the composition analyses are taken into account. Due to the narrowness of the layers, overlap of the electron beam with surrounding fuel and matrix may have an influence on some of the layer compositions that were measured, and there may have been variability in the phases that were present at each measurement location in the interaction layer, which will affect the final data. As a result, no meaningful $(\mathrm{Al}+\mathrm{Si})(\mathrm{U}+\mathrm{Mo})$ ratios could be determined from the full set of composition data generated for the annealing study samples. Typically, the interaction layers generated in out-of-pile diffusion couples are much thicker and produce more consistent composition results. However, if selected composition measurements are used from the thickest interaction layers in the annealing study samples, where overlap of the electron beam is of less concern, some comments can be 
made about interaction layer composition. For example, measurements from the Al-2Si matrix sample annealed at $475^{\circ} \mathrm{C}$ for 4 hours developed a phase layer nearest the unreacted U-7Mo with around 40 at $\%$ $\mathrm{Si}$ and a layer nearest the unreacted matrix with approximately 20 at $\% \mathrm{Si}$. Layers with similar Si contents have been observed in reported diffusion couple experiments using U-7Mo and Al-Si alloys. ${ }^{11}$ However, it is the exact phases that are found in an interaction layer that are of most interest and not just the composition of a layer, which is just an average composition of a mixture of phases present at a particular location. These phases are the ones that will ultimately go amorphous during irradiation and so it is their behavior in reactor that will play a role in dictating how the overall interaction layer will behave. Therefore, a characterization technique must be used that can definitively identify phases. For example, transmission electron microscopy (TEM) can definitively identify the phases in an interaction layer through electron diffraction, and consequently this technique will be used to characterize the interaction layers in some of the samples discussed in this report. This will allow for the identification of the specific phases present in the interaction layers. The results of this TEM investigation will be discussed in a different report.

\subsection{Comparison of FMI Layers in Annealing Study Samples to Those Observed in Typical Fuel Plates Fabricated at $500^{\circ} \mathrm{C}$}

As mentioned earlier, the main goal of the annealing experiments discussed in this report was to identify an annealing treatment that could be performed on fuel plates fabricated at relatively low temperatures, like $425^{\circ} \mathrm{C}$, to generate FMI layers similar in thickness and uniformity to those produced when fabricating a fuel plate at $500^{\circ} \mathrm{C}$. Obviously, the layers produced in the annealing treatments conducted at $500^{\circ} \mathrm{C}$ generated very similar layers compared to those in an as-fabricated fuel, and so a comparison to these samples is similar to making comparisons to as-fabricated fuel. However, if one wants to work at lower temperatures to potentially limit the amount of fuel plate rejects due to the formation of blisters on the surface of a fuel plate, or some other reject criterion, one could consider the annealing treatments performed at $450^{\circ} \mathrm{C}$ or $475^{\circ} \mathrm{C}$. For the $450^{\circ} \mathrm{C}$ experiments, the Al-6Si matrix sample developed substantial FMI layers that had an average thickness near 2 microns. They were uniform around the U-7Mo particles and enriched in Si. With respect to the $475^{\circ} \mathrm{C}$ experiments, both the $\mathrm{Al}-5 \mathrm{Si}$ and Al-6Si matrix samples produced substantial FMI layers. The average FMI layer thicknesses were near 1.5 microns, and in cases where the layers were even thicker they were still enriched in Si. When selecting an ideal matrix Si content for a fuel plate, one should also consider the fact that there should be an adequate supply of $\mathrm{Si}$ in all regions of the fuel meat matrix to keep the interaction layer stable during irradiation. This would suggest that in order for all local regions of dispersion fuel meat to have enough $\mathrm{Si}$, one should select a matrix with a relatively high Si content (like 5 or $6 \mathrm{wt} \%$ ). Conveniently, fuel plates with these matrix Si contents also produce the most substantial interaction layers around the U-7Mo particles during the different annealing treatments. 


\section{CONCLUSIONS}

Annealing experiments have been completed that investigated the development of Si-rich fuel/matrix interaction layers in U-7Mo dispersion fuels plates fabricated at a relatively low temperature, and as a result of the microstructural characterization of these samples, the following conclusions can be drawn:

1. Based on SEM microstructural characterization of U-7Mo alloy particles in annealed samples, decomposition of the $\gamma$-phase U-7Mo alloy occurs during fabrication of U-7Mo dispersion fuel plates at the relatively low temperature of $425^{\circ} \mathrm{C}$. Further decomposition occurs during heat treatments of these fuel plates at $450^{\circ} \mathrm{C}, 475^{\circ} \mathrm{C}, 500^{\circ} \mathrm{C}$, and $525^{\circ} \mathrm{C}$ for $4,4,2$, and 1 hour(s), respectively. Relatively large amounts of decomposition can occur in the U-7Mo alloy before the stability of Si-rich interaction layers at the U-7Mo/matrix interface is impacted, in terms of its thickness, uniformity, or composition.

2. Si-rich interaction layers will develop in U-7Mo dispersion samples with $\mathrm{Al}-\mathrm{xSi}(\mathrm{x}=2,4,5$, or $6 \mathrm{wt} \%)$ that are fabricated at the relatively low temperature of $425^{\circ} \mathrm{C}$. Further exposure to $450^{\circ} \mathrm{C}, 475^{\circ} \mathrm{C}$, $500^{\circ} \mathrm{C}$, or $525^{\circ} \mathrm{C}$ for $4,4,2$, or 1 hour(s) will result in a slight increase in thickness and uniformity around the U-7Mo particles, with the largest average thickness, based on image analysis, being approximately 2 microns. The least interaction layer uniformity was observed for Al-2Si matrix samples exposed to the different annealing treatments, and the layer uniformity for the Al-4Si, Al-5Si, and Al-6Si matrix samples was similar. The composition of the layers that develop through additional heating treatments will be very similar to those that developed during fabrication at $425^{\circ} \mathrm{C}$.

3. A heat treatment of $450^{\circ} \mathrm{C}$ for 4 hours using a U-7Mo/Al-6Si fuel plate or a heat treatment of $475^{\circ} \mathrm{C}$ for 4 hours using $\mathrm{U}-7 \mathrm{Mo} / \mathrm{Al}-5 \mathrm{Si}$ or $\mathrm{U}-7 \mathrm{Mo} / \mathrm{Al}-6 \mathrm{Si}$ fuel plates can be employed to produce similar Si-rich interaction layers around U-7Mo fuel particles compared to those produced in fuel plates with AA6061 cladding that are fabricated at $500^{\circ} \mathrm{C}$. 


\section{REFERENCES}

1. A. Leenaers, S. Van den Berghe, E. Koonean, C. Jarousse, F. Huet, M. Trotabas, M. Boyard, S. Guillot, L. Sannen, M. Verwerft, J. Nucl. Mater. 335 (2004) 39-47.

2. Y. S. Kim, G. L. Hofman, H. J. Ryu, J. Rest, in: Proc. of the 25th International Meeting on Reduced Enrichment for Research Reactors, Boston, MA, 2005.

3. G. L. Hofman, Y. S. Kim, H. J. Ryu, D. Wachs, and M. R. Finlay, in: Proc. of the 26th International Meeting on Reduced Enrichment for Research Reactors, Capetown, South Africa, 2006.

4. D. D. Keiser, Jr., A. B. Robinson, J.-F. Jue, P. Medvedev, D. M. Wachs, and M. R. Finlay, J. Nucl. Mater. 393 (2009) 311-320.

5. J. Gan, D. D. Keiser, Jr., D. M. Wachs, A. B. Robinson, B. D. Miller, and T. R. Allen, J. Nucl. Mater. 396 (2010) 234-239.

6. A. B. Robinson, D. M. Wachs, D. E. Burkes, and D. D. Keiser, in: Proc. of the 28th International Meeting on Reduced Enrichment for Research Reactors, Washington, D. C. 2008.

7. K. Farrell, J. O. Stiegher, and R. E. Gehlbach, Metallography 3 (1970) 275-284.

8. D. D. Keiser, Jr., J. F. Jue, J. Gan, A. B. Robinson, and B. D. Miller, in: Proc. of the 28th International Meeting on Reduced Enrichment for Research Reactors, Washington, D. C., 2008.

9. D. D. Keiser, Jr., B. Yao, E. Perez, and Y. H. Sohn, in: Proc. of the 29th International Meeting on Reduced Enrichment for Research Reactors, Beijing, China, 2009.

10. L. S. Castleman, J. Nucl. Mater. 3 (1961) 1-15.

11. D. L. Porter and A. Ewh, "Interaction Layer Characteristics in U-xMo Dispersion/Monolithic Fuels", Idaho National Laboratory Report, INL/EXT-10-17972 (2010).

12. J. M. Park, H. J. Ryu, S. J. Oh, D. B. Lee, and C. K. Kim, in: Proc. of the 26th International Meeting on Reduced Enrichment for Research Reactors, Capetown, South Africa, 2006. 